DANIELLE POMPEU NORONHA PONTES

EVOLUÇÃO DE SOFTWARE BASEADA EM AVALIAÇÃO DE ARQUITETURAS 
DANIELLE POMPEU NORONHA PONTES

\section{EVOLUÇÃO DE SOFTWARE BASEADA EM AVALIAÇÃO DE ARQUITETURAS}

Dissertação apresentada à Escola Politécnica da Universidade de São Paulo para a obtenção do título de Mestre em Engenharia.

Área de Concentração:

Sistemas digitais.

Orientador:

Prof. Dr. Reginaldo Arakaki

SÃO PAULO

2012 
Este exemplar foi revisado e alterado em relação à versão original, sob responsabilidade única do autor e com a anuência de seu orientador.

São Paulo, 09 de maio de 2012.

Assinatura do autor

Assinatura do orientador

FICHA CATALOGRÁFICA

Pontes, Danielle Pompeu Noronha

Evolução de software baseada em avaliação de arquiteturas /

D.P.N. Pontes. -- ed.rev. -- São Paulo, 2012. $99 \mathrm{p}$.

Dissertação (Mestrado) - Escola Politécnica da Universidade de São Paulo. Departamento de Engenharia de Computação e Sistemas Digitais.

1. Arquitetura de software (Avaliação) 2. Engenharia de Software 3. Softwares (Evolução) I. Universidade de São Paulo. Escola Politécnica. Departamento de Engenharia de Computação e Sistemas Digitais II. t. 


\section{DEDICATÓRIA}

Ao meu esposo Pontes Filho, pela compreensão. Às minhas filhas queridas Sofia e Clarissa que alegram e iluminam todos os meus dias. Aos meus pais que sonharam este sonho comigo por muitos anos e a Deus que colocou todos eles em minha vida. 


\section{AGRADECIMENTOS}

Meus agradecimentos,

A DEUS, que com sua imensa grandeza me deu forças nesta jornada.

Às minhas filhas Sofia e Clarissa, que sempre me proporcionou momentos de alegria e ternura.

Ao meu esposo Pontes Filho pelo incentivo, paciência e amor.

Ao meu orientador Prof. Reginaldo Arakaki pela dedicação e rigor na orientação deste trabalho.

A meus pais, que me incentivaram a continuar.

Aos colegas da Dr Tech e da Universidade Estadual do Amazonas, pela amizade e incentivo.

Aos professores do mestrado pelos valiosos conhecimentos e experiências transmitidas para minha formação.

Aos colegas da turma pelo companheirismo e prazer de convívio.

A todos, que assim como eu, acreditam em um futuro melhor. 
Eu pedi forças... E DEUS me deu dificuldades para me fazer forte. Eu pedi sabedoria... E DEUS me deu problemas para resolver. Eu pedi prosperidade... E DEUS me deu cérebro e músculos para trabalhar.

Eu pedi coragem... E DEUS me deu perigo para superar. Eu pedi amor... E DEUS me deu pessoas com problemas para ajudar.

Eu pedi favores... E DEUS me deu oportunidades. Eu não recebi nada do que pedi... Mas recebi tudo que precisava.

Ao Senhor, Jesus Cris, Mestre Supremo, meu eterno agradecimento. 


\section{RESUMO}

Este trabalho discorre sobre o estudo da utilização do método de avaliação ATAM como referência para um roteiro para evolução arquitetural. $O$ estudo apresentado está dividido em duas partes: a elaboração de um roteiro para evolução de software e a aplicação do roteiro em um ambiente real de um sistema para automação de linhas aéreas. O objetivo é avaliar o uso do método de avaliação de arquitetura para direcionar a evolução do software. As diretrizes geradas neste trabalho orientam as ações a serem tomadas com base em evidências obtidas pela avaliação, possibilitando ao software que exiba os atributos de qualidade desejados.

Palavras chaves: Arquitetura de Software. Evolução de Software. ATAM. Requisitos Não-Funcionais. Avaliação Arquitetural. 


\begin{abstract}
This paper discusses the study of the use of ATAM evaluation method as a reference to a roadmap for architectural evolution. The present study is divided into two parts: the preparation of a roadmap for software development and implementation of the roadmap in a real environment of a system for automation of airlines. The goal is to evaluate the use of architecture evaluation method to direct the evolution of software. The guidelines generated in this work have guided the actions to be taken based on evidence obtained by the evaluation, enabling the software that displays the desired quality attributes.
\end{abstract}

Word-key: Software Architecture. Software Evolution. ATAM. Non-functional requirements. Architectural Evaluation. 


\section{LISTA DE ILUSTRAÇÕES}

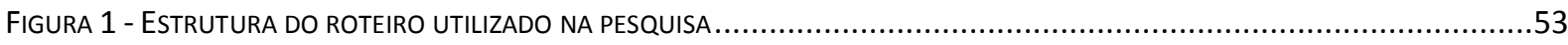

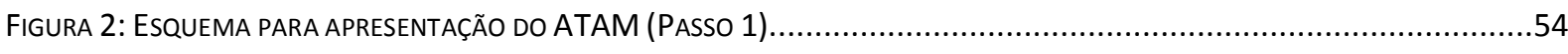

FIGURA 3: ESQUEMA PARA APRESENTAR OS OBJETIVOS DO NEGÓCIO (PASSO 2) .......................................................55

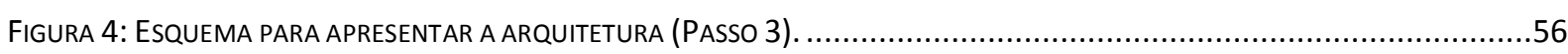

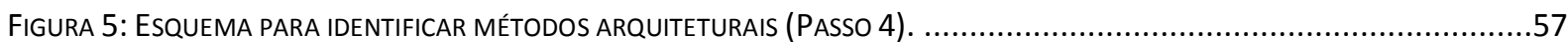

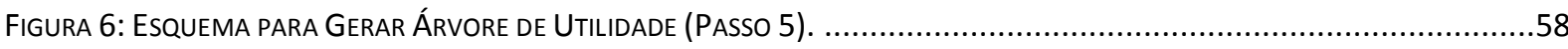

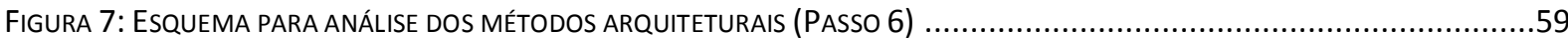

FIGURA 8: ESQUEMA PARA REALIZAR O BRAINSTORM E PRIORIZAÇÃO DE CENÁRIOS (PASSO 7)............................................60 


\section{LISTA DE QUADROS}

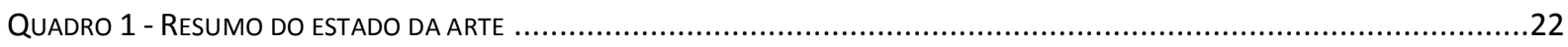

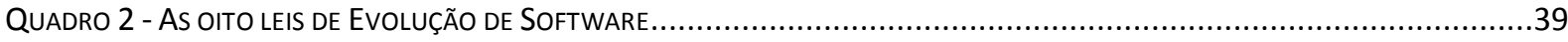

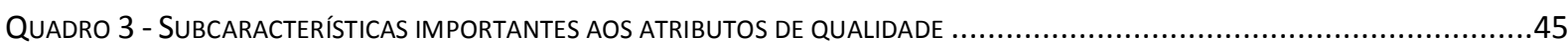

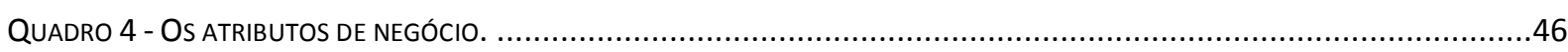

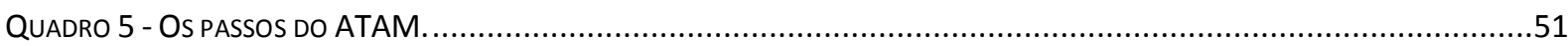

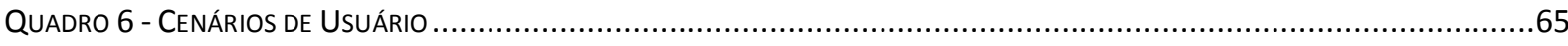

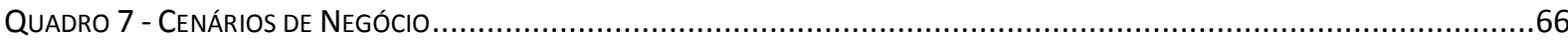

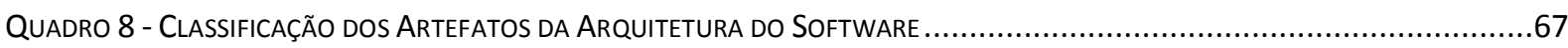

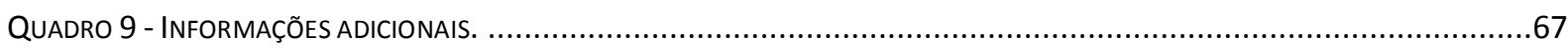

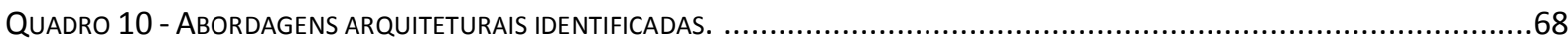

QuAdro 11 - CLASSIFICAÇÃo dos CENÁRIOS (1a VERSÃo dA ÁrVoRE DE UTILIDADE) .................................................69

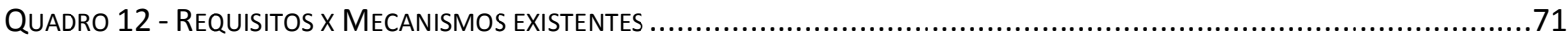

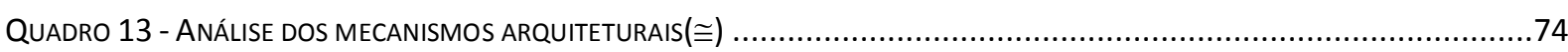

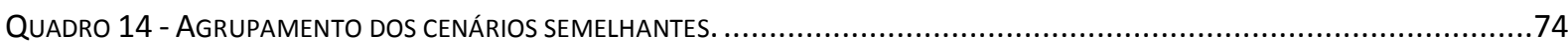

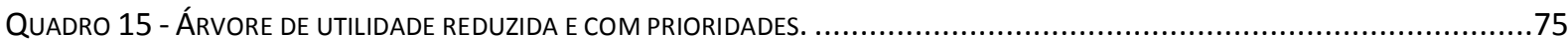

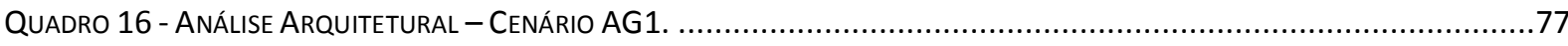

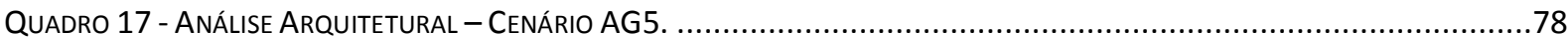

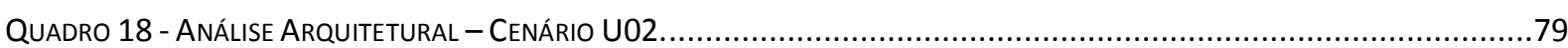

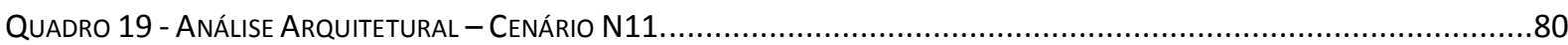

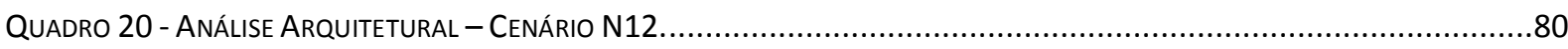

QUADRO 21 - TÁTICAS SUGERIDAS CLASSIFICADAS DE ACORDO COM OS PONTOS DE VISTAS ODP......................................84

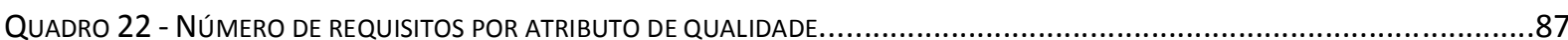




\section{LISTA DE ABREVIATURAS, SIGLAS e TERMOS}

$A G$

ATAM

AU

DA

Erosão arquitetural

HoPLAA

IEC

ISO

ISO 42010

ISO/IEC 10746

ISO/IEC 10746-3
Agrupamento

Architecture Tradeoff Analysis Method

Árvore de Utilidade, conjunto de Atributos de qualidades

relevantes ao sistema

Decisão arquitetural

A degradação do software que acontece devido à

violação da arquitetura por programadores.

Holistic Product Line Architecture Assessment

International Electrotechnical Commission

International Organization for Standardization

Systems and Software Engineering - Recommended

practice for architectural description of software-intensive systems.

Basic Reference Model of Open Distributed Processing.

Basic Reference Model of Open Distributed Processing -

Part-3: Prescriptive Model.

ISO/IEC 9126-1:2007 Norma ISO para qualidade de produto de software.

ISO/IEEE 1471-2000 Recommended Practice for Architecture Description of

Software-Intensive Systems.

$\mathrm{OO}$

Orientado à Objetos

Origin Analysis

Método para analisar mudanças estruturais do software.

(TU; GODFREY, 2002).

Phase out

Fase de descarte do sistema.

RM-ODP

Reference Model for Open Distributed Processing

RNF

Requisito não funcional

SAAM

Software Architecture Analysis Method

SAEV

Software arquitecture Evaluation, modelo proposto em

(SADOU; TAMZALIT; OUSSALAH, 2005).

SQL

Struct Query Langage

StagedModel
Modelo descritivo de evolução de software. 
Trade-off

VBSE
Expressão que define uma situação em que há conflito de escolha. Refere-se, a perder uma qualidade ou aspecto de algo, mas ganhando em troca outra qualidade ou aspecto.

Value-Based Software Engineering 


\section{SUMÁRIO}

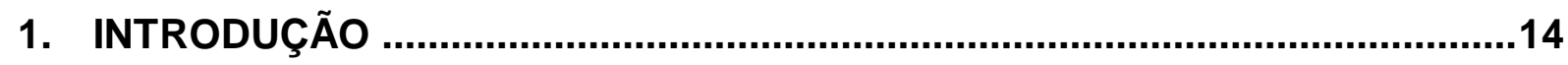

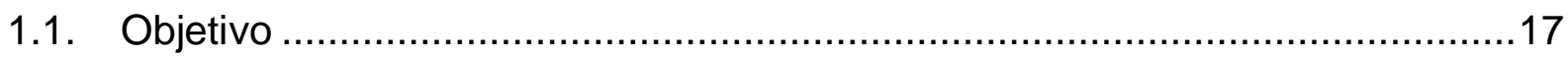

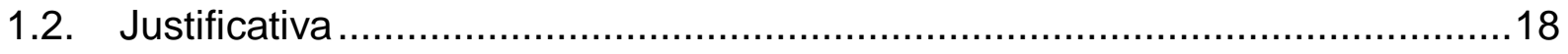

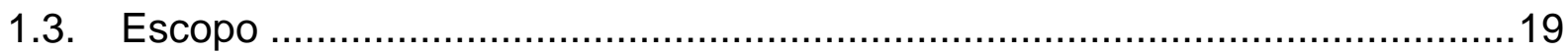

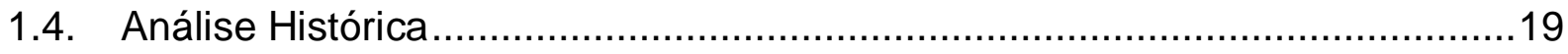

1.4.1 Evolução de Software dentro do ciclo de desenvolvimento............................20

1.4.2 Evolução de Software a partir das funcionalidades ......................................20

1.4.3 Evolução de Software a partir da arquitetura ............................................20

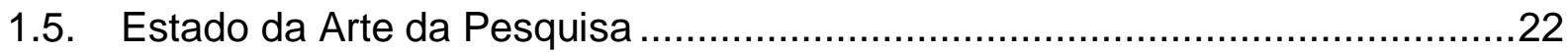

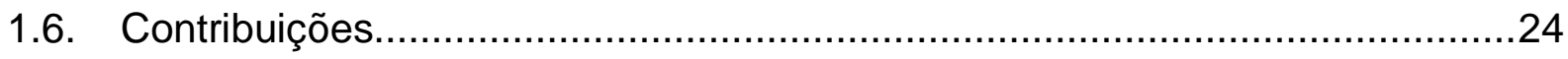

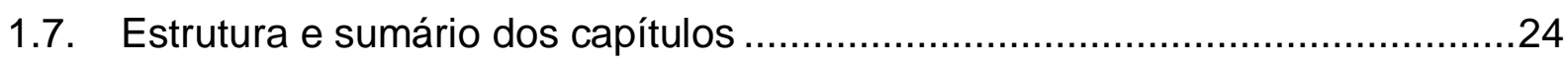

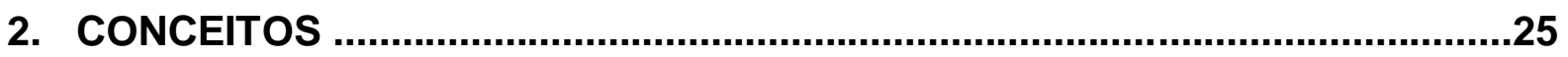

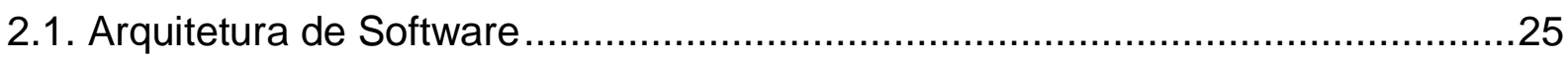

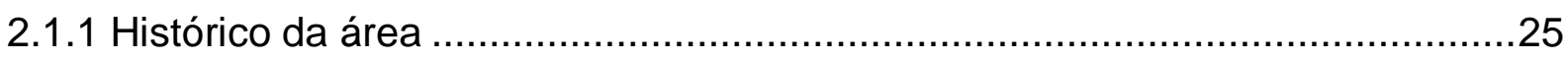

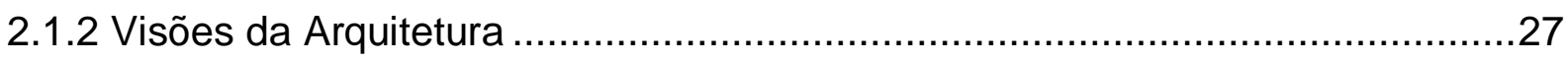

2.1.3 O modelo de referência RM-ODP ISO/IEC 10746.....................................29

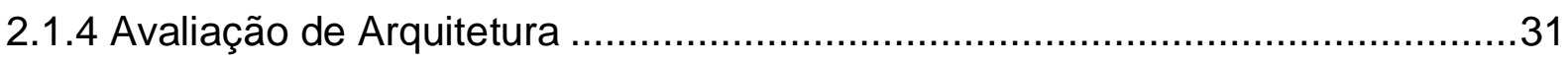

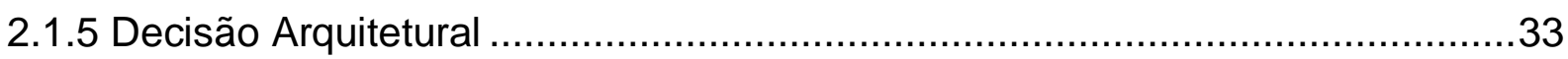

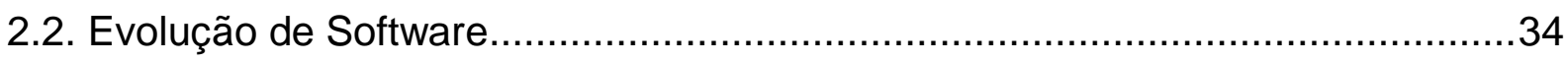

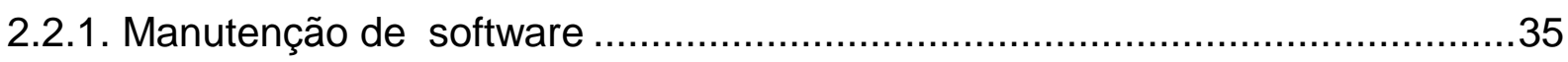

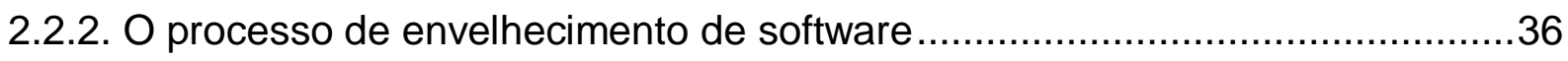

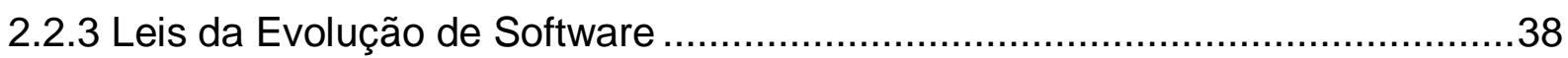

2.3. Requisitos não-funcionais e atributos de qualidade ....................................40

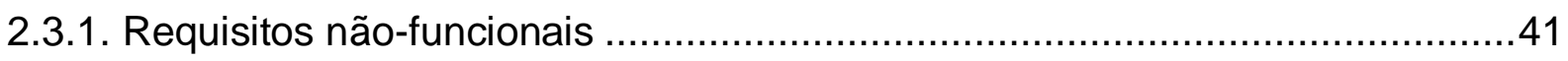

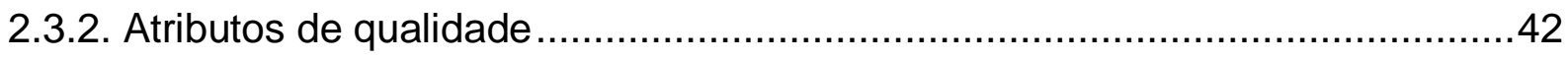


3. ROTEIRO PARA AVALIAÇÃO DE ARQUITETURA …...................................53

3.1 Avaliação do sistema através do ATAM .................................................53

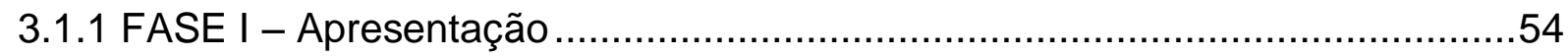

3.1.2 FASE 2 - Investigação e Análise .....................................................56

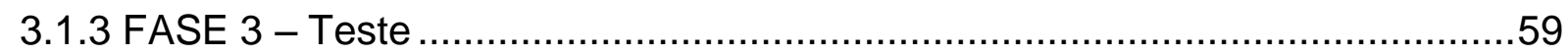

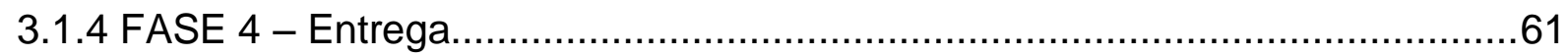

3.2 Especificar o plano de evolução para o Sistema ........................................62

4. APLICAÇÃO DO ROTEIRO: UM EXEMPLO DE AVALIAÇÃO ......................64

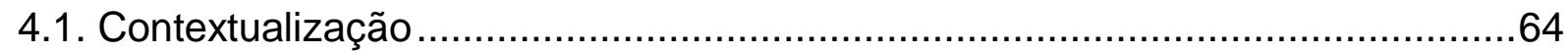

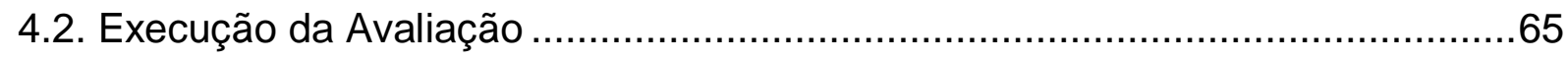

4.2.1. Passo 4 - Identificando métodos arquiteturais ......................................67

4.2.2. Passo 5 - Gerar a árvore de utilidade (Agrupamento e Priorização dos

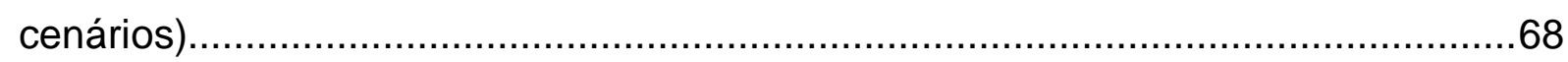

4.2.3. Passo 6 - Análise dos métodos(abordagem) arquiteturais .........................70

4.2.4. Passo 7 - Brainstorm e priorização de cenários ..................................... 73

4.2.5. Passo 8 - Análise dos mecanismos arquiteturais ....................................76

4.2.6. Passo 9 - Consolidar resultados ....................................................... 81

4.3 Aspectos do Plano de Ação para Evolução ................................................. 82

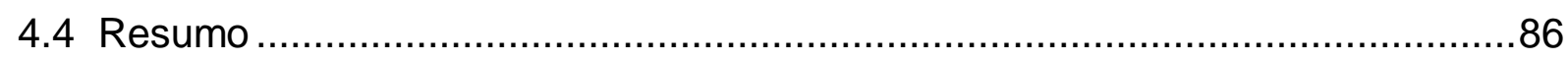

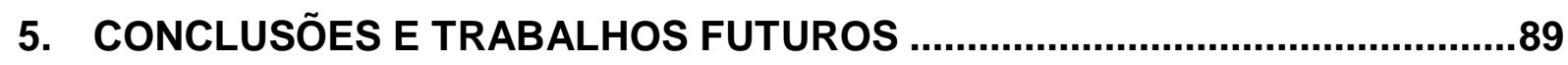

6. REFERÊNCIAS .................................................................................92 


\section{INTRODUÇÃO}

O êxito em longo prazo de um software não é determinado em uma única versão. Em vez disso, o sucesso é definido pela facilidade com que o software é capaz de evoluir e continuar a atender às novas exigências de mercado. Não se trata apenas das alterações dos requisitos funcionais. Os requisitos de qualidade também mudam com o tempo (SVAHNBERG,2003). Baseado nos autores (BASS et al. 1998b), (BOSCH 2000) e (BENGTSSON 2002), o sucesso a longo prazo dos sistemas de software é determinado pelo atendimento dos requisitos de qualidade.

No início da utilização de um software, atributos de qualidade como extensibilidade e adaptabilidade podem ser importantes para aumentar o número de recursos suportados. Mais tarde, a solicitação de novas funcionalidades estabiliza e as necessidades que surgem são relacionadas aos atributos de qualidade, como confiabilidade e desempenho, por exemplo. Nesta fase, o produto concorre com outros que possuem características semelhantes e, conseqüentemente, os atributos de qualidade oferecem uma vantagem competitiva. Eventualmente, um produto é substituído por um mais novo que possui uma arquitetura mais compatível com as novas tecnologias. Nesta fase, o produto é estável em termos do número de recursos e da qualidade. Outros fatores que podem tornar um software mais competitivo no mercado estão relacionados a atributos de qualidades como custo de produção e custo de plataforma de hardware, o qual influencia e restringe a atuação do software no mercado. (SVAHNBERG,2003)

Como uma das soluções para a problemática da evolução do software o autor faz a seguinte colocação:

O software tornou-se mais e mais difícil de entender, manter ou adaptar, e difícil de reusar e evoluir. Isso acontece devido ao aumento do tamanho e complexidade dos softwares e pela rápida evolução das tecnologias de processamento de dados. A arquitetura de Software esta emergindo como uma solução para esta problemática (SADOU; TAMZALIT; OUSSALAH, 2005, p.01, tradução nossa). 
Na mesma linha de argumentação usada por Sadou, Chávez (2009) em seu trabalho cita os autores Krutchen, Obbink e Staford (2006) que afirmam que do ponto de vista prático é possível controlar e supervisionar o desenvolvimento e evolução de sistemas através da arquitetura de software.

De acordo com Garlan e Perry em (GARLAN; PERRY, 1995) a arquitetura de software pode expor as dimensões através das quais um sistema deve evoluir. Dessa forma, ao torná-las explícitas, os mantenedores do sistema podem compreender melhor as implicações das mudanças e, assim, mais precisamente estimar custos de modificações. Além disso, as descrições da arquitetura podem separar as preocupações da funcionalidade de um componente da forma como este componente está ligado a outros componentes. Isto permite que se altere o mecanismo de conexão para lidar com problemas, tais como a evolução do desempenho, interoperabilidade, prototipagem e reutilização.

Todo software está em um contínuo processo evolutivo. Essa evolução surge a partir de sucessivas mudanças: para consertar erros, aumentar desempenho ou atender outros requisitos de qualidade necessários para se adaptar a novos ambientes. [(PORTER, 1997) p.120, Tradução nossa].

Sistemas que não são capazes de evoluir correm o risco de um desuso ou descontinuidade prematura, pois o software está embutido em um ambiente de constantes mudanças sejam elas ligadas a aspectos sociais ou ambientais (GODFREY; GERMAN, 2008). As mudanças sociais geralmente envolvem mudanças funcionais e as mudanças ambientais afetam mais frequentemente a arquitetura do software. Características importantes deste processo de aprimoramento é que ele seja constante, ágil e que não gere degradação do software ao longo da evolução.

Um aspecto importante para evitar ou pelo menos atrasar essa erosão arquitetural ${ }^{1}$ é compreender a evolução do software. Em outras palavras, em vez de evoluir a arquitetura de software a cada nova mudança que ocorre, a arquitetura original deve ser capaz de permitir os tipos mais comuns de evolução. Assim,

\footnotetext{
${ }^{1} \mathrm{~A}$ erosão arquitetural acontece devido à violação da arquitetura por programadores. Esse termo é apresentado por Perry e Wolf (1992)
} 
poucas mudanças são necessárias na arquitetura e, portanto, a vida do sistema é prorrogada.

De forma geral os termos evolução, manutenção e erosão são usados indiferentemente quando se fala de software, existe uma importante diferença semântica entre eles. Como Parnas (1994) e outros apontam, manutenção conota a idéia de manter um software existente rodando sem mudar o design, isso sugere a mudança de partes desgastadas em caso de sistemas físicos. Na prática a manutenção de software requer a mudança do design do sistema: corrigindo erros, adaptando o sistema para uso em novos ambientes, adicionando novas características. A erosão é o efeito colateral gerado por manutenções feitas de forma desordenada.

Evolução subtende a idéia de mudança essencial que não esta clara no termo manutenção. A evolução sugere novos designs evoluindo de sistemas antigos. Finalmente pode ser argumentado que manutenção e evolução oferecem diferentes perspectivas da natureza da mudança. (GODFREY; GERMAN, 2008). É a inovação e não a preservação, que direciona a mudança de software: um sistema moderno adaptado a novos ambientes evolui de um sistema antigo. (GODFREY; GERMAN, 2008).

Em (TU; GODFREY, 2002) os autores acreditam que um dos desafios na pesquisa em evolução de software é como analisar as mudanças estruturais dos sistemas. O autor utiliza o termo arquitetura de software para se referir a estrutura de um sistema, enfatizando a organização dos componentes e os relacionamentos entre eles. Para obter o sucesso neste processo, a evolução da arquitetura deve ser identificada e gerenciada para manter a coerência da arquitetura. (SADOU; TAMZALIT; OUSSALAH, 2005). Desta forma, enquanto a manutenção degrada a vida e a confiabilidade do software, a evolução planeja mudanças que permitirão um tempo de vida longo ao software.

Um dos efeitos colaterais originados pela confusão entre os termos manutenção de software e evolução de software tem sido a pouca atenção dada aos modelos de processos que suportem uma evolução continuada de sistemas de longo tempo de vida. O clássico modelo em cascata trata a manutenção meramente como um passo final do processo de desenvolvimento. Nem mesmo em modelos mais recentes, como o iterativo incremental, existem estágios específicos para 
manutenção e evolução, nestes modelos, as consecutivas interações modelam a evolução do software durante o seu desenvolvimento. (GODFREY; GERMAN, 2008).

Bennett e Rajlich (2000) apresentam um modelo descritivo de evolução de software chamado de StagedModel de manutenção e evolução que sumarizam muitas dessas idéias. O modelo é dividido em quatro estágios: Desenvolvimento

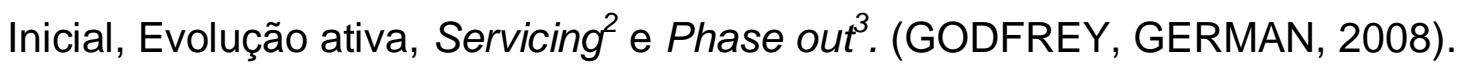

Considerando o objeto dessa investigação, cumpre reportar-se ao estágio do Phase out. Neste existe claramente a decisão de substituir ou eliminar o sistema inteiramente por causa do alto custo de manutenção ou pelo surgimento de novas soluções tecnológicas. Para tanto o autor da ênfase a elaboração de uma estratégia de saída. Diferentemente dessa perspectiva, esta pesquisa aponta, por fim, outra direção: pensar em uma estratégia que planeje a criação de uma nova versão para possibilitar a sobrevivência do software no mercado.

\subsection{Objetivo}

O Objetivo deste trabalho é realizar um estudo sobre a utilização do método de avaliação ATAM para apoiar a evolução arquitetural de um sistema de software através de um aplicação prática.

Para realizar este estudo serão elaborados um roteiro de avaliação e um exemplo prático. O Roteiro para avaliação de arquitetura de software terá como referência o método de avaliação de arquitetura de software ATAM e como objetivo, gerar um plano de evolução a partir de sua arquitetura, assegurando a longevidade do sistema no mercado. $O$ exemplo prático da aplicação deste roteiro será em um ambiente real de uma empresa de aviação.

A contribuição deste trabalho está na aplicação da avaliação da arquitetura para direcionar a criação de uma nova versão do sistema que atenda a novos requisitos não funcionais, permitindo a manutenção ou recolocação do produto no mercado. $\mathrm{A}$

\footnotetext{
${ }^{2}$ Fase de manutenção do sistema com foco de mantê-lo funcionando. Riscos e custos altos.

${ }^{3}$ Fase de análise da descontinuação do sistema. Migração para outro sistema.
} 
evolução será em passos lentos, mas planejados. Esse planejamento está diretamente ligado ao planejamento estratégico da empresa.

\subsection{Justificativa}

O mercado de desenvolvimento de software tem apresentado mudanças significativas no que diz respeito à construção de sistemas. Atualmente encontramse sistemas complexos instanciados nos mais diversos ramos de atividade o que dificulta qualquer tentativa de substituição de plataforma, sistema ou fornecedor. Entretanto o processo de envelhecimento de um software é natural e inevitável, o que gera uma necessidade constante de evolução dos sistemas que esperam e precisam ser mantidos ativos por um período grande de tempo. Outro fator relevante a ser apontado é que parte dos sistemas coorporativos instanciados no mercado apresenta problemas estruturais que afetam negativamente alguns requisitos fundamentais de qualidade, o que demanda uma evolução estrutural para adequar a novas exigências do usuário. Mudar sistemas sem técnica prejudica alguns aspectos de qualidade da arquitetura. Para decidir como implementar mudanças, é preciso usar um método que permita o controle de qualidade da arquitetura.

Adaptar os sistemas as novas necessidades do mercado tais como: integração, flexibilidade, federação, transparência, qualidade do serviço e segurança pode ser apontada como uma maneira de aumentar o tempo de vida de um sistema. Esta área de estudo tem evoluído significativamente.

Durante a tentativa de atender as necessidades de mercado situações nas quais há conflito de escolha (trade-off) sempre surgem. Um método estruturado ajuda a garantir que questões importantes serão tratadas mais cedo, durante os estágios de análise de requisitos e projeto quando os problemas podem ser resolvidos de forma mais barata. Dentro do processo proposto para evolução de software optou-se por utilizar o método de avaliação ATAM para apoiar a evolução arquitetural. Este método orienta os seus usuários, a descobrirem os conflitos entre os requisitos e apontar as melhores soluções para arquitetura de software. 
Este trabalho parte do conceito que a evolução de software acontece com a evolução arquitetural do sistema. Por isso, estará focado na análise dos requisitos não-funcionais desconsiderando a evolução do software a partir da inserção de novas funcionalidades (requisitos funcionais). Como método de apoio para desenhar a evolução será utilizado o método de avaliação arquitetural - ATAM.

\subsection{Escopo}

Este trabalho estará focado na análise dos requisitos não-funcionais como um meio de planejar a evolução de um software através de mecanismos arquiteturais. Como referencia a ISO 10746, a ISO 9126 e métodos científicos como o ATAM são utilizados para suportar as atividades desta pesquisa.

Bass Graff em (GRAAF, 2007) distingue claramente dois tipos de transformações durante a vida de um software. Segundo o autor os modelos e processos existentes envolvem tipicamente transformações verticais, do abstrato para o concreto, como acontece no ciclo de desenvolvimento de software. Por outro lado atividades como manutenção e evolução, típicas em qualquer software, envolvem transformações horizontais como a migração do sistema de uma plataforma para outra. Este trabalho propõe o planejamento para execução de transformações horizontais que envolvem aspectos arquiteturais do sistema.

\subsection{Análise Histórica}

A evolução de Software é bem estudada no livro editado por Mens e Demeyer, Software Evolution (MENS; DEMEYER, 2008) e nos trabalhos de Parnas (PARNAS, 1994), Van Gurp e Bosch (GURP; BOSCH, 2002) e Eick et al (EICK et al., 2001). Outros trabalhos importantes para a contextualização do tema são (MENS; WERMELINGER; DUCASSE, 2005), (GODFREY, GERMAN, 2008), (NIKORA; MUNSON, 2003). 
No estudo bibliográfico realizado neste trabalho foi possível distinguir três tipos de iniciativas para tratar a evolução.

\subsubsection{Evolução de Software dentro do ciclo de desenvolvimento}

Muitos autores analisam a evolução do software durante o processo de desenvolvimento. Chávez (2009) em "Um Processo para o controle da evolução da Arquitetura de Software Baseado em ODP." discute sobre o processo de evolução da arquitetura de software considerando o seu desenvolvimento, projeto, construção e manutenção, como um conjunto de passos evolutivos no seu ciclo de vida, cujas iterações estão associadas ao ciclo de vida do software. Em cada etapa do processo de desenvolvimento são geradas novas expectativas que a arquitetura de software precisa satisfazer, gerando em cada iteração, novas versões dos modelos ou mesmo refinamentos dos anteriores.

\subsubsection{Evolução de Software a partir das funcionalidades}

Evolução originada do incremento de novas funcionalidades no software. Estas iniciativas estão muito relacionadas com o termo manutenção de software e as leis de Lehman (LEHMAN M., 1996).

\subsubsection{Evolução de Software a partir da arquitetura}

Neste tipo de iniciativa há uma maior preocupação com o estudo da evolução da arquitetura através do uso de técnicas ou elementos arquiteturais, para se adequar a novos ambientes operacionais e requisitos não-funcionais. 
Alguns estudos propõem o uso de métodos de avaliação arquitetural. $O$ objetivo do trabalho apresentado em (GUIMARAES, 2008) é fornecer um método que auxilie a manutenção de sistemas que se tornaram inadequados aliando a arquitetura de software com a manutenção na forma de fases interativas e com o uso de técnicas arquiteturais como avaliação de arquitetura.

$\mathrm{Na}$ tese de doutorado de Mikael Svahnberg (2003) o autor apresenta um estudo sobre evolução de arquiteturas de software e o que pode ser feito para apoiar esta evolução. Esse estudo se concentra em três aspectos específicos de apoio a evolução: como garantir que a combinação correta de atributos de qualidade seja satisfeita (seleção de arquitetural), os meios técnicos disponíveis para apoiar as mudanças no sistema de software (variabilidade), e que tipos de mudanças podem ocorrer durante a evolução (categorias de evolução). É introduzido um método de avaliação e seleção de arquitetura, baseado no ATAM e no SAAM (Software Architecture Analysis Method, que se concentram em garantir que a arquitetura de software selecionada é a arquitetura candidata com o maior potencial para o cumprimento de um conjunto especial de atributos de qualidade. (SVAHANBERG03, 2003).

Muitas iniciativas propõem o desenvolvimento de ferramentas que auxiliem nesse processo de evolução. A maioria das ferramentas que exploram a evolução da arquitetura de um sistema utiliza um método baseado no tempo, o qual mostra como um sistema tem mudado em um dado intervalo de tempo. Alguns deles estão em (MCNAIR; GERMAN; WEBER-JAHNKE, 2007), (RANK, 2005) e (HINDLE et al, 2007). Em (RANK, 2005) é proposto um ambiente de engenharia de software reflexiva. Esse ambiente permite a produção de software que seja fácil de usar. A criação do software irá manipular uma coleção de visões, incluindo código de baixo nível e visão arquitetural de alto nível que serão interligados através de reflexões. Em (HINDLE et al, 2007) é descrito um método e uma ferramenta para modelar, extrair e animar evolução arquitetural. Toma como base as mudanças no código para extrair as mudanças e utiliza animação para visualizar.

Em (TU; GODFREY, 2002) os autores desenvolveram um método para analisar mudanças estruturais do software chamado "Origin Analysis". Por sua vez em (SADOU; TAMZALIT; OUSSALAH, 2005) os autores propõem um modelo de evolução de arquitetura de software (SAEV). 
No quadro 1 é possível observar um resumo do estado da arte apresentado.

Quadro 1-Resumo do estado da arte

\begin{tabular}{|l|l|l|}
\hline \multicolumn{1}{|c|}{ Tipo de Evolução } & \multicolumn{1}{|c|}{ Subtipo } & \multicolumn{1}{c|}{ Referencias } \\
\hline Ciclo de desenvolvimento & \multicolumn{1}{|c|}{ (CHAVEZ, 2009) } \\
\hline Funcional & Módulos & (GALL, H. et al., 1997) \\
\hline & Leis de Lehman & (LEHMAN, 1997), (LEHMAN, 1996) \\
\hline \multirow{5}{*}{ Arquitetural } & Avaliação & (SVAHANBERG, 2003), (GUIMARAES, 2008) \\
\cline { 2 - 3 } & Modelo & $\begin{array}{l}\text { (GRAAF, 2007), } \\
\text { (SADOU; TAMZALIT; OUSSALAH, 2005) }\end{array}$ \\
\cline { 2 - 3 } & Ferramentas & (MCNAIR, 2009), (RANK, 2005), (HINDLE et al, 2007) \\
\cline { 2 - 3 } & Método & $\begin{array}{l}\text { (GODFREY; GERMAN, 2008),( BENNET E; } \\
\text { RAJLICH, 2000) }\end{array}$ \\
\hline
\end{tabular}

\subsection{Estado da Arte da Pesquisa}

Considerando os trabalhos em torno de avaliação de arquitetura de software foram encontradas as seguintes pesquisa.

Em (OLUMOFIN; MISIC, 2005) os autores ampliam o método ATAM para a avaliação de arquiteturas de software de famílias de produtos. Neste trabalho é apresentado o método HoPLAA (Holistic Product Line Architecture Assessment) que estende o ATAM com o tratamento qualitativo de análise de pontos de variação e da geração dependente do contexto, classificação e priorização de cenários de atributos de qualidade. É uma abordagem holística que analisa as vantagens e desvantagens dos atributos de qualidade não só para a arquitetura de linha de produto, mas considera ainda as arquiteturas de produtos individuais. Além disso, prescreve um tratamento qualitativo da análise de pontos de variação com base em cenários. Com este estudo os autores incrementam corpo de pesquisas existentes e experiências industriais na avaliação de arquiteturas de um único produto, ao definir o foco sobre a especificidade de arquiteturas de software de linha de produtos.

Em (RIVA; ROSSO, 2006) os autores trabalharam no domínio de família de produtos de software incluindo evolução do software e experiências de avaliações de arquitetura de software para uma família de produtos de software (MACCARI, 2002; ROSSO,2005; ROSSO,2006). 
Em (BARBACCl et al.2003) os autores descrevem uma avaliação ATAM da arquitetura de software de sistemas aviônicos desenvolvido para o Technology Applications Program Office of the U.S. Army . O sistema e chamado de Common Avionics Architecture System, desenvolvido por Rockwell Collins em Cedar Rapids, lowa. Considerando que a arquitetura de software é um dos fatores determinantes da qualidade do software, é de fundamental importância para uma organização como o Departamento de Defesa, a capacidade de avaliar arquiteturas de software antes que eles sejam finalizados. Desta forma é possível reduzir substancialmente o risco de que os sistemas entregues não atinjam suas metas de qualidade. Este trabalho não tem como foco a evolução da arquitetura de um software já existente.

O artigo (ROSSO, 2006) apresenta um trabalho dentro do contexto de avaliação de arquitetura para evolução de software. Neste trabalho o autor discute as experiências adquiridas na aplicação de três diferentes técnicas de avaliação, dentre elas o ATAM. As técnicas apresentadas incluem cenário de avaliação baseada em arquitetura de software, avaliação de desempenho e software baseado em experiência de avaliação. Segundo o autor, as várias técnicas de avaliação estudadas são complementares e, quando utilizadas em conjunto, constituem uma ferramenta eficaz para que o arquiteto de software possa manter e evoluir um sistema de software de grande intensidade.

Em um trabalho mais recente, (DIAS, 2010) é apresentado um roteiro que propõe a utilização das ferramentas da arquitetura de software e da engenharia de software guiada por valor, ou VBSE (Value-Based Software Engineering), para apoiar o processo decisório e justificar a evolução tecnológica através da atualização da arquitetura. $\mathrm{O}$ propósito é contrir para que o sistema continue adicionando valor à organização por mais tempo. $O$ trabalho se concentra em unir a força das ferramentas de avaliação e medição de arquitetura (como o ATAM) com os princípios da VBSE, trazendo foco ao negócio e ao valor gerado pelo sistema à organização usuária, sem perder o rigor dos processos da engenharia de software. 


\subsection{Contribuições}

A contribuição deste trabalho é ajudar na compreensão de:

- como a evolução arquitetural ocorre em um sistema de software,

- como avaliar e selecionar uma arquitetura de software que reúna um conjunto especial de atributos de qualidade.

O roteiro apresentado neste trabalho contribui para que um software baseado em uma arquitetura se adapta às exigências de qualidade do ambiente em que esta inserido, sendo capaz de evoluir com sucesso e consequentemente se mantendo no mercado por mais tempo.

\subsection{Estrutura e sumário dos capítulos}

O restante do trabalho está organizado da seguinte forma: no Capítulo 2 apresentam-se os conceitos e definições necessários para a compreensão da arquitetura de software e evolução de software. No Capítulo 3 é descrito o roteiro utilizado para avaliação da arquitetura e elaboração do plano de evolução que é o foco principal desta pesquisa. No Capítulo 4 descreve-se a aplicação do exemplo desenvolvido nesta pesquisa para a compreensão da evolução do processo de avaliação. O Capítulo 5 apresenta os resultados e as discussões desta pesquisa e, finalmente, no Capítulo 6 são apresentadas as referências bibliográficas utilizadas na pesquisa. 


\section{CONCEITOS}

\subsection{Arquitetura de Software}

Arquitetura de software é a ponte entre os objetivos de negócio e o sistema realizado (CLEMENTS et al., 2002). Para que o sistema se torne adequado, a arquitetura deve ser moldada de forma a atender uma série de requisitos funcionais e requisitos de qualidade (não funcionais) que reflitam os objetivos do negócio.

O projeto arquitetural de grandes sistemas tem sido determinante no sucesso de um sistema: a escolha de uma arquitetura inapropriada pode ter efeitos desastrosos (GARLAN; PERRY, 1995).

\subsubsection{Histórico da área}

A ênfase em Arquitetura de Software como disciplina aconteceu apenas durante a década de 1990 com autores como Perry e Wolf (1992) e Garlan e Shaw (1994).

Perry e Wolf tiveram uma grande contribuição introduzindo a definição para arquitetura de software em seu artigo seminal Foundations for the Study of Software Architecture (1992).

A definição que eles propõem consiste na fórmula:

Arquitetura $=($ Elementos, Organização, Decisões $)$

De acordo com essa definição, a arquitetura de software é um conjunto de elementos arquiteturais que possuem alguma organização. Os elementos e sua organização são definidos por decisões tomadas para satisfazer objetivos e restrições. 
A visão sobre arquitetura de software de Garlan e Shaw (1994) tornou-se importante por conter três aspectos.

O primeiro é por eles serem explícitos em quando devem ser aplicados os conhecimentos de arquitetura de software: quando o tamanho e a complexidade dos sistemas de software crescem.

O segundo é por serem claros na separação de tarefas entre o projeto detalhado e o projeto arquitetural. O projeto detalhado se preocupa com algoritmos e estruturas de dados. O projeto arquitetural se preocupa com os elementos e organização do sistema como um todo, envolvendo: decisões sobre as estruturas, a estrutura global de controle que será usada, protocolos de comunicação, sincronização e acesso a dados, atribuição de funcionalidade a elementos do sistema e ainda a distribuição física dos elementos.

O terceiro aspecto cita que o processo de projeto da arquitetura precisa se preocupar com atributos de qualidade do sistema envolvendo decisões que impactarão no comportamento do sistema em termos de escala e desempenho, entre outros atributos de qualidade.

A visão de Bass e outros (BASS; CLEMENTS; KAZMAN, 2003) é explícita quanto ao papel da abstração na arquitetura (quando fala de propriedades externamente visíveis), e também quanto ao papel das múltiplas visões arquiteturais (estruturas do sistema), deixando clara a importância das visões arquiteturais muito usadas em modelos arquiteturais como o RM-ODP por exemplo.

Por fim é importante mencionar o padrão ISO/IEEE 1471-2000. O propósito da criação deste padrão foi o de ajudar no consenso entre autores, estudantes e profissionais sobre o que é e para que serve a arquitetura de software.

Sua definição de arquitetura de software é a seguinte: "Arquitetura é a organização fundamental de um sistema incorporada em seus componentes, seus relacionamentos com o ambiente, e os princípios que conduzem seu design e evolução".

A definição acima é consistente com as anteriores por também mencionar que arquitetura compreende estrutura (ou elementos ou componentes), relações, e decisões (ou princípios). No entanto, ela vai além ao adicionar mais uma preocupação à arquitetura: conduzir a evolução do software. 
Outras definições são encontradas na literatura, mas para esta pesquisa essas três definições são importantes e complementares, pois colocam importantes conceitos como decisões, preocupação com atributos de qualidade do sistema e evolução que são conceitos básicos para o desenvolvimento deste trabalho.

\subsubsection{Visões da Arquitetura}

Visão é um dos mais importantes conceitos associados com arquitetura de software. Segundo Len Bass e outros visão é uma representação de um conjunto coerente de elementos arquiteturais e as relações entre eles. As visões são mecanismos que permite separar conceitos enquanto a arquitetura de um sistema é construída ou analisada. (BASS; CLEMENTS; KAZMAN, 2003)

Clements et. al. (2002), afirma que a arquitetura de software é uma entidade abstrata e complexa, que não pode ser descrita e compreendida por todos os participantes apenas valendo-se de um único modelo ou mecanismo de representação. Para tanto, as visões permitem considerar uma arquitetura a partir de diferentes perspectivas.

Por exemplo, considere as preocupações de dois diferentes interessados no sistema: o implementador e o responsável pela disponibilidade do sistema em produção. O primeiro está preocupado com elementos como: módulos, classes e algoritmos que ele e seu time terão que construir, como e com quais subsistemas esses módulos irão se comunicar ou ainda quais restrições de comunicação foram impostas em seu design. Por outro lado, o responsável pela disponibilidade está preocupado em como o software está distribuído entre as máquinas, que funcionalidades serão afetadas caso um conjunto específico de máquinas deixe de funcionar, ou como será possível realizar a troca de um servidor sem afetar o tempo de início de uma transmissão de vídeo.

É possível observar que há preocupações distintas entre os dois interessados e assim perceber que dimensões diferentes da arquitetura são necessárias para satisfazê-los. 
Para o primeiro, a arquitetura deve mostrar que módulos lógicos (pacotes, classes, bibliotecas) compõem o sistema, além das relações de comunicação e restrição entre eles. Já para o segundo, a arquitetura deve mostrar como o sistema está dividido fisicamente, quais partes do sistema estão executando em quais computadores, quais os links físicos entre esses computadores, etc.

Clements e outros citam que visões arquiteturais comuns incluem:

Visões Funcionais ou lógicas: É uma abstração das funções do sistema e seus relacionamentos. Exemplos de componentes são: abstrações do sistema e elementos de domínio. Exemplos de relacionamentos são dependências e fluxo de dados entre os componentes.

Visões de Concorrência ou dinâmicas: Mostra que processos ou threads serão criados e como eles irão se comunicar e compartilhar recursos. Exemplos: processos, threads e protocolos presentes no sistema,

Visões de Código: É a visão que interessa ao programador. Os componentes dessa visão são classes, objetos, procedures, e funções e suas abstrações em componentes, camadas ou módulos. O relacionamento é chamado de invocação de métodos.

Visões de desenvolvimento ou implementação: Também de interesse do desenvolvedor. É a visão que estrutura o código fonte em repositórios que os desenvolvedores criam, modificam e gerenciam, Os componentes desta visão são tipicamente, arquivos e diretórios e o principal relacionamento entre eles e o "está contido em".

Visões físicas: definir onde as partes dinâmicas executarão, ou seja, onde e em quais máquinas os diversos executáveis do software estarão implantados, além de como eles vão se comunicar.

Algumas referências importantes sobre visões arquiteturais são: The $4+1$ View Model of Architecture de Kruchten (1995), Documenting Software Architectures: Views and Beyond de Clements et al (2002) e o padrão ISO/IEEE 1471-2000.

A Norma ISO 42010 (ISO/IEC 2007 apud CHÁVEZ, 2009) organiza os conceitos de representação de arquiteturas. De acordo com a norma, as descrições da arquitetura de software estão conformadas pelo conjunto de visões que 
representam de forma concreta os pontos de vista e os interesses associados a cada participante. As visões são representadas através de modelos, os quais são abstrações, normalmente representadas de forma gráfica de acordo com uma linguagem de modelagem ou notação. (CHÁVEZ, 2009)

Nesta pesquisa consideramos as visões utilizando o modelo de referência ODP.

\subsubsection{O modelo de referência RM-ODP ISO/IEC 10746}

O Modelo de referência para Processamento Distribuído Aberto (RM-ODP) é um framework para a especificação de sistemas distribuídos baseado em cinco pontos de vista. De acordo com o padrão ISO 42010 (ISO/IEC 2007 apud CHAVEZ, 2009) um ponto de vista fornecem um padrão ou template, a partir do qual é possível desenvolver visões individuais, estabelecer os objetivos e a audiência para uma visão e as técnicas para sua criação e análise. (CHÁVEZ, 2009).

O RM-ODP representa vários aspectos e características de sistemas através destas cinco abstrações que são: empresa, informação, computação, engenharia e tecnologia. Esses pontos de vista são independentes entre si, mas complementares. Jorge Becerra (1998) explica a origem dos cinco níveis de abstração com a seguinte colocação:

A Norma ISO/IEC 10746-3 contém as informações relacionadas com a definição das especificações dos cinco pontos de vista, com as funções ODP e com as transparências a implementar. Estas informações contêm as características que qualificam o sistema distribuído como aberto. (BECERRA, 1998)

Com base nas definições de Becerra (1998) e de Chávez (2009), os pontos de vistas são definidos da seguinte maneira:

Ponto de vista de empresa: Este ponto de vista especifica o modelo de negócios da empresa definindo os requisitos do sistema. Ele especifica quais necessidades de negócio são satisfeitas pela arquitetura. É um documento utilizado para validação com o cliente. Segundo Becerra (1998), neste ponto de vista são 
definidos o objetivo e escopo da empresa, as políticas que define a atuação do sistema, e as políticas que definem o inter-relacionamento da empresa com entidades externas.

Ponto de vista de informação: O ponto de vista de informação é especificado através do uso de esquemas, os quais descrevem o estado (semântica do processamento) e a estrutura (semântica da informação) de um objeto. Ele captura o estado e a estrutura de um objeto num instante específico do tempo.

Em (BECERRA, 1998) o autor disserta que a estrutura do ponto de vista da informação ou a semântica da informação é definida dentro de três tipos de esquemas:

- Esquema invariante: conjunto de condições ou predicados que sempre são verdadeiros aplicados a um ou a um conjunto de objetos informação. Estas condições regulamentam os possíveis estados ou mudanças de estados dos objetos informação.

- Esquema estático: é a especificação de um estado de um objeto ou conjunto de objetos informação, em um ponto específico dentro do tempo de processamento.

- Esquema dinâmico: define todos os estados de um objeto ou conjunto de objetos informação dentro do tempo de processamento.

Ponto de vista de computação: O ponto de vista de computação é utilizado para especificar as funcionalidades de uma aplicação. É baseado em objetos que possuem características como o encapsulamento de dados e processamento. Uma especificação computacional define os objetos do sistema suas atividades e as interações que ocorrem entre eles. Os objetos estão conectados por ligações através das quais as interações acontecem ou por outros objetos (de ligação) que descrevem interações complexas entre objetos. (CHÁVEZ, 2009). Neste ponto de vista existe a preocupação com a distribuição das aplicações dentro do sistema, sem se preocupar com a infra-estrutura de comunicação (BECERRA, 1998)

Ponto de vista de engenharia: O ponto de vista de engenharia é usado para especificar os aspectos da distribuição de um sistema. Ele define o modelo que conforma uma infra-estrutura de sistemas distribuídos. As entidades principais deste ponto de vista são os objetos e os canais. (CHÁVEZ, 2009). Os objetos são classificados e dois tipos: objetos básicos de engenharia (correspondentes com os 
objetos do ponto de vista de computação) e os objetos de infra-estrutura como, por exemplo, o objeto "protocolo de comunicação". Um canal corresponde a uma ligação ou a um "objeto de ligação" no ponto de vista de computação.

Ponto de vista de tecnologia: Descreve a implementação do sistema e as informações requeridas para seus testes. O padrão ODP tem poucas regras aplicáveis à especificação de tecnologia.

\subsubsection{Avaliação de Arquitetura}

A avaliação arquitetural consiste em caracterizar e avaliar os documentos arquiteturais através de métodos ou procedimentos sistemáticos (BAHSOON e EMMERICH, 2003). Essa avaliação verifica principalmente se as informações descritas no documento estão consistentes e se a arquitetura nele representada atende aos requisitos especificados para o produto (BARCELOS, 2006). Avaliação arquitetural é um dos aspectos entre muitos outros que garantem o sucesso do software, pois asseguram o controle de qualidade e a garantida de qualidade do sistema. O resultado de uma avaliação arquitetural forma a base para tomada de decisões sobre como continuar, ou não, com o desenvolvimento da arquitetura de software. Tais decisões são necessárias em todas as fases do desenvolvimento do software, como por exemplo, na fase de elicitação de requisitos, criação e projeto da arquitetura, planejamento da manutenção. Em (CLEMENTS et al., 2002) os autores apontam duas possíveis fases de avaliação arquitetural, em estágios iniciais e em estágios finais do clico de vida do software:

- Avaliação de arquiteturas que são executadas para auxiliar a tomada de decisões durante os estágios iniciais do desenvolvimento do software, neste caso a avaliação é feita para aumentar o entendimento da arquitetura de software, dos atributos de qualidade requeridos. As bases principais desse tipo de avaliação são a experiência dos desenvolvedores e cenários baseados em requisitos que estão nos documentos de requisitos.

- Avaliações que são conduzidas durante estágios mais avançados do ciclo de vida do Software. Neste caso já existe, ao menos, um projeto detalhado 
disponível no qual métricas concretas podem ser coletadas para avaliar a arquitetura de software com respeito a um ou mais atributos de qualidade.

Outra distinção pode ser feita levando em consideração as técnicas usadas por diferentes métodos de avaliação arquitetural. Em (CLEMENTS et al., 2002) os autores distingue as técnicas entre questionamentos e raciocínio.

Entre os métodos existentes o ATAM se destaca por estar centrado na

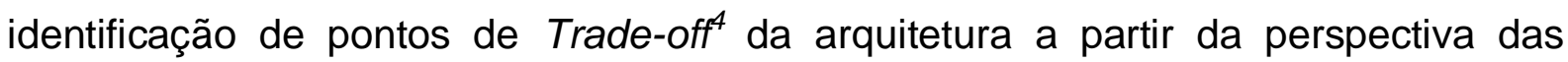
exigências de qualidade do produto.

O ATAM tem um bom histórico de aplicações bem sucedidas na prática [(BARBACCl et al. 2003), (BASS 2003)], além disso, sua característica mais relevante, e que não é encontrada em outros métodos, é a análise de tradeoff entre os atributos de qualidade diferentes (OLUMOFIN;MISIC 2005). A avaliação da qualidade de arquiteturas de sistemas como o avaliado neste trabalho requer que os requisitos específicos de arquiteturas sejam contabilizados.

No processo executado neste trabalho o foca esta na avaliação em estágios finais com o objetivo de avaliar o sistema atual para delinear as mudanças necessárias para a nova versão. Entre as diversas técnicas existentes a mais adequada para o uso no processo proposto é a técnica de avaliação de arquitetura com base em cenários e entre os métodos que utilizam esta técnica optou-se pelo ATAM como meio de apoiar as decisões arquiteturais. O ATAM além de ser baseado em cenários também é uma técnica de raciocínio usando saídas quantitativas.

Rafael Barcelos em sua dissertação (BARCELOS, 2006) apresenta uma revisão sistemática onde realiza uma comparação entre 27 abordagens de avaliação de arquiteturas. Nesta comparação é possível observar que o método ATAM é um dos métodos de avaliação mais completos. A completude do método não é razão suficiente para sua escolha o fato relevante é que o ATAM se concentra principalmente em identificar as abordagens e os estilos arquiteturais utilizados na especificação da arquitetura analisada, pois eles representam a forma que o arquiteto utilizou para adequar a arquitetura aos requisitos de qualidade especificados.

\footnotetext{
${ }^{4}$ Um ponto de trade-off é uma propriedade que afeta mais que um atributo e é um ponto sensitivo para pelo menos um atributo de qualidade. (DOBRICA; NIEMELA, 2002).
} 
Em (BAHSOON;EMMERICH, 2003) os autores fazem um levantamento sobre os métodos de avaliação de software de arquitetura. Em seguida, focam para uma classe emergente de métodos que avalia arquiteturas de software para alcançarem estabilidade e evolução. $\mathrm{O}$ artigo define a estabilidade da arquitetura e formula 0 problema de avaliar arquiteturas de software para a estabilidade e evolução. Segundo os autores, de uma perspectiva evolutiva, as revisões são atividades preventivas para retardar a decomposição (como referido por Parnas) e limitar o efeito de envelhecimento software (PARNAS,1994]. Avaliações de arquitetura representam um esforço de sábios de redução de risco e são relativamente baratos (CLEMENTS,2002).

Segundo os autores o ATAM não só revela o quanto uma arquitetura satisfaz os requisitos de qualidade, mas também revela como esses requisitos de qualidade interagem uns com os outros a partir dos trade-offs. O ATAM é um método de avaliação de arquitetura baseado em cenários. Um cenário descreve a interação do sistema a partir do ponto de vista do usuário.

\subsubsection{Decisão Arquitetural}

No processo de desenvolvimento de arquitetura de software as decisões não são explicitamente documentadas, mas estão implícitas nos modelos e arquiteturais construídas.

Apoio a decisões de engenharia de software é um complemento para reutilização de experiências em uma organização de desenvolvimento. $O$ foco de métodos de apoio à decisão é estruturar experiências para formar uma imagem mais clara, para que uma decisão possa ser tomada.

Algumas justificativas para o uso de técnicas de apoio à decisão são:

- Problemas de decisão são muitas vezes mal compreendidos e/ou descrito.

- As decisões são feitas no último momento e / ou sob pressão de tempo. 
- As decisões não se baseiam em modelos empiricamente avaliados, o melhor conhecimento e experiência e uma boa metodologia.

- As decisões são tomadas sem levar em conta as perspectivas de todas as partes envolvidas.

- As decisões não são explicadas aos envolvidos.

\subsection{Evolução de Software}

Um sistema adequado é aquele que possui uma arquitetura moldada para implementar uma série de requisitos funcionais e requisitos de qualidade (requisitos não funcionais) necessários para atender os objetivos de negócio para o qual o sistema foi proposto. Um sistema pode se tornar inadequado ao longo do tempo devido à erosão. Esse fenômeno é também conhecido como, envelhecimento de software (Software Aging) (PERRY;WOLF, 1992) ou erosão de arquitetura (JAKTMAN;LEANEY;IU, 1999).

Essencialmente o problema acontece devido à necessidade de evolução do software. A evolução consiste na realização de alterações para atender novos requisitos consertar defeitos ou otimizar atributos de qualidade (manutenções adaptativas, corretivas e de aperfeiçoamento) (SWANSON, 1976).

Os autores TU. Q e GODFREY. M. W., definem a evolução de software em "An Integrated Approach for Studying Architectural Evolution", da seguinte forma:

\footnotetext{
A Evolução de Software, uma das disciplinas emergente da engenharia de software, explora os mecanismos que afetam mudanças e fornece guidelines para melhorar o processo de evolução de software. [(TU; GODFREY, 2002), tradução nossa].
}

Esta pesquisa está essencialmente ligada à evolução de software no contexto da evolução da arquitetura de sistemas que fazem parte de uma linha de produto com o objetivo de dar suporte para construção de uma nova versão do software. A seguir é feito uma descrição das características e conceitos fundamentais da evolução de software. 
Evolução de software é o fenômeno de mudança que ocorre no software ao longo dos anos e das múltiplas versões, desde seu início até o completo abandono do sistema.

PORTER em "Fundamental Laws and Assumptions of Software Maintenance" (1997) afirma que todo software esta em um contínuo processo evolutivo. Essa evolução surge a partir de sucessivas alterações: para consertar erros, aumentar desempenho ou atender outros requisitos de qualidade e se adaptara novos ambientes. É importante salientar que essas mudanças não estão somente relacionadas com a adição e remoção de funcionalidades, mas também estão relacionadas com a manutenção do código ao longo do ciclo de vida do software. A manutenção pode aprimorar ou deteriorar tanto atributos externos de qualidade do software (percebidos pelos usuários), como por exemplo, desempenho, tolerância a falhas, disponibilidade, quanto atributos internos (percebidos pelos envolvidos no desenvolvimento) como, por exemplo, testabilidade, legibilidade, reusabilidade.

\subsubsection{Manutenção de software}

No atual estágio de maturidade, a engenharia de software passa a dedicar maior atenção à atividade de manutenção de software. Essa postura decorre, em parte, da crescente quantidade de software em funcionamento nas organizações ao redor de todo globo, que por representarem investimentos significativos, precisam continuar em funcionamento através dos anos, momento no qual surge a necessidade de manutenção de software.( PADUELLI, 2007).

A atividade de manutenção de software é caracterizada pela modificação de um produto de software já entregue ao cliente, para a correção de eventuais erros, melhora em seu desempenho, ou qualquer outro atributo, ou ainda para adaptação desse produto a um ambiente modificado (IEEE, 1998).

Embora a definição trate genericamente qualquer produto de software, existem diferenças entre a manutenção de softwares com propósitos distintos. Essa distinção é explicada por Pfleeger (2001), que estabelece três categorias de sistemas. 
A primeira categoria classifica softwares construídos com base em especificações rígidas e bem definidos. Nesse tipo de software dificilmente haverá necessidade de manutenção. A segunda categoria agrupa softwares que constituem implementações de soluções aproximadas para problemas do mundo real o desenvolvimento da solução desejada descreve o problema de forma abstrata e define os requisitos de software a partir dessa abstração. A terceira categoria considera mudanças no ambiente onde o software vai ser utilizado.

Atividades de manutenção de software são caracterizadas por intervenções no produto de software de forma a evitar a sua deterioração. Um software não se desgasta como peças de um equipamento, mas se deteriora no sentido de os objetivos de suas funcionalidades cada vez menos se adequarem ao ambiente externo.

\subsubsection{O processo de envelhecimento de software}

Segundo CHRISTOPH (2004), acreditar que uma vez que um software realize corretamente os requisitos estabelecidos para os quais ele foi construído, ele nunca mais precisará ser modificado, é um erro, pois sistemas sofrem de um processo semelhante ao envelhecimento humano. Isso é impulsionado pelo fato de que o mundo real está em constante mudança, e sistemas são feitos para refletir comportamentos do mundo real (GALL, H. et al., 1997), desta forma é necessário que o software acompanhe as mudanças de requisitos impostas pelo ambiente na qual ele está inserido. O não acompanhamento dessas mudanças pode implicar em perda de qualidade por parte do software ou até mesmo na descontinuidade do mesmo.

PARNAS em "Software Aging" (1994) afirma que entender as causas do envelhecimento de software se faz necessário para que seja possível tomar medidas para limitar seus efeitos, temporariamente reverter os danos causados por ele e se preparar para o dia em que este software não seja mais viável. 
Segundo o autor:

Existem dois tipos de envelhecimento de software: o primeiro ocorre quando há falhas na adaptação do software para atender os novos requisitos, e o segundo ocorre devido ao resultado provocado pela forma como as mudanças são realizadas no software (PARNAS, 1994 p 279).

No primeiro caso o software precisa passar por uma mudança estrutural para se adequar há um novo ambiente operacional. O segundo caso é gerado por manutenções inadequadas que afetam a estrutura, com o passar do tempo novas mudanças se tornará mais difícil e cara. Caso não seja feita uma reestruturação do software, este chegará a um ponto onde novas atualizações ficarão inviáveis.

As desvantagens causadas pelo envelhecimento de um software são a perda de desempenho devido a modificações não adequadas na sua estrutura interna, número crescente de novos erros devidos a alterações indevidas no código e perda de usuários devido à falta de meios para concorrer com versões mais recentes de sistemas semelhantes. Os efeitos do envelhecimento podem ser atrasados ou minimizados, desde que sejam tomados alguns cuidados no desenvolvimento e evolução do software em questão. Segundo PARNAS (1994) os cuidados mais importantes são:

1. Estruturar o software para a evolução: Sempre que um software tenha uma expectativa de vida longa, sua estrutura deve ser feita visando facilitar a evolução. Como não é possível saber com exatidão quais mudanças serão feitas no futuro, devem ser avaliadas as partes do software que estarão mais sujeitas a mudanças no decorrer de sua vida útil e desenvolvê-las de forma que estas mudanças ocorram mais facilmente.

2. Documentar adequadamente: Nem sempre a documentação de um projeto é escrita pela pessoa mais qualificada para tanto, e mesmo que esta venha a ser escrita adequadamente, é sempre necessário que seja atualizada a contento à medida que novas mudanças forem sendo feitas no código.

3. Revisar a estrutura: Sempre que a estimativa de vida útil do software seja longa, revisões da estrutura são fundamentais. As revisões devem começar 
antes mesmo da codificação, tais revisões são baratas, rápidas e podem poupar muito tempo e recursos no futuro.

O processo de envelhecimento de um software é inevitável, o que gera uma necessidade constante de evolução por parte de todos os sistemas que esperam se manter ativos por um longo período. Para entender o processo evolutivo em questão, é necessário entender as oito leis da evolução de software, estas leis também são conhecidas pelo nome de "Leis de Lehman" (LEHMAN, 1996).

\subsubsection{Leis da Evolução de Software}

As oito leis da evolução de software, também conhecidas por "Leis de Lehman", começaram a ser formuladas entre as décadas de 70 e 90, com a análise do processo de programação da IBM, (LEHMAN, 2001, 1996). A princípio imaginavam que todas as leis se aplicassem a qualquer evolução de software, mas estudos como apresentados em (TU; GODFREY, 2002) com o Software Livre, mostram que nem sempre isto é verdade. Neste artigo o autor mostra que o crescimento evolutivo de um software diminui ao longo do tempo e parte do crescimento vem de adições de novas funcionalidades e suporte a novas arquiteturas, e não de simples correções de erros de versões anteriores.

Também foi observado por Godfrey (2002) que projetos como o do Linux parece não obedecerem à terceira lei de Lehman, e que o esforço incremental gasto em cada versão não permanece constante durante a vida do sistema como diz a lei. Como evidencia verifica-se a grande discrepância na variação de tamanho entre os arquivos fontes de uma versão para outra (variando de alguns bytes a alguns megabytes em cada versão) e o aparecimento de novos arquivos fontes adicionados ao software. Percebe-se ainda, que o subsistema responsável pelos drivers possui um crescimento bem superior aos demais subsistemas, o que mostra que muito deste esforço incremental adicional vem do fato do surgimento de novos drivers para dar suporte a novos equipamentos. 
O Quadro 2 apresenta as oito leis.

Quadro 2 - As oito leis de Evolução de Software

\begin{tabular}{|l|l|}
\hline Mudança contínua & $\begin{array}{l}\text { "Um sistema de informação que é usado deve ser continuamente } \\
\text { adaptado, caso contrário se torna progressivamente menos satisfatório", }\end{array}$ \\
\hline Complexidade crescente & $\begin{array}{l}\text { "A medida que um programa é alterado, sua complexidade cresce a } \\
\text { menos que um trabalho seja feito para mantê-la ou diminuí-la". }\end{array}$ \\
\hline Auto-regulação & $\begin{array}{l}\text { "O processo de evolução de software é auto-regulado próximo à } \\
\text { distribuição normal com relação às medidas de produtos e atributos de } \\
\text { processos". }\end{array}$ \\
\hline $\begin{array}{l}\text { Conservação da estabilidade } \\
\text { organizacional }\end{array}$ & $\begin{array}{l}\text { "A taxa de atividade global efetiva média em um sistema em evolução é } \\
\text { constante sobre o tempo de vida do produto". }\end{array}$ \\
\hline Conservação da Familiaridade & $\begin{array}{l}\text { "Durante a vida produtiva de um programa em evolução, o índice de } \\
\text { alterações em versões sucessivas é estatisticamente invariante". }\end{array}$ \\
\hline Crescimento contínuo & $\begin{array}{l}\text { "O conteúdo funcional de um programa deve ser continuamente } \\
\text { aumentado para manter a satisfação do usuário durante seu tempo de } \\
\text { vida". }\end{array}$ \\
\hline Qualidade decrescente & $\begin{array}{l}\text { "Programas apresentarão qualidade decrescente a menos que sejam } \\
\text { rigorosamente mantidos e adaptados às mudanças no ambiente } \\
\text { operacional". }\end{array}$ \\
\hline Sistema de retorno & $\begin{array}{l}\text { "Processos de programação de software constituem sistemas de multi- } \\
\text { loop,multi-level e devem ser tratados como tais para serem modificados e } \\
\text { melhorados com sucesso". }\end{array}$ \\
\hline
\end{tabular}

As leis de Lehman ajudam a compreender como ocorre o processo evolutivo de um Software no seu aspecto funcional. No entanto devido ao avanço das técnicas, processos e práticas de desenvolvimento e manutenção de software nos últimos 10 anos, além do aumento de projetos de software livre no cenário mundial, verificou-se a partir de alguns estudos de casos que as leis da evolução de software necessitam de uma revisão profunda. Um dos fatos que talvez levem a esta revisão, é que os estudos que levaram as formulações das leis usaram como base processos de desenvolvimento de sistemas baseados em sistemas centralizados e corporativos, com código fechado e de grande porte com poucos concorrentes no mercado e para uso de grandes corporações. Tais características em nada se assemelham a sistemas atuais (como por exemplo, os projetos de software livre) que são geralmente feitos e mantidos em sistemas descentralizados e coletivamente por uma comunidade ou mesmo uma equipe de desenvolvimento distribuída. (SCACCHI, 2004).

Considerando que um dos principais objetivos de se projetar uma arquitetura é o de atingir a qualidade desejada pelos interessados no sistema, fica claro o papel da arquitetura em conduzir a evolução do software, uma vez que ela conterá 
decisões que contribuirão para a preservação da qualidade do sistema durante seu ciclo de vida.

\subsection{Requisitos não-funcionais e atributos de qualidade}

Um software tem como objetivo atender aos seus requisitos funcionais e nãofuncionais. Os requisitos funcionais descrevem as funções que o software deve ser capaz de realizar, ou seja, o que o sistema faz. Já os requisitos não-funcionais descrevem as qualidades e restrições de como o sistema realiza suas funções, ou seja, como o sistema funciona. Um software, portanto, deve exibir atributos de qualidade que atendam aos seus requisitos.

A arquitetura de software descreve como o software atende aos requisitos não-funcionais para alcançar os atributos de qualidade através das diversas decisões presentes na arquitetura. Para conceber essas decisões arquiteturais e, portanto, para projetar a arquitetura, é de fundamental importância que o arquiteto conheça tanto os objetivos a serem alcançados pelo software, quanto às ferramentas para alcançá-los. Em outras palavras é essencial que ele conheça tanto os atributos de qualidade, quanto técnicas e padrões de design arquitetural que, ao serem implementados, possibilitam ao software que exiba os atributos de qualidade desejados.

Nesta seção, será apresentada uma visão geral do assunto, abordando diversos atributos que devem ser alcançados tendo como objetivos:

- Identificar o que são atributos de qualidade e qual é sua influência na arquitetura de software;

- Relacionar atributos de qualidade a decisões arquiteturais que os proporcionam;

- $\quad$ Entender que os atributos de qualidade se relacionam e como eles se relacionam. 


\subsubsection{Requisitos não-funcionais}

Os requisitos não-funcionais estão relacionados à qualidade da realização dos requisitos funcionais, ou seja, como essas funções são realizadas, e por isso podem ser identificados nas colocações dos diversos stakeholders sobre os requisitos funcionais ou podem ser explicitamente impostos pelos diversos stakeholders do software.

Requisito não-funcional pode ser definido como a descrição de propriedades, características ou restrições que o software apresenta exibidas por suas funcionalidades.

Exemplo de requisitos não-funcionais:

- (RNF01): O sistema deve permitir o chek-in de passageiro por diversas interfaces diferentes: navegador de internet, celular, aplicação-cliente compatível com os sistemas operacionais Windows e Linux;

- (RNF02): O sistema deve suportar até 3 mil atendimentos de passageiros por dia em operações de 2 minutos;

As restrições feitas pelos requisitos não-funcionais são várias e podem incluir restrições ao processo de desenvolvimento, restrições para atingir ou manter compatibilidade, e restrições legais, econômicas ou de interoperabilidade.

As restrições ao processo de desenvolvimento podem ser feitas pela imposição de padrões ou linguagens de desenvolvimento. Por exemplo, um requisito não-funcional de um sistema pode ser determinar que o software seja implementado em uma determinada linguagem, dado que a equipe responsável pela operação e manutenção seja experiente nessa linguagem.

Os requisitos não-funcionais podem ainda ser divididos em três tipos:

- Requisito não-funcional de produto: Requisito que especifica as características que um sistema ou subsistema deve possuir. Estão relacionados à qualidade do software e são alcançados pelos atributos de qualidade. Por exemplo, grau de confiabilidade, nível de eficiência, portabilidade para diversos sistemas operacionais, são atributos de qualidade que o software deve exibir. 
- Requisito não-funcional de processo: Requisito que restringe o processo de desenvolvimento do software. Esse tipo de requisito é encontrado em empresas ou organizações que possuem um processo já definido.

- Requisitos não-funcionais externos: Requisito derivado do ambiente em que o sistema é desenvolvido, que pode ser tanto do produto quanto do processo. $O$ ambiente pode ser tanto a organização, como políticas que devem ser seguidas, quanto à legislação vigente do país em que o sistema está operando.

Os livros Software Engineering, de Sommerville (2004), Requirements Engineering: Processes and Techniques, de Sommerville e Kotonya (KOTONYA; SOMMERVILLE, 2008), Software Engineering: A Practitioner's Approach de Pressman (1994), dedicam alguns capítulos a este assunto. No entanto, o foco desses livros é no papel dos requisitos de software no processo de desenvolvimento. Já o artigo Defining Non-Functional Requirements, de Malan e Bredemeyer (MALAN; BREDEMEYER, 2001), é mais voltado à influência dos requisitos na arquitetura.

\subsubsection{Atributos de qualidade}

Bass e outros no livro Software Architecture in Practice, mostra o papel dos atributos de qualidade na arquitetura de software. Além dele, Gorton (GORTON, 2006) faz uma pequena introdução a este assunto ao tratar do estudo de caso presente em Essential Software Architecture. Os livros Software Systems Architecture, de Rozanski (ROZANSKI,1995), e Code Complete, de Steve McConnell, também dedicam seções aos atributos de qualidade de software, sendo o primeiro em nível de design arquitetural e o segundo em nível de design detalhado.

É comum encontrar a afirmação que o software possui requisitos nãofuncionais a serem atendidos, é que exibe atributos de qualidade que atendem aos requisitos em questão. Portanto, atributos de qualidade estão mais relacionados aos objetivos já alcançados, enquanto requisitos são os objetivos propostos. 
Segundo Dobrica (2002), "Um atributo de qualidade é uma característica nãofuncional de um componente e sistema" (DOBRICA, 2002 p. 639).

A arquitetura permite que o software atenda aos atributos de qualidade especificados. Já que a especificação dos atributos é feita pelos requisitos (normalmente não-funcionais), requisitos e atributos de qualidade partilham diversas características. Alguns autores usam ambas as expressões com o mesmo sentido.

Assim como acontece com os requisitos não funcionais, os atributos não existem isoladamente e, por afetarem partes em comum da arquitetura, afetam também outros atributos de qualidade. Eis que surgem os trade-offs entre os

atributos de qualidade. É papel do arquiteto, conhecer e resolver os trade-offs entre os atributos de qualidade durante as fases de design e implementação.

Uma das principais preocupações da arquitetura é o atendimento aos atributos de qualidade do sistema, também referenciados como Requisitos Não Funcionais. Atributos de qualidade determinam a maneira como o sistema executará suas funcionalidades. Esses atributos são impostos pelos diversos interessados no sistema e podem ser classificados em três tipos: atributos do produto, atributos organizacionais, e atributos externos.

Atributos de qualidade do produto são aqueles que ditam como o sistema vai se comportar. A seguir relacionamos os atributos de qualidade que serão usados como referência para avaliação arquitetural realizada neste trabalho.

Atributos de qualidade organizacionais são consequências de políticas ou procedimentos organizacionais. Em outras palavras, o sistema deve respeitar padrões ou regras impostas por uma ou mais organizações envolvidas para atender a esses requisitos.

\subsubsection{Padrão ISO/IEC 9126-1:2007}

O Padrão ISO/IEC 9126-1:2007 é um padrão internacional para avaliação de software. Na primeira parte do padrão são apresentadas as qualidades internas e externas do software. Essas qualidades são apresentadas na forma de uma lista 
exaustiva de características ou atributos de qualidade. Os atributos que um software deve possuir para que possamos dizer que ele é de qualidade são os seguintes:

- Funcionalidade: É a capacidade do software de realizar as funções que foram especificadas. Apesar de parecer óbvio, seu propósito é claro quando avaliado se esse sistema faz menos do que é esperado dele. Neste caso ele não serve, mesmo que o pouco que ele faça, seja feito de forma usável e confiável ou eficientemente.

- Confiabilidade: Um sistema é confiável, quando é capaz de manter algum nível de desempenho quando funcionando sob circunstâncias determinadas. A confiabilidade é normalmente definida sob períodos de tempo. Vale observar que, a medida de confiabilidade pode ser sazonal, definidas a partir de cenários críticos que acontecem em uma determinada época do ano.

- Usabilidade: Usabilidade é a medida da facilidade de o usuário executar alguma funcionalidade do sistema. Essa facilidade está ligada diretamente à compreensibilidade, à facilidade de aprendizado, à operabilidade, a quanto o usuário se sente atraído pelo sistema e à adesão de padrões de usabilidade, que são as subcaracterísticas desse atributo de qualidade.

- Eficiência: A eficiência ou desempenho é talvez a qualidade mais buscada durante o desenvolvimento de software, uma vez que ela é a mais percebida pelos usuários. Ela é a qualidade relacionada ao uso de recursos do sistema quando esse provê funcionalidade e é também a com que os desenvolvedores mais se preocupam.

- Manutenibilidade: é uma qualidade, às vezes, negligenciada pelos usuários, mas muito importante aos desenvolvedores. Ela é a capacidade de o software ser modificado em seu processo de evolução.

- Portabilidade: O último atributo de qualidade presente no padrão ISO/IEC 9126-1:2007 é o de portabilidade. Esse atributo é a medida de adaptações necessárias para que o sistema tenha seus requisitos ou ambientes de execução modificados, podendo ser o ambiente de software, de hardware ou organizacional. Esse atributo é importante, por exemplo, para jogos e aplicativos para celulares, uma vez que é desejável que eles sejam capazes de executar no maior número de plataformas e modelos diferentes, mas também é desejável que o custo para tornar isso possível seja baixo. Portanto, não faz sentido que o mesmo aplicativo seja 
reimplementado diversas vezes, mas sim que seja projetado de forma a minimizar o esforço para alterar o ambiente de hardware.

É importante enfatizar que essa lista tem como objetivo ser exaustiva. Portanto, de acordo com a norma, todas as qualidades que venham a ser requisitadas ao software estão presentes nessa lista. No padrão, cada característica é ainda quebrada em subcaracterísticas, que são mais específicas, a fim de facilitar o entendimento e a avaliação. Algumas subcaracterísticas importantes a cada atributo de qualidade estão apresentadas no Quadro 3:

Quadro 3 - Subcaracterísticas importantes aos atributos de qualidade

\begin{tabular}{|c|c|c|}
\hline & FUNCIONALIDADE & REQUISITO \\
\hline \multirow{4}{*}{$\begin{array}{l}\frac{0}{0} \\
\frac{\pi}{0} \\
\frac{0}{0} \\
\frac{0}{0} \\
\frac{0}{0} \\
\text { 5 } \\
4\end{array}$} & Adequação & Capacidade de prover as funções necessárias para os objetivos dos usuários. \\
\hline & Precisão & Capacidade de prover os resultados com o grau de precisão adequado. \\
\hline & Interoperabilidade & Capacidade de interagir com outros sistemas. \\
\hline & Segurança & $\begin{array}{l}\text { Capacidade de funcionar segundo os princípios de autenticação, autorização, } \\
\text { integridade e não repudiação. }\end{array}$ \\
\hline \multirow{3}{*}{$\begin{array}{l}\frac{0}{0} \\
\frac{\pi}{0} \\
\frac{0}{0} \\
0 \\
0 \\
0 \\
0 \\
0\end{array}$} & Maturidade, & Capacidade de se prevenir de falhas resultantes de faltas de software. \\
\hline & Tolerância a falhas, & $\begin{array}{l}\text { Capacidade de manter alguma qualidade de serviço em caso de faltas de } \\
\text { software ou comportamento imprevisto de usuários, software ou hardware. }\end{array}$ \\
\hline & Recuperabilidade, & $\begin{array}{l}\text { Ou resiliência, é a capacidade do sistema voltar ao nível de desempenho } \\
\text { anterior as falhas de software, hardware ou devido ao comportamento } \\
\text { imprevisto de usuários, e recuperar os dados afetados, caso existam. }\end{array}$ \\
\hline \multirow{4}{*}{ 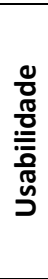 } & Compreensibilidade & Capacidade de o usuário entender o sistema. \\
\hline & & \\
\hline & Facilidade de aprendizado & $\begin{array}{l}\text { Está ligada diretamente à compreensibilidade. No entanto, neste caso, a } \\
\text { qualidade é a de o usuário aprender a usar o software, caso ele saiba que o } \\
\text { software serve para ele. }\end{array}$ \\
\hline & Operabilidade & Capacidade de o usuário operar ou controlar o sistema. \\
\hline \multirow{2}{*}{$\frac{\pi}{\frac{\pi}{U}}$} & Desempenho & $\begin{array}{l}\text { Comportamento no tempo, ou a capacidade do sistema de alcançar a resposta } \\
\text { dentro do período de tempo especificado }\end{array}$ \\
\hline & Uso de recursos & $\begin{array}{l}\text { Ou escalabilidade capacidade de o software exigir mais ou menos recursos de } \\
\text { acordo com suas condições de uso. }\end{array}$ \\
\hline \multirow{3}{*}{ 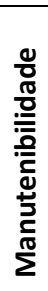 } & Analisabilidade & $\begin{array}{l}\text { Grau de facilidade com que podemos procurar por deficiências no software ou } \\
\text { por partes que devem ser modificadas para algum fim. }\end{array}$ \\
\hline & Modificabilidade & Capacidade de realizar mudanças de implementação no sistema \\
\hline & Testabilidade & Capacidade de o software ter suas mudanças validadas. \\
\hline \multirow{3}{*}{$\begin{array}{l}\frac{0}{0} \\
\frac{\pi}{0} \\
\frac{0}{0} \\
0 \\
0 \\
0 \\
0\end{array}$} & Adaptabilidade & $\begin{array}{l}\text { Capacidade de o software ser portado para outro ambiente sem precisar de } \\
\text { modificações além das previstas. }\end{array}$ \\
\hline & Instalabilidade & Capacidade de o software ser instalado em algum ambiente específico. \\
\hline & Co-existência & $\begin{array}{l}\text { Capacidade de o software compartilhar recursos em um mesmo ambiente com } \\
\text { outros sistemas. }\end{array}$ \\
\hline
\end{tabular}




\subsubsection{Atributos de Negócio}

Além dos atributos de qualidade apresentados existem ainda alguns atributos adicionais que merecem ser citados. São chamados os atributos de qualidade de negócio, que, apesar de não serem ligados diretamente ao software, têm grande influência sobre sua arquitetura. Eles são importantes porque influenciam principalmente as decisões de resolução de conflitos dos atributos apresentados anteriormente.

Os atributos de negócio são apresentados no Quadro 4.

Quadro 4 - Os atributos de negócio.

\begin{tabular}{|c|c|c|}
\hline \multirow{5}{*}{ 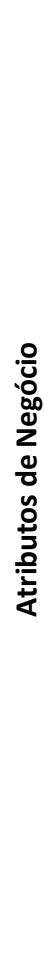 } & Mercado-alvo & $\begin{array}{l}\text { O arquiteto só é capaz de priorizar os atributos de qualidade em seu design se conhecer o } \\
\text { público e o mercado para o qual o software está sendo construído. Por exemplo, se o alvo é } \\
\text { o publico geral portabilidade e funcionalidade são importantes. Por outro lado, para } \\
\text { sistemas especialistas, é possível priorizar a eficiência em detrimento da portabilidade ou da } \\
\text { usabilidade, uma vez que os usuários comuns desse sistema são operadores qualificados. }\end{array}$ \\
\hline & Time-to-market & $\begin{array}{l}\text { É o tempo entre a concepção do software e sua entrega no mercado. Esse atributo se torna } \\
\text { importante, principalmente, quando a janela de oportunidade é pequena devido a produtos } \\
\text { concorrentes. }\end{array}$ \\
\hline & Custo e benefício & $\begin{array}{l}\text { Como os recursos financeiros para se desenvolver o software são limitados, cada decisão } \\
\text { arquitetural deve ter seu custo e o benefício proporcionado analisados e, com base nessa } \\
\text { análise, priorizados ou até mesmo descartados. Essa análise deve levar em conta o } \\
\text { ambiente de desenvolvimento em questão: capacidades do time de desenvolvimento, } \\
\text { ferramentas disponíveis para o reuso e os objetivos do software. }\end{array}$ \\
\hline & Vida útil & $\begin{array}{l}\text { O design de sistemas de grande vida útil deve priorizar diferentes atributos de qualidade se } \\
\text { os compararmos com o design de sistemas de vida mais curta, como protótipos. No } \\
\text { primeiro tipo de sistemas, atributos de manutenibilidade e portabilidade são mais } \\
\text { valorizados; no segundo, são priorizados atributos de eficiência e funcionalidade. }\end{array}$ \\
\hline & $\begin{array}{ll}\text { Agenda } & \text { de } \\
\text { lançamento } & \end{array}$ & $\begin{array}{l}\text { O design do software é muito dependente de como ele vai ser disponibilizado a público. Por } \\
\text { exemplo, se o software será disponibilizado em fases distintas que englobarão diferentes } \\
\text { conjuntos de funcionalidades, ele deve ser dividido de modo que funcione sem as partes } \\
\text { que ainda não foram disponibilizadas, mas facilite tanto a modificabilidade, facilitando a } \\
\text { adição de novas funcionalidades, quanto à interoperabilidade entre diferentes versões. Já } \\
\text { se o software será disponibilizado sem possibilidade de posterior atualização, como } \\
\text { acontece em muitos sistemas embarcados, preocupações de modificabilidade e } \\
\text { interoperabilidade entre versões podem ser descartadas. }\end{array}$ \\
\hline
\end{tabular}

Informações sobre atributos de qualidade de negócio podem ser encontradas nos livros Software Architecture in Practice, de Bass et al, e Beyond Software Architecture de Hohmann (HOHMANN, 2003). 


\subsubsection{Conflitos}

Dois ou mais requisitos podem reforçar o mesmo atributo de qualidade, caso isso ocorra, o design da solução que atenda a um dos requisitos afetará apenas positivamente o design da solução que atenda aos outros requisitos. Por outro lado os requisitos de software podem gerar impacto em um ou mais atributos de qualidade, relacionados a requisitos diferentes. Quando isso ocorre, o impacto pode resultar em reforço do atributo ou em conflito.

O principal motivo que faz com que atributos de qualidade conflitem é por eles serem impostos por stackholders diferentes. As preocupações conflitantes entre diferentes interessados podem gerar conflitos nos atributos de qualidade. É tarefa do arquiteto resolver, ponderar, ou ao menos mediar esses conflitos, considerando assim os diversos trade-offs envolvidos para se alcançar os objetivos do software, através da arquitetura.

Resumindo, atributos de qualidade se relacionam de forma que um pode ajudar ou mesmo dificultar o atendimento de outros, gerando conflitos. Essas relações entre atributos acontecem mesmo que eles sejam de tipos diferentes. Por exemplo, em um sistema de mensagens instantâneas com os seguintes requisitos:

(RNF-A): O sistema de check-in deve permitir a autenticação dos usuários.

(RNF-B): Uma passagem vendida por uma agencia não pode ser alterada por outra.

Observe que os requisitos RNF-A e RNF-B se relacionam, uma vez que afetam a alguns aspectos de segurança do sistema. Eles se reforçam visto que é possível encontrar uma solução para RNF-A que facilite RNF-B e vice-versa. A solução no caso é a utilização criptografia de chave pública: tanto ela pode ser usada para autenticação de usuários quanto pode ser usada para encriptação de mensagens.

Por outro lado, requisitos conflitantes são mais comuns e adicionam dificuldade durante o design das soluções. Isso ocorre porque a solução para um requisito conflitante afeta negativamente outro requisito. Assim, o design do software 
terá que considerar diversos trade-offs a fim satisfazer melhor aos requisitos mais importantes, já que atender a todos de forma ótima não é possível.

Adicionando alguns requisitos de usabilidade ao sistema de envio de mensagem esses novos requisitos certamente afetarão negativamente à solução apresentada. Isso ocorre porque é comum que soluções de segurança afetem aos requisitos de usabilidade, visto que essas soluções adicionam conceitos não familiares aos usuários (por exemplo, chaves criptográficas) ou adicionam mais passos para que os usuários realizem suas tarefas (por exemplo, inserir login e senha)

Outro exemplo de conflito: o atributo de qualidade desempenho pode afetar os níveis de testabilidade e entendimento do sistema (usabilidade).

\section{Cenário: (Desempenho X Testabilidade)}

Uma forma de melhorar o desempenho do sistema é diminuir os níveis de indireção usados na comunicação entre dois elementos. Uma maneira simples é fazer com que algumas chamadas presentes na camada de apresentação usassem diretamente a camada de persistência, sem usar a regra de negócio. Desta forma as chamadas da apresentação ficam mais rápidas, uma vez que menos chamadas remotas seriam executadas. No entanto, quando diminui a camada de abstração entre dois elementos inicialmente distintos, aumenta 0 acoplamento entre eles e, portanto, dificulta o entendimento ou mesmo a testabilidade.

Como outro exemplo observe que o atributo de segurança afeta dois atributos distintos: o desempenho e a usabilidade do sistema. 


\section{Cenário: (Segurança X Desempenho)}

Uma forma de aumentar a segurança de um sistema operacional é requerer autorização do usuário para a realização de certas operações. No entanto, o processo de verificação do usuário (além de todos os elementos e abstrações do sistema relacionado à segurança: unidade certificadora, unidade verificadora, listas de controle de acesso, entre outros.) deteriorará o desempenho da aplicação, dado que consumirá recursos que poderiam ser destinados à operação em si - não a um aspecto dito não-funcional dela. Além disso, o sistema vai ficar menos usável, uma vez que pedirá uma verificação, seja senha, impressão digital, ou certificado, para cada operação sensível a ser executada.

Os atributos de desempenho e portabilidade também podem ser conflitantes observe o seguinte cenário:

\section{Cenário: (Desempenho X Portabilidade)}

Um cliente de um jogo para celular requisitou que o jogo tivesse um bom desempenho nos diversos aparelhos disponíveis no mercado. No entanto, o gerente de projeto sugere que o tempo gasto para portar o software de um aparelho para outro seja mínimo, uma vez que o prazo do projeto em questão é curto. Podemos então observar dois requisitos conflitantes: desempenho e portabilidade.

Esse conflito ocorre porque as técnicas para alcançar ambos os requisitos são divergentes. Para Alcançar portabilidade, normalmente é necessário o uso de diversas camadas de abstração, principalmente de hardware. No entanto, a adição dessas camadas de abstração significa uma perda em desempenho, uma vez que aumentará o número de chamadas necessárias para se realizar qualquer operação. E isso se torna ainda mais significativo no caso dos aparelhos celulares, que podem ser limitados em termos de recursos computacionais como processador ou memória. Assim, a arquitetura do sistema terá que ponderar entre as técnicas disponíveis de modo que atenda em parte cada requisito e, assim, ambos os interessados fiquem satisfeitos.

Dois outros atributos de qualidade que normalmente conflitam são os atributos usabilidade e segurança, como veremos no cenário a seguir. Nesse caso, ambos os atributos foram requisitados pelo mesmo interessado, o usuário, e, mesmo assim, se tornaram conflitantes. 


\section{Cenário: (Usabilidade X Segurança)}

Quando usando um sistema operacional, um mesmo usuário procura atributos de segurança e usabilidade para suas operações. Para segurança, ele deseja que suas operações no sistema ou seus resultados não sejam afetados por ações de outros usuários. Esse atributo, que na arquitetura implicará em soluções de autenticação, verificação, listas de permissões, etc., imporá que as tarefas realizadas por qualquer usuário eventualmente terão sua autenticidade e permissão verificadas. Essa interrupção para realizar as devidas autorizações deteriora o atendimento do atributo de usabilidade, uma vez que o usuário terá suas atividades interrompidas por algo que não gera resultado para ele.

Assim como os interesses de cada stakeholder não são isolados e podem afetar os de outro por meio dos requisitos não-funcionais, os atributos de qualidade não surgem isolados no software. Uma decisão arquitetural feita com o objetivo de alcançar um atributo de qualidade pode ter efeito em outros atributos. Por uma decisão arquitetural nunca ser isolada no design da arquitetura, o arquiteto deve sempre entender quais atributos a decisão afeta, seja positivamente ou negativamente, e fazer as devidas concessões caso ela afete atributos de qualidade conflitantes. As técnicas de design arquitetural não afetem cada atributo de software isoladamente o que leva aos conflitos.

\subsubsection{Método de Avaliação de Arquitetura por Trade-off (ATAM)}

O ATAM é um método de avaliação que estende a análise de sistemas permitindo que ela seja repetível e transacional. Tendo um método estruturado ajuda a garantir que as questões importantes sobre a arquitetura são levantadas o mais cedo possível. Durante os estágios de levantamento de requisitos e projeto podem ser descobertos problemas que descobertos mais cedo são mais baratos para resolver. Este método guia os stakholders na observação dos conflitos e para resolução destes conflitos na arquitetura de Software. 
O Quadro 5 apresentada a seguir mostra os passos do ATAM

Quadro 5- Os passos do ATAM.

\begin{tabular}{|c|c|c|c|}
\hline \multirow{5}{*}{ 选 } & ETAPAS & RESUTADO & DESCRIÇÃO \\
\hline & 1 - APRESENTAR O ATAM & $\begin{array}{l}\text { Esclarecer aos } \\
\text { stakeholders }\end{array}$ & $\begin{array}{l}\text { Neste passo é realizada uma reunião onde é descrito o } \\
\text { método para os participantes do projeto } \\
\text { (stakeholders), apresentando as expectativas da } \\
\text { avaliação, aprender sobre os as metas de qualidades } \\
\text { principais para o sistema e conhecer junto ao arquiteto } \\
\text { a arquitetura inicial do negócio e os principais cenários. }\end{array}$ \\
\hline & $\begin{array}{l}2 \text { - APRESENTAR BUSINESS } \\
\text { DRIVERS }\end{array}$ & $\begin{array}{l}\text { Especialista } \\
\text { apresenta } \\
\text { situação crítica de } \\
\text { negócio }\end{array}$ & $\begin{array}{l}\text { Neste passo começa o ATAM propriamente dito. São } \\
\text { reunidos os stakeholders mais importantes do sistema } \\
\text { para facilitar a geração de idéias de cenários de } \\
\text { usuários, falhas, e antecipar mudanças. }\end{array}$ \\
\hline & $\begin{array}{l}3 \text { - APRESENTAR } \\
\text { ARQUITETURA }\end{array}$ & $\begin{array}{l}\text { High-level } \\
\text { alinhado com } \\
\text { plano de negócio }\end{array}$ & $\begin{array}{l}\text { A arquitetura é apresentada em detalhes e os cenários } \\
\text { mais importantes e ilustrativos são traçados sobre a } \\
\text { arquitetura, ajudando a entender o sistema e, em } \\
\text { particular, como dados e fluxos são controlados. Os } \\
\text { analistas tentam identificar e sondar as ramificações } \\
\text { de estilos arquitetônicos aqui. }\end{array}$ \\
\hline & $\begin{array}{l}4 \text { - IDENTIFICAR } \\
\text { ABORDAGEM } \\
\text { ARQUITETURAL }\end{array}$ & $\begin{array}{l}\text { Soluções } \\
\text { diferentes são } \\
\text { destacadas e } \\
\text { discutidas }\end{array}$ & $\begin{array}{l}\text { É utilizado um conjunto de padrões de qualidade e } \\
\text { questões de atributos específicos para garantir que os } \\
\text { requisitos de qualidade são atendidos pelos cenários. } \\
\text { Em particular nós observamos se as condições limites } \\
\text { tenham sido consideradas }\end{array}$ \\
\hline 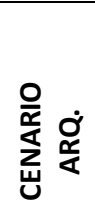 & $\begin{array}{l}5 \text { - GERAR ÁRVORE DE } \\
\text { UTILIDADE. }\end{array}$ & $\begin{array}{l}\text { Core business } \mathrm{x} \\
\text { requisitos } \\
\text { técnicos mapa } \\
\text { cenário }\end{array}$ & $\begin{array}{l}\text { Os stakeholders votam nos cenários que acham mais } \\
\text { importantes. Durante esta fase eles podem sugerir } \\
\text { agrupamentos de cenários. Depois que a votação esta } \\
\text { completa, os avaliadores determinam um ponto de } \\
\text { corte com até } 15 \text { cenários. }\end{array}$ \\
\hline \multirow{3}{*}{ 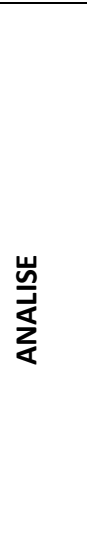 } & $\begin{array}{l}6 \text { - ANÁLISE E ELEMENTOS } \\
\text { ARQUITETURA }\end{array}$ & $\begin{array}{l}\text { Cada cenário é } \\
\text { analisado e } \\
\text { priorizado } \\
\text { Criticidade } \\
\text { Sensibilidade }\end{array}$ & $\begin{array}{l}\text { Neste passo o arquiteto observa cada atributo de } \\
\text { qualidade estratégico dos cenários especificados, } \\
\text { mostrando como eles afetam a arquitetura e como a } \\
\text { arquitetura responde a esses atributos (por exemplo, } \\
\text { para atributos como desempenho, segurança e } \\
\text { disponibilidade). }\end{array}$ \\
\hline & $\begin{array}{l}\text { 7- BRAINSTORM PARA } \\
\text { PRIORIZAÇÃO DE CENÁRIOS }\end{array}$ & $\begin{array}{l}\text { Grupo de } \\
\text { stakeholders } \\
\text { Expansão de } \\
\text { cenários }\end{array}$ & $\begin{array}{l}\text { O arquiteto guia a analise mostrando porque a } \\
\text { arquitetura atende a os requisitos do atributo, como } \\
\text { iluminado pelo cenário de interesse. O analista } \\
\text { constrói modelos de cada atributo de qualidade } \\
\text { baseado nas informações do arquiteto. }\end{array}$ \\
\hline & $\begin{array}{l}8 \text { - ANALISA SOLUÇÕES } \\
\text { ARQUITETURA }\end{array}$ & Repete item 6 & $\begin{array}{l}\text { Para achar os pontos de conflitos é necessário localizar } \\
\text { todos os elementos arquiteturais importantes onde } \\
\text { existem múltiplos pontos sensitivos. }\end{array}$ \\
\hline ๖ั & $\begin{array}{l}9-\text { FORNECEM } \\
\text { DOCUMENTOS PARA } \\
\text { STAKEHOLDERS }\end{array}$ & Comunicação & $\begin{array}{l}\text { Esse plano é um conjunto de recomendações para } \\
\text { reestruturar a arquitetura sob a luz dos resultados da } \\
\text { analise. Adicionalmente devem ser levantadas } \\
\text { questões sobre a documentação como: informação } \\
\text { arquitetural, cenários, informação ambiental, detalhes } \\
\text { de restrições e justificativas para os requisitos de } \\
\text { qualidade. }\end{array}$ \\
\hline
\end{tabular}

O método é dividido em 9 etapas, o primeiro passo introduz o método para os participantes em duas etapas, que apresentam os objetivos do negócio e as soluções arquiteturais respectivamente. 
A etapa 4 identifica as principais abordagens de arquitetura responsável pela qualidade do sistema.

A etapa 5 cria a árvore utilidade $(A U)$, que refina os direcionamentos de negócio em metas de qualidade e em cenários concretos que representem os objetivos.

As etapas finais identificam a sensibilidade de arquitetura (decisão arquiteturais chave para um atributo de qualidade específico) pontos de trade-offs (decisões arquiteturais que envolvem múltiplos atributos de qualidade) e riscos. (COLQUITT; LEANEY, 2007). 


\section{ROTEIRO PARA AVALIAÇÃO DE ARQUITETURA}

O processo utilizado para criação do plano de evolução tem como referência o método de avaliação de arquiteturas - ATAM. A figura 1 apresenta um esquema do processo.

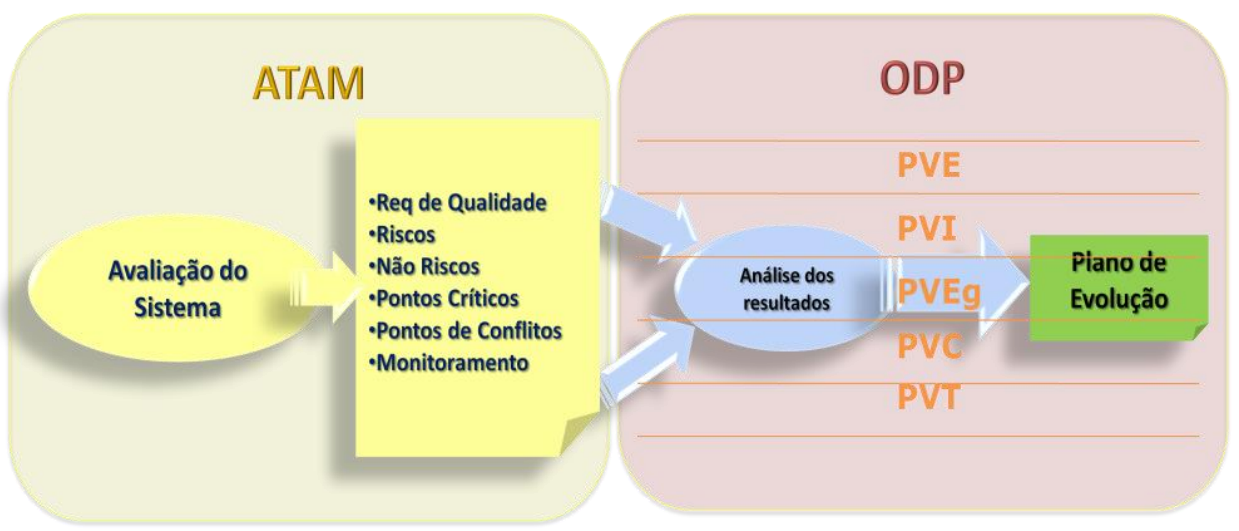

Figura 1 - Estrutura do roteiro utilizado na pesquisa

O roteiro inicia com a aplicação dos 9 passos do método de avaliação ATAM. O resultado gerado será resumido em um relatório contendo os novos requisitos de qualidade, os riscos, não riscos, pontos críticos, pontos de conflitos, monitoramento e as Decisões Arquiteturais que foram levantadas. Estes dados serão analisados pelos avaliadores e Estratégias serão elaboradas para cada ponto de vista do modelo de referência ODP. Desta avaliação será gerado o Plano de evolução que orientarão as ações que devem ser executadas pelos envolvidos em cada ponto de vista.

Nas seções seguintes são apresentadas as atividades executada em cada passo com base no método de referência.

\subsection{Avaliação do sistema através do ATAM}

O método de avaliação ATAM possui 9 passos bem definidos. O processo utilizado neste trabalho toma como base os 9 passos realizando adaptações nas 
atividades executadas em cada passo no sentido de observar as leis de evolução do software. Os passos foram agrupados nas fases relacionadas a seguir:

\subsubsection{FASE I- Apresentação}

A apresentação envolve a troca de informação entre os participantes. O objetivo é que os envolvidos conheçam e entendam sobre o método usado para avaliação e a equipe de avaliadores conheça a arquitetura do sistema avaliado. Esta fase é composta pelos passos 1,2 e 3 detalhados a seguir.

\subsubsection{Passo 1-Apresentar o ATAM}

O líder da avaliação descreve o método da avaliação para os participantes (CLEMENTS; KAZMAN; KLEIN, 2009). A figura 2 resume os artefatos utilizados neste passo, as atividades desenvolvidas e as saídas. Este passo tem como objetivo esclarecer o processo aos envolvidos, que pode ser feito por memorandos, reuniões ou conferências. Como saída devem ser registradas evidências da realização das atividades.

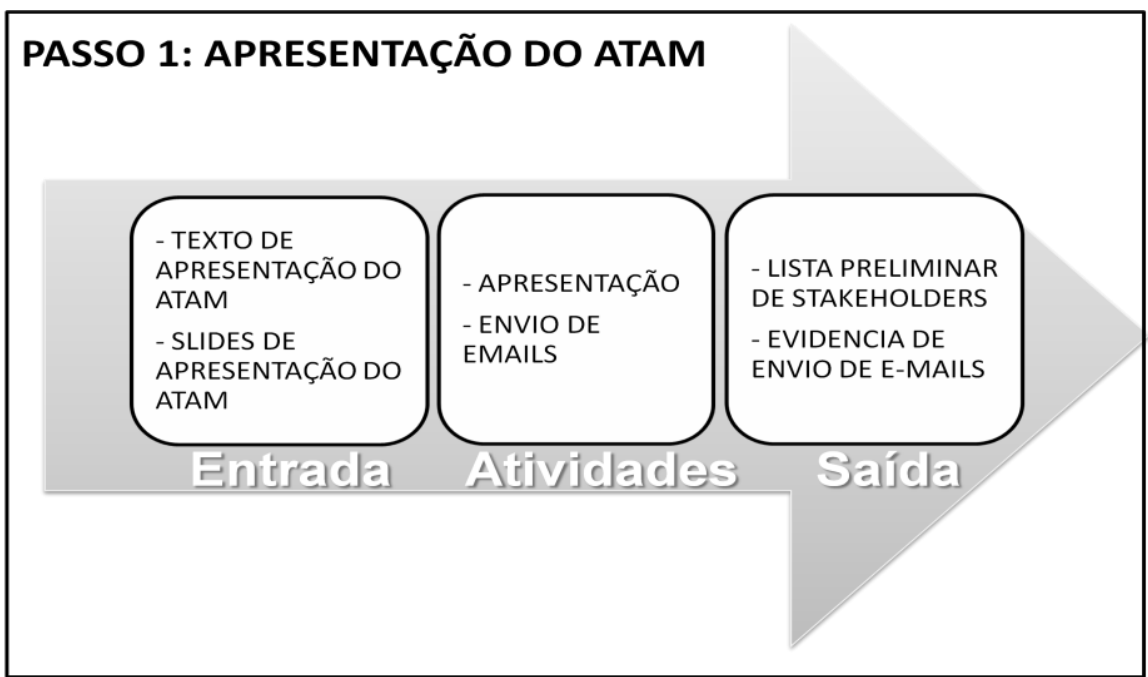

Figura 2: Esquema para apresentação do ATAM (Passo 1). 
No caso de impossibilidades na reunião do stakholders deve ser preparado um documento explicando o processo, os envolvidos e o papel de cada envolvidos e deve ser enviado aos participantes.

\subsubsection{Passo 2-Apresentar os objetivos de negócio}

O representante do projeto descreve quais são os objetivos de negócio que motivam os esforços da equipe, o que resultam nas características de qualidade de interesse do sistema (CLEMENTS; KAZMAN; KLEIN, 2009). A figura 3 resume os artefatos utilizados neste passo, as atividades desenvolvidas e as saídas. São apresentadas as documentações do sistema e suas principais características e restrições. As saídas serão necessárias para o desenvolvimento dos próximos passos.

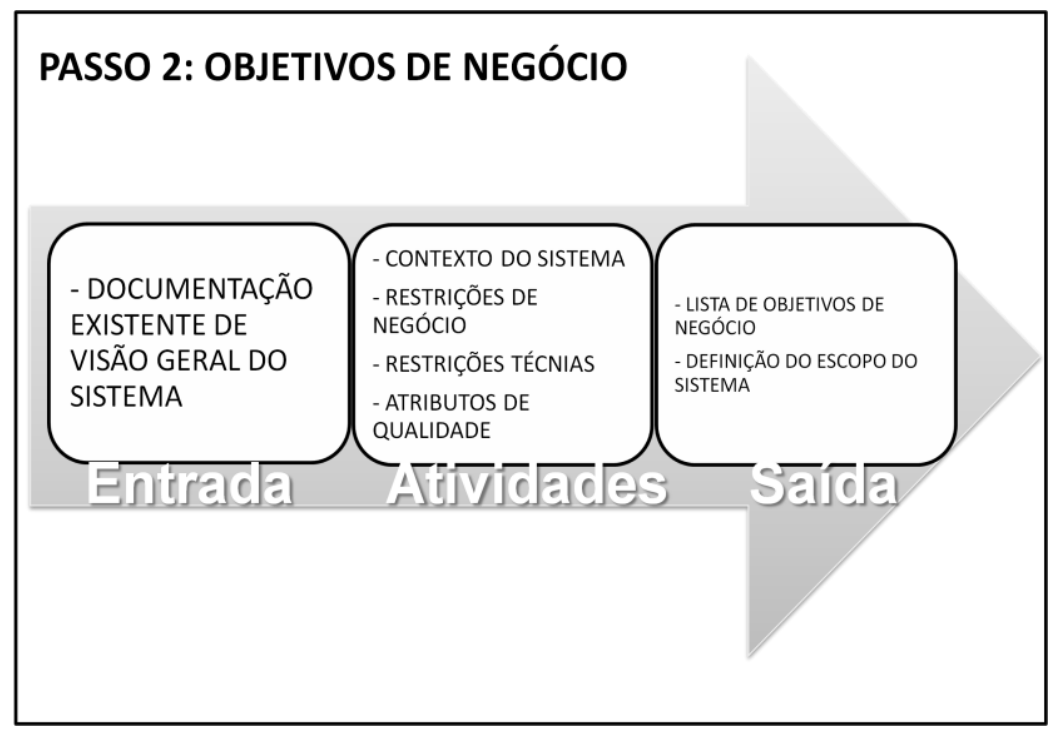

Figura 3: Esquema para apresentar os objetivos do negócio (Passo 2).

Como saída é importante destacar os objetivos de negócios através de cenários que representem os objetivos do cliente. 


\subsubsection{Passo 3 - Apresentação da arquitetura}

O arquiteto descreve a arquitetura do sistema dando ênfase a como atendem aos objetivos de negócio requeridos (CLEMENTS; KAZMAN; KLEIN, 2009). A figura 4 resume os artefatos utilizados neste passo, as atividades desenvolvidas e as saídas. São necessários para a execução destas atividades: o escopo do sistema, a lista de objetivos de negócios e de atributos de qualidade. O resultado deste passo é uma documentação mais completa da arquitetura do sistema. Estendendo o método original este roteiro propões que a documentação seja organizada de acordo com as visões ODP com o objetivo de facilitar posteriormente as ações corretivas e evolutivas para reestruturação da arquitetura.

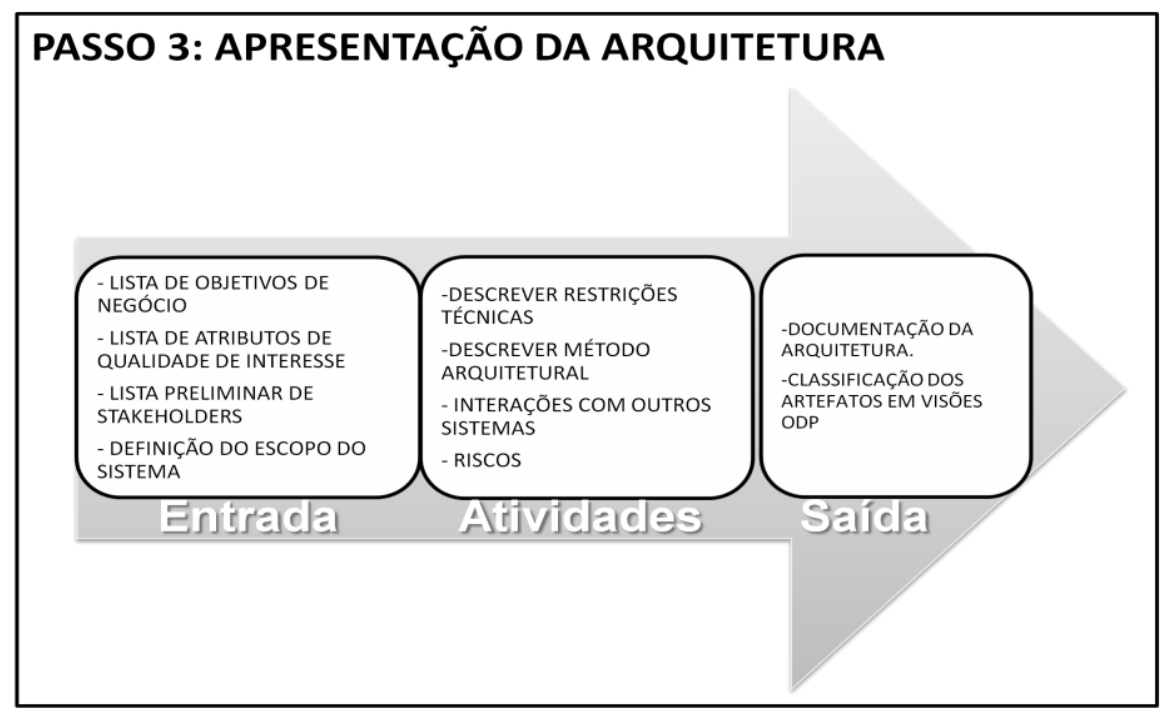

Figura 4: Esquema para apresentar a arquitetura (Passo 3).

Nesta fase é sugerido que sejam tiradas todas as dúvidas em relação a arquitetura atual do sistema.

\subsubsection{FASE 2 - Investigação e Análise}

Composta pelos passos 4, 5 e 6 envolve um estudo da arquitetura e das necessidades. A seguir são detalhados os passos. 
Neste passo são extraídos os elementos (métodos e estilos) arquiteturais existentes na estrutura arquitetural atual pelo time de avaliadores, mas eles não são analisados (CLEMENTS; KAZMAN; KLEIN, 2009). O objetivo é a verificação da cobertura dos cenários. A figura 5 resume os artefatos utilizados neste passo, as atividades desenvolvidas $\mathrm{e}$ as saídas. O resultado deste passo é uma documentação dos métodos e estilos encontrados.

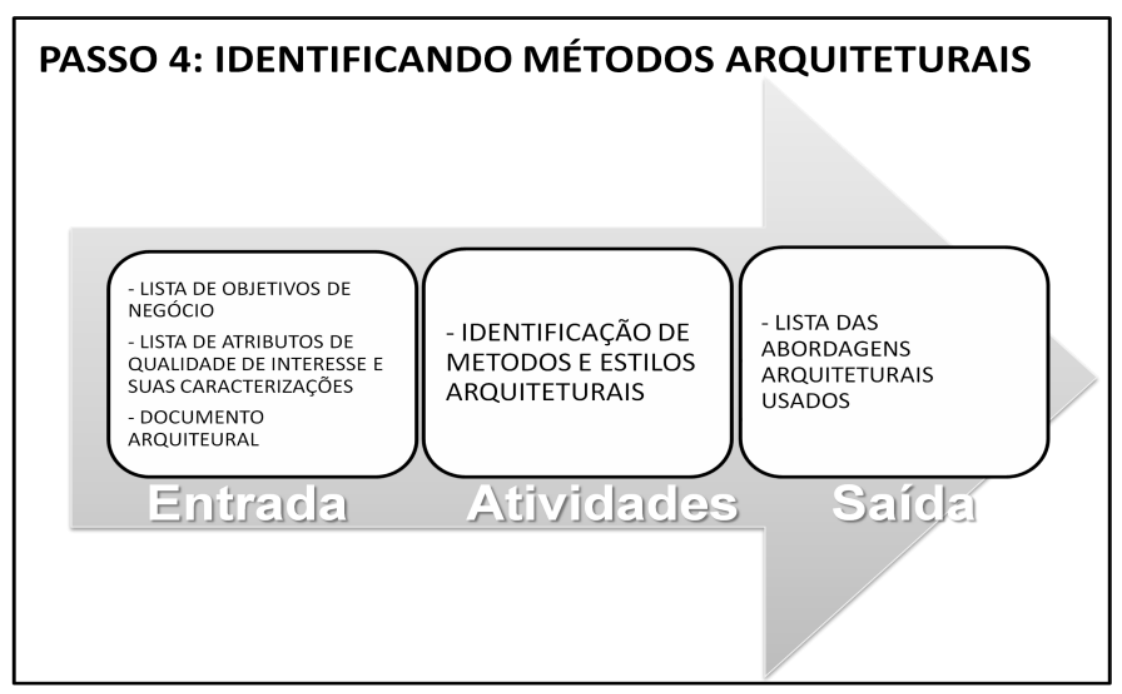

Figura 5: Esquema para identificar métodos arquiteturais (Passo 4).

\subsubsection{Passo 5 - Gerar a árvore de utilidade}

Nesta aplicação o passo 5 concentra na geração da AU a partir dos cenários apresentados no passo 3. Os atributos de qualidade são extraídos dos cenários especificados anteriormente. $O$ detalhamento dos cenários com a identificação dos estímulos e respostas, agrupamentos e priorizações sugeridos em (CLEMENTS; KAZMAN; KLEIN, 2009) ficam para os próximos passos.

Os requisitos identificados no passo 3 devem ser classificados em uma AU onde são definidos os atributos de qualidades requeridos. É importante nesta fase 
que os cenários sejam detalhados com informações complementares que permitam uma aferição e verificação do que estava sendo requerido.

A Figura 6 resume os artefatos utilizados neste passo, as atividades desenvolvidas e as saídas. Caso a equipe de arquitetos tenha uma árvore de utilidade primária ela deverá constar como entrada. Isso acontece em equipes que já trabalham com o método. O resultado deste passo é uma documentação da árvore de utilidade elaborada pelos avaliadores.

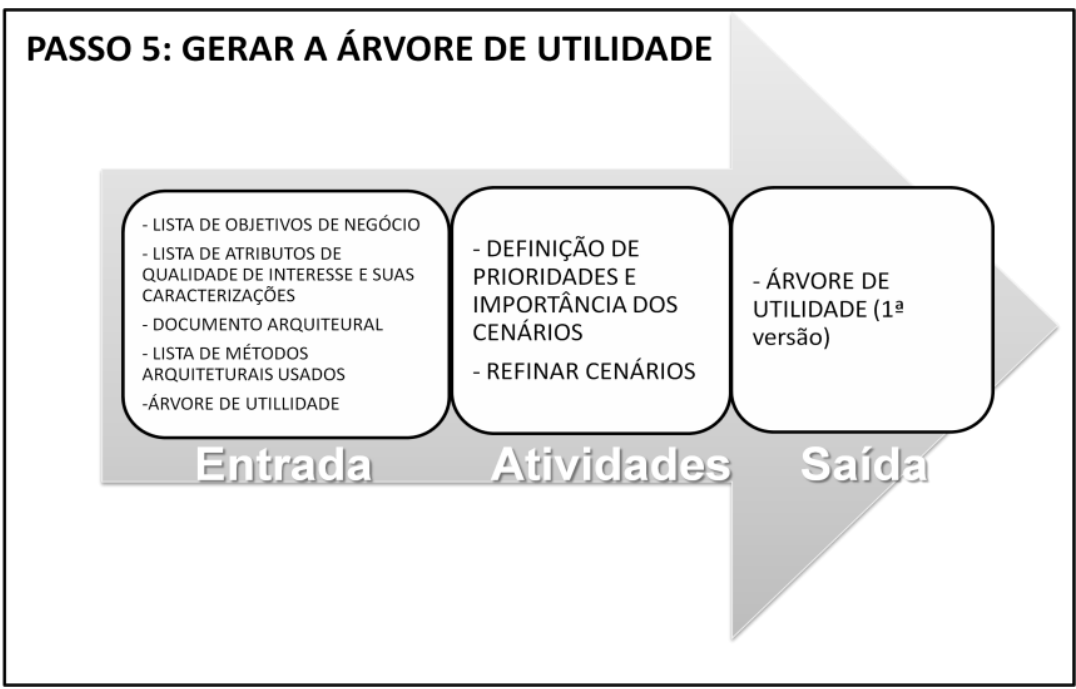

Figura 6: Esquema para Gerar Árvore de Utilidade (Passo 5).

\subsubsection{Passo 6 - Análise dos métodos arquiteturais}

Assim como no passo anterior a execução do trabalho deverá levar em consideração todos os cenários (requisitos) levantados. Neste passo deverá ser realizada uma análise das abordagens existentes na arquitetura em relação aos cenários elicitados no passo 3, informando quais cenários são atendidos parcialmente, totalmente ou não são atendidos. A Figura 7 resume os artefatos utilizados neste passo, as atividades desenvolvidas e as saídas. 


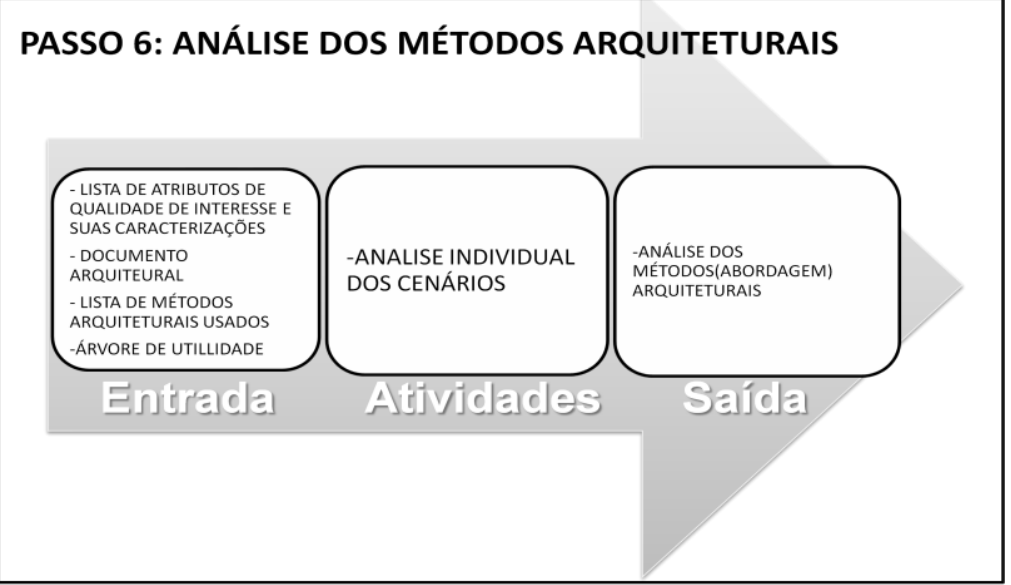

Figura 7: Esquema para análise dos métodos arquiteturais (Passo 6)

\subsubsection{FASE 3 - Teste}

Composta pelos passos 7 e 8, esta fase envolve um estudo da arquitetura e das necessidades. A seguir são detalhados os passos.

\subsubsection{Passo 7-Brainstorm e priorização de cenários}

O passo 7 reúne as atividades de maior importância dentro do processo. Sugere-se que um brainstorm seja realizado com todos os stakholders em busca de cenários adicionais. Em seguida deverá ser realizada, a partir da $\mathrm{AU}$, uma análise dos mecanismos arquiteturais que pode ser representado através de um mapa tendo como objetivo visualizar os cenários semelhantes ou conflitantes. Aqueles que forem semelhantes podem gerar um agrupamento. Este agrupamento irá reduzir a árvore de utilidade. A atividade seguinte é a priorização dos cenários que deve ser feito através de votação.

$\mathrm{Na}$ priorização os principais cenários de um sistema são categorizados de acordo com os atributos de qualidade a que estão relacionados e então classificados em função de sua importância e complexidade, considerando a percepção de 
negócio e arquitetura. As duas variáveis de priorização podem ser classificadas em alta $(A)$, médias $(M)$ e baixas $(A)$ de acordo com as características dos requisitos.

Entre os cenários de alta prioridade podem aparecer conflitos que exigirão uma tomada de decisão por parte dos interessados. A Figura 8 resume os artefatos utilizados neste passo, as atividades desenvolvidas e as saídas. Nesta aplicação a lista de riscos é tratada nos passos posteriores.

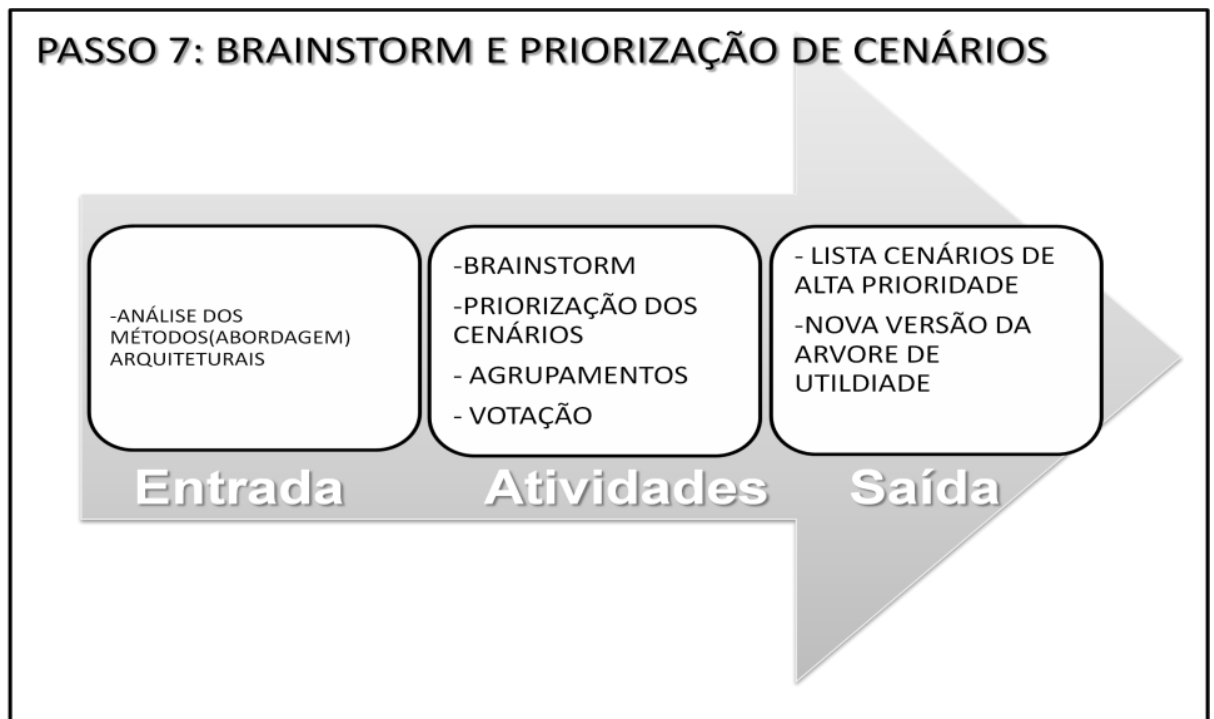

Figura 8: Esquema para realizar o brainstorm e priorização de cenários (Passo 7).

\subsubsection{Passo 8 - Análise dos métodos arquiteturais}

Este passo reitera as atividades do passo 6 e usa os cenários prioritários do passo 7.

A análise arquitetural é formulada através de um template (CLEMENTS,2003), onde são descritos o estímulo, resposta e abordagem arquitetural existente e será realizada para cada cenário de alta prioridade definidos no passo.

Neste passo, os mecanismos são analisados segundo o seguinte método (CLEMENTE, 2003): atributos de qualidade são realizados por táticas arquiteturais que direcionam os mecanismos de arquitetura. 


\subsubsection{FASE 4 - Entrega}

\subsubsection{Passo 9-Consolidar os resultados}

Baseados nos resultados são elaborados relatórios que são apresentados aos envolvidos. Todas as informações coletadas, as análises e as decisões são documentadas e entregues.

Com base nas informações coletadas durante a avaliação são apresentados os resultados aos envolvidos. Informações como analise arquitetural dos cenários prioritários, pontos sensitivos e trade-offs são consolidados em um documento.

Os artefatos resultantes do processo de avaliação através do ATAM são adequados para pautar a estratégia da evolução do software.

- Conjunto de Requisitos de Qualidade;

- Conjunto de Riscos e não riscos;

- Conjunto de Pontos sensitivos e críticos;

- Pontos de Conflitos;

- Plano de Monitoramento de Riscos

Com base nas informações coletadas durante a avaliação são apresentados os resultados aos envolvidos. Informações como analise arquitetural dos cenários prioritários, pontos sensitivos e trade-offs são consolidados em um único documento que irá pautar a estratégia da evolução do software.

Observando os cenários prioritários que se destacaram no processo os avaliadores determinam a linha de ação. Vão destacar os pontos sensitivos e os Trade-offs.

Cada risco, não-risco, ponto sensitivo, trade-off identificados esta associado com o alcance de um ou mais refinamento do atributo de qualidade na árvore de utilidade. Os riscos e não riscos devem constar no plano de monitoramento dos riscos. 


\subsection{Especificar o plano de evolução para o Sistema}

De posse dos resultados da avaliação é realizada uma análise dos resultados no sentido de elaborar o plano de evolução. Todos os resultados citados a seguir são referências para o plano de evolução.

- Conjunto de Requisitos de Qualidade

- Conjunto de Riscos e não riscos

- Conjunto de Pontos sensitivos e críticos

- Pontos de conflitos

- Plano de Monitoramento de Riscos

Os avaliadores irão analisar cada requisito e as táticas resultantes do processo irão direcionar as ações que devem ser tomadas para evolução do software de acordo com os requisitos colocados como meta. Os trade-offs irão indicar quais as perdas e ganhos entre as táticas conflitantes. E por fim os riscos apontam os fatores e variáveis que devem ser observados, monitorados e controlados durante o processo de evolução. Este conjunto de resultados forma as decisões arquiteturais que serão analisadas com o objetivo de traçar as diretivas para evolução de cada ponto de vista ODP de acordo com o seu nível de abstração. Desta forma 0 arquiteto e sua equipe poderão elaborar um planejamento estratégico para o desenvolvimento da nova versão do produto direcionado a partir dos pontos de vista ODP ,que são:

- Ponto de Vista de Empresa

- Ponto de Vista Tecnologia

- Ponto de vista de Informação

- Ponto de Vista de Engenharia

- Ponto de Vista de Computação 
Estas informações irão compor a estratégia da empresa na elaboração do plano para evolução do software.

O documento final do resultado da avaliação será a base para a estratégia da evolução a ser adotada pela empresa. Este documento identifica pontos críticos na arquitetura do sistema que deverão ser trabalhados para atender as exigências do mercado garantindo a sua estabilidade e sobrevivência. 


\section{APLICAÇÃO DO ROTEIRO: UM EXEMPLO DE AVALIAÇÃO}

\subsection{Contextualização}

Neste capítulo será apresentado um exemplo de aplicação do método de avaliação de arquitetura de software ATAM em um ambiente real de um sistema para aviação com o objetivo de gerar um plano de evolução para assegurar a longevidade do sistema no mercado. Algumas informações foram alteradas para proteger a identidade e a propriedade intelectual do produto e dos envolvidos.

O sistema avaliado tem como contexto a Gestão de Companhias Aéreas, consiste em um sistema integrado para gestão de linhas áreas que contempla todos os setores da companhia. A empresa responsável por manter, comercializar e desenvolver o produto será chamada de Empresa $E$ e os clientes da empresa $E$ serão referenciados por Clientes de $\mathrm{E}$.

O sistema é atualmente é utilizado por 7 empresas entre linhas aéreas e taxi aéreo. O sistema já possui 8 anos de existência e os proprietários querem realizar uma evolução planejada e controlada. Para este estudou os esforços foram concentrados no módulo de Controle Técnico e Manutenção.

O objetivo da avaliação é gerar informação que possa guiar o lançamento de uma nova versão do software que atenda as necessidades estratégicas das gerencias e dos atuais clientes no sentido de alcançar a continuidade do software no mercado atual e futuro.

\section{Os participantes da avaliação e do planejamento de evolução são:}

- Arquiteto da Empresa E: É um dos principais desenvolvedores do produto tendo participado do projeto de desenvolvimento desde seu início como estagiário de programação e atualmente e gerente de projeto. Fica localizado no escritório da matriz em Manaus. Será referenciado como Arquiteto.

- Sócio Diretor da Empresa E: Analista de Sistema com larga experiência na área de desenvolvimento. Responsável por toda a análise do sistema desde o início. 
Experiente em consultoria para empresas de aviação e conhecedor do negócio, está muito próximo dos clientes nas implantações e solicitações de manutenções. Fica na filial da empresa no Rio de Janeiro. Será referenciado como Contratante.

- Clientes de E: Engenheiros e técnicos das empresas Clientes. Eles são as principais fontes das necessidades e falhas dos sistemas. Estão sempre solicitando mudanças, melhorias e inovações. A maioria está localizada nos estados do Rio de Janeiro, outros no Exterior e em outros estados. Será referenciado como Cliente

- Especialista na Avaliação: Pessoa que irá intermediar as interações e realizará a avaliação. Estará localizada na Matriz em Manaus. Será referenciado como Avaliador.

\subsection{Execução da Avaliação}

De acordo com as fases do ATAM descritas em (CLEMENTS, 2002) a avaliação tem início com uma reunião entre o líder do time de avaliadores com as pessoas chave do cliente e o arquiteto do cliente. O passo seguinte consiste em identificar os objetivos de Negócio. Dentro deste propósito foram identificadas duas fontes de requisitos baseadas nas expectativas dos clientes de $\mathrm{E}$ e do sócio diretor. Era de suma importância abordar esses dois conjuntos de stakeholders, pois os clientes possuem informações acerca das deficiências do sistema e o Sócio possui uma visão estratégica do mercado.

As atividades destes passos tiveram como resultados os cenários descritos no Quadro 6 e 7. O Quadro 6 apresenta os cenários colocados pelos clientes e são referenciados por "Cenários de Usuários" por tratar dos requisitos dos usuários do sistema.

Quadro 6- Cenários de Usuário

\begin{tabular}{|l|}
\hline U01: O sistema deve permitir o rastreamento da execução da manutenção \\
\hline U02: As transações do sistema de manutenção não podem ser executadas no tempo maior que 5 segundos \\
\hline U03: Ao ocorrer uma falha o sistema deve ser capaz de reconhecê-la \\
\hline U04: O sistema deve ser intuitivo e de fácil aprendizagem. \\
\hline U05: O sistema deve permitir a inserção de novas funções de forma rápida e barata \\
\hline U06: O sistema deve se manter estável durante o registro das manutenções \\
\hline U07: Garantir a integridade do numero de horas e ciclos voados durante a inserção do relatório de vôo, através de uma verificação \\
\hline
\end{tabular}


Neste quadro os cenários falam da deficiência do sistema na sua operação, como o U02 que trata do tempo das transações do sistema de manutenção. Devido à experiência dos envolvidos, alguns requisitos não estão tecnicamente completos. Nos passos seguintes eles serão trabalhados para tratarem a real necessidade dos clientes.

O quadro 7 apresenta um conjunto de cenários que estão relacionados com atributos de negócio, para distinguir dos cenários anteriores, esses são tratados por "Cenários de Negócios".

Quadro 7 - Cenários de Negócio

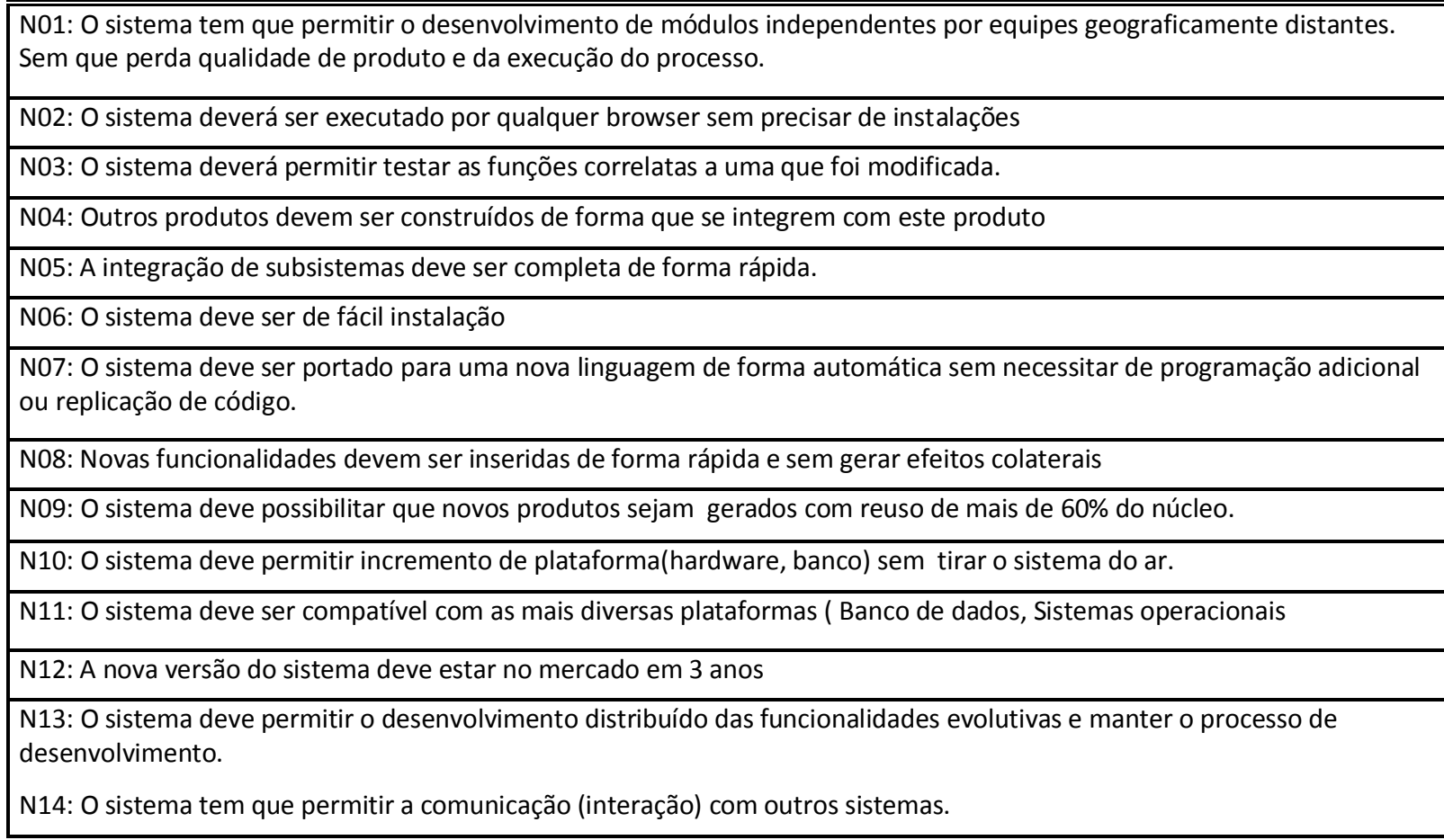

Neste caso a preocupação esta baseada em requisitos que permitem uma longevidade do sistema.

O processo de obtenção dos cenários de negócio permitiu que partes interessadas dessem suas contribuições com os cenários que refletem seus interesses e passassem para a equipe de avaliadores a compreensão de como a arquitetura acomodará suas necessidades. Os cenários foram coletados sem que nenhuma desaprovação e quase nenhum esclarecimento fossem fornecidos. Os cenários tendem a refletir a ênfase particular e os interesses imediatos dos indivíduos, desta forma, uma variedade de cenários era do interesse particular aos dois grupos montado (clientes e sócio). 
O Quadro 8 expõe a classificação dos cenários levantados de acordo com os atributos de qualidade. Esta é uma primeira versão da árvore de utilidade, nos passos a seguir ela será complementada com outras informações.

Cumprindo os requisitos do Passo 3 a equipe de desenvolvimento e o arquiteto do cliente apresentaram a arquitetura atual da ferramenta e uma série de documentos da arquitetura do sistema.

De acordo com o padrão ODP a documentação apresentada pode ser classificada como apresenta o Quadro 8:

Quadro 8 - Classificação dos Artefatos da Arquitetura do Software

\begin{tabular}{|l|l|}
\hline \multicolumn{1}{|c|}{ Visão } & \multicolumn{1}{c|}{ Artefato } \\
\hline Ponto de Vista de Empresa & Caderno de encargos desatualizado \\
\hline Ponto de Vista Tecnologia & Plataforma e Tecnologias \\
\hline Ponto de vista de Informação & $\begin{array}{l}\text { Modelo Entidade e Relacionamento } \\
\text { Caderno de encargos desatualizado }\end{array}$ \\
\hline Ponto de Vista de Engenharia & $\begin{array}{l}\text { Esquema de distribuição dos módulos } \\
\text { Esquema de módulos ( divisão ) } \\
\text { Esquemas de infra-estrutura }\end{array}$ \\
\hline Ponto de Vista de Computação & Caderno de encargos desatualizado \\
\hline
\end{tabular}

Como é frequente, a documentação inicial apresentada era muito vaga e documentação arquitetural adicional foi solicitada. Assim, informações adicionais foram pedidas, sob a forma de perguntas (Quadro 9), no sentido de esclarecer as dúvidas remanescentes da documentação. Entre o primeiro e o segundo dia da avaliação o contratante respondeu a muitas destas perguntas e produziu uma documentação arquitetural mais completa.

Quadro 9 - Informações adicionais.

\begin{tabular}{l} 
Como as funcionalidades são divididas nos termos dos módulos, das funções, dos APIs, das camadas, \\
etc.? \\
\hline $\begin{array}{l}\text { Quais são as facilidades existentes na arquitetura de software para o autoteste e o monitoramento de } \\
\text { componentes de software? }\end{array}$ \\
\hline $\begin{array}{l}\text { Quais facilidades existem na arquitetura de software para a redundância, monitoração, e como a } \\
\text { consistência de dados é mantida? }\end{array}$ \\
\hline Que dependências funcionais existem entre o software e os componentes? \\
\hline Quais dados são mantidos na base de dados, qual o tamanho, quanto ele muda? \\
\hline Qual a frequência e o volume de dados são transmitidos entre os componentes de sistema? \\
\hline
\end{tabular}

\subsubsection{Passo 4- Identificando métodos arquiteturais}

O método ATAM auxilia na identificação das abordagens e estilos arquiteturais porque através deles é possível entender como a arquitetura implementa os atributos de qualidades prioritários. 
Os métodos arquiteturais definem a estrutura do sistema e descreve as maneiras como ela pode crescer, responder as mudanças, se integrar com outros sistemas assim por diante.

A abordagem arquitetural inclui uma descrição dos tipos de componentes e sua topologia, uma descrição dos padrões de dados e controle interações entre os componentes, e uma descrição informal dos benefícios do uso deste estilo.

Os estilos e as abordagens arquiteturais identificados estão relatados no Quadro 10:

Quadro 10 - Abordagens arquiteturais identificadas.

O sistema utiliza a tecnologia $\mathrm{OO}$ em 2 camadas

O software utiliza um pacote padrão para definição de interface.

O sistema prevê controle de mudança com mapeamento das alterações realizadas e componentes afetados.

O sistema utiliza banco de dados relacional com uso de triggers e procedures.

O sistema esta baseado na filosofia cliente/servidor.

O sistema permite acesso simultâneo.

O sistema possui módulo de segurança com controle de acesso e log de operações.

O sistema possui mecanismo para tolerância a falhas operacionais e de banco.

Parte do sistema foi desenvolvida através de uma metodologia certificada, o que garante a padronização da documentação

O Quadro 10 lista as abordagens arquiteturais existentes na arquitetura do sistema essas abordagens tratam pontos arquiteturais importantes, como manutenibilidade e segurança, mas não são suficientes para a nova realidade de requisitos.

\subsubsection{Passo 5-Gerar a árvore de utilidade (Agrupamento e Priorização dos cenários)}

Nesta aplicação foi definido um método de trabalho com os requisitos identificados no passo 3, classificando-os em uma árvore de utilidade onde são definidos os atributos de qualidades requeridos. Nesta fase os requisitos foram detalhados com informações complementares que permitiam uma aferição e verificação do que estava sendo requerido. O Quadro 11 apresenta a primeira versão da árvore de utilidades que classifica os cenários de acordo com os atributos de qualidade. 
Quadro 11 - Classificação dos Cenários (1aㅡ versão da Árvore de Utilidade).

\begin{tabular}{|c|c|c|}
\hline & & \\
\hline$\stackrel{0}{\pi}$ & Adequação & $\begin{array}{l}\text { N1: O sistema deve abranger } 100 \% \text { das funcionalidades da versão } \\
\text { anterior }\end{array}$ \\
\hline 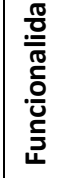 & Precisão & $\begin{array}{l}\text { U07: Garantir a integridade do número de horas e ciclos voados durante } \\
\text { a inserção do relatório de vôo, com verificação através de cálculos com } \\
\text { porcentagem de acerto de } 99,9998 \% \text { das operações. }\end{array}$ \\
\hline$\frac{0}{0}$ & Tolerância a falhas & $\begin{array}{l}\text { U08: O sistema deve ser capaz de proteger os dados de entradas } \\
\text { incorretas através de um controle de ocorrência de falhas } \\
\text { Fórmula: (\# falhas evitadas / \# casos de teste) } \\
\text { Interpretação: } 0 \leq x \leq 1 \text {; quanto mais próximo de } 1 \text {, melhor } \\
\text { Entradas: relatórios de teste e de operação }\end{array}$ \\
\hline 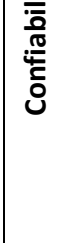 & Recuperabilidade, & $\begin{array}{l}\text { U03: Ao ocorrer uma falha o sistema deve ser capaz de reconhecer a } \\
\text { falha e recuperar o estado do sistema anterior à falha, a partir do } \\
\text { número de falhas previstas e evitadas no código } \\
\text { Fórmula: (\# falhas evitadas / \# casos de teste) } \\
\text { Interpretação: } 0 \leq x \leq 1 \text {; quanto mais próximo de } 1 \text {, melhor } \\
\text { Entradas: relatórios de teste e de operação }\end{array}$ \\
\hline $\begin{array}{l}\frac{0}{0} \\
\frac{\pi}{0} \\
\frac{\pi}{0} \\
\frac{\pi}{00} \\
\end{array}$ & Compreensibilidade & $\begin{array}{l}\text { U04: O sistema deve ser intuitivo e de fácil aprendizagem, } \\
\text { os usuários operadores devem ser capaz de operar o sistema com } 3 \\
\text { horas de treinamento }\end{array}$ \\
\hline 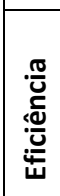 & Desempenho & $\begin{array}{l}\text { U2 As transações do sistema de manutenção não podem ser executadas } \\
\text { no tempo maior que } 5 \text { segs }\end{array}$ \\
\hline & Analisabilidade & $\begin{array}{l}\text { U01: O sistema deve permitir o rastreamento da execução da } \\
\text { manutenção da aeronave atendendo o prazo de no máximo } 15 \text { minutos } \\
\text { após a solicitação. }\end{array}$ \\
\hline$\frac{0}{0}$ & Modificabilidade & $\begin{array}{l}\text { N08: Novas funcionalidades devem ser inseridas em no máximo } 5 \text { dias e } \\
\text { sem gerar efeitos colaterais }\end{array}$ \\
\hline$\frac{\text { 을 }}{\frac{0}{2}}$ & & $\begin{array}{l}\text { U05: O sistema deve permitir a inserção de novas funções no prazo } \\
\text { máximo de } 5 \text { dias. }\end{array}$ \\
\hline$\sum_{\frac{\pi}{\pi}}^{\bar{\pi}}$ & & $\begin{array}{l}\text { U06: O sistema deve se manter estável durante o registro das } \\
\text { manutenções }\end{array}$ \\
\hline & & $\begin{array}{l}\text { N10: O sistema deve permitir o incremento de plataforma (hardware e } \\
\text { software) sem tirar o sistema do ar. }\end{array}$ \\
\hline & Testabilidade & $\begin{array}{l}\text { N03: O sistema deverá permitir testar as funções correlatas a uma que } \\
\text { foi modificada no prazo de } 1 \text { dia. }\end{array}$ \\
\hline & Adaptabilidade & $\begin{array}{l}\text { N02: O sistema deverá ser executado pelos browsers Firefox, internet } \\
\text { explorer, ophera e safari, sem precisar de instalações. }\end{array}$ \\
\hline$\frac{0}{\pi}$ & & $\begin{array}{l}\text { N11: O sistema deve ser compatível com os banco de dados: SQL Server, } \\
\text { Oracle, my SQL e com os sistemas operacionais Linux, Windows e Mac } \\
\text { OS }\end{array}$ \\
\hline$\frac{\text { 을 }}{\frac{10}{00}}$ & Instalabilidade & $\begin{array}{l}\text { N06: O sistema deve ser de fácil instalação com tempo máximo de } \\
\text { instalação de } 15 \text { minutos. }\end{array}$ \\
\hline $\bar{\AA}$ & Co-existência & $\begin{array}{l}\text { N04: Outros produtos devem ser construídos de forma que se integrem } \\
\text { com este produto }\end{array}$ \\
\hline & & $\begin{array}{l}\text { N05: A integração de subsistemas deve ser completa em no máximo } 5 \\
\text { dias. }\end{array}$ \\
\hline
\end{tabular}




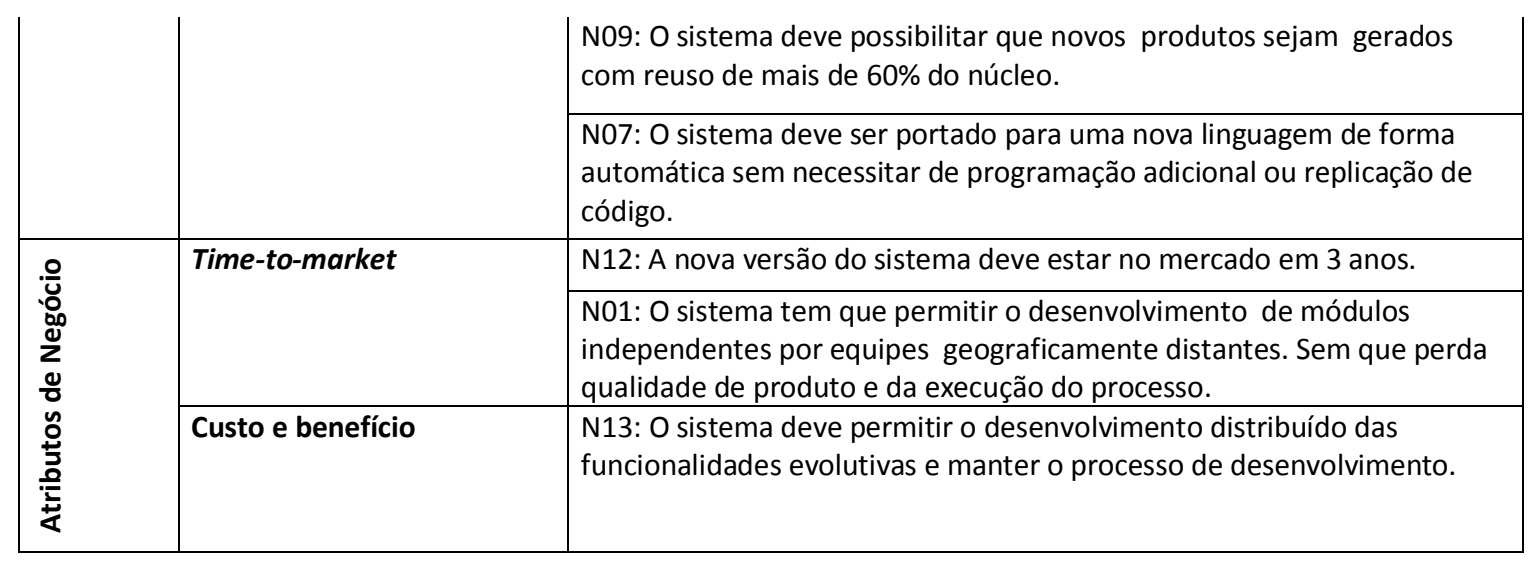

\subsubsection{Passo 6 - Análise dos métodos(abordagem) arquiteturais}

A análise arquitetural é formulada para identificar como os requisitos da árvore de utilidade são atendidos pelos mecanismos da arquitetura, comentados na coluna Abordagem Arquitetural Existente do quadro 12.

O foco neste momento é identificar os métodos arquiteturais ou decisões que implementam os novos requisitos na arquitetura atual. Para tanto a equipe de avaliadores analisou as novas as abordagens arquiteturais existentes levantadas no passo anterior e os novos requisitos para identificar quais destes não são atendidos ou são atendidos parcialmente. O quadro 12 resume esta tarefa relacionado em duas colunas os novos requisitos e a abordagem arquitetural existente. Em alguns casos existem mecanismos que atendem parcialmente ao requisito, mas precisam de algum ajuste, como por exemplo o tempo de resposta. 
Quadro 12 - Requisitos x Mecanismos existentes

\begin{tabular}{|c|c|}
\hline Novos Requisitos & Abordagem Arquitetural Existente \\
\hline $\begin{array}{l}\mathrm{N} 1: \text { O sistema deve abranger } 100 \% \text { das } \\
\text { funcionalidades da versão anterior }\end{array}$ & NÃO SE APLICA \\
\hline $\begin{array}{l}\text { U07: Garantir a integridade do numero de horas } \\
\text { e ciclos voados durante a inserção do relatório de } \\
\text { vôo, através de uma verificação. }\end{array}$ & $\begin{array}{l}\text { ATENDE PARCIALMENTE: } \\
\text { Atualmente o sistema não implementa as regras } \\
\text { de negócios que garantam a integridade das } \\
\text { horas voadas durante a inserção dos relatórios de } \\
\text { vôos. Mas o sistema utiliza a implementação no } \\
\text { banco que facilita a verificação de regras de } \\
\text { negócios. }\end{array}$ \\
\hline $\begin{array}{l}\text { U08: O sistema deve ser capaz de proteger os } \\
\text { dados de entradas incorretas através de um } \\
\text { controle de ocorrência de falhas. } \\
\text { Fórmula: (\# falhas evitadas / \# casos de } \\
\text { teste) } \\
\text { Interpretação: } 0 \leq x \leq 1 \text {; quanto mais } \\
\text { próximo de 1, melhor } \\
\text { Entradas: relatórios de teste e de } \\
\text { operação }\end{array}$ & $\begin{array}{l}\text { ATENDE PARCIALMENTE: } \\
\text { Cerca de } 40 \% \text { das interfaces possuem algum tipo } \\
\text { de verificação para proteção do sistema. Não } \\
\text { existe um mecanismo automatizado para essa } \\
\text { verificação }\end{array}$ \\
\hline $\begin{array}{l}\text { U03: Ao ocorrer uma falha o sistema deve ser } \\
\text { capaz de reconhecer a falha e recuperar o estado } \\
\text { do sistema anterior à falha, a partir do número } \\
\text { de falhas previstas e evitadas no código } \\
\text { Fórmula: (\# falhas evitadas / \# casos de } \\
\text { teste) } \\
\text { Interpretação: } 0 \leq x \leq 1 \text {; quanto mais } \\
\text { próximo de 1, melhor } \\
\quad \text { Entradas: relatórios de teste e de } \\
\text { operação }\end{array}$ & $\begin{array}{l}\text { ATENDE: } \\
\text { A arquitetura atual prevê a ocorrência de falhas } \\
\text { de banco e de execução. }\end{array}$ \\
\hline $\begin{array}{l}\text { U04: O sistema deve ser intuitivo e de fácil } \\
\text { aprendizagem com medida através do número de } \\
\text { funções evidentes com o propósito de medir a } \\
\text { proporção de funções que são evidentes ao } \\
\text { utilizador } \\
\quad \text { Fórmula: (\# funções evidentes / \# } \\
\text { funções) }\end{array}$ & $\begin{array}{l}\text { NÃO ATENDE: } \\
\text { A arquitetura atual não possui nenhum } \\
\text { dispositivo, mecanismo ou estratégia que gere } \\
\text { interfaces intuitivas. }\end{array}$ \\
\hline $\begin{array}{l}\text { U2: As transações do sistema de manutenção não } \\
\text { podem ser executadas no tempo maior que } 5 \\
\text { segundos }\end{array}$ & $\begin{array}{l}\text { NÃO ATENDE: } \\
\text { A arquitetura atual não permite este tipo de } \\
\text { controle }\end{array}$ \\
\hline $\begin{array}{l}\text { U01: O sistema deve permitir o rastreamento da } \\
\text { execução da manutenção da aeronave } \\
\text { atendendo o prazo de no máximo } 15 \text { minutos } \\
\text { após a solicitação. }\end{array}$ & $\begin{array}{l}\text { ATENDE PARCIALMENTE: } \\
\text { A arquitetura atual armazena log de todas as } \\
\text { operações realizadas no sistema }\end{array}$ \\
\hline $\begin{array}{l}\text { N08: Novas funcionalidades devem ser inseridas } \\
\text { em no máximo } 5 \text { dias e sem gerar efeitos } \\
\text { colaterais }\end{array}$ & $\begin{array}{l}\text { ATENDE PARCIALMENTE: } \\
\text { O processo de desenvolvimento adotado agiliza a } \\
\text { inserção de novas funcionalidades com controle } \\
\text { das funções afetadas }\end{array}$ \\
\hline
\end{tabular}




\begin{tabular}{|c|c|}
\hline $\begin{array}{l}\text { U05: O sistema deve permitir a inserção de novas } \\
\text { funções no prazo máximo de } 5 \text { dias. }\end{array}$ & $\begin{array}{l}\text { ATENDE PARCIALMENTE: } \\
\text { O processo de desenvolvimento adotado agiliza a } \\
\text { inserção de novas funcionalidades com controle } \\
\text { das funções afetadas }\end{array}$ \\
\hline $\begin{array}{l}\text { U06: O sistema deve se manter estável durante o } \\
\text { registro das manutenções }\end{array}$ & $\begin{array}{l}\text { ATENDE PARCIALMENTE: } \\
\text { O processo de desenvolvimento adotado agiliza a } \\
\text { inserção de novas funcionalidades com controle } \\
\text { das funções afetadas }\end{array}$ \\
\hline $\begin{array}{l}\text { N10: O sistema deve permitir o incremento de } \\
\text { plataforma (hardware e software) sem tirar o } \\
\text { sistema do ar. }\end{array}$ & $\begin{array}{l}\text { ATENDE PARCIALMENTE: } \\
\text { A arquitetura atual esta implementada em } \\
\text { plataforma Borland compatível com o Windows } \\
\text { com banco de dados Oracle }\end{array}$ \\
\hline $\begin{array}{l}\text { N03: O sistema deverá permitir testar as funções } \\
\text { correlatas a uma que foi modificada no prazo de } \\
1 \text { dia. }\end{array}$ & $\begin{array}{l}\text { ATENDE PARCIALMENTE: } \\
\text { O processo de desenvolvimento adotado agiliza a } \\
\text { inserção de novas funcionalidades com controle } \\
\text { das funções afetadas }\end{array}$ \\
\hline $\begin{array}{l}\text { N02: O sistema deverá ser executado pelos } \\
\text { browsers Firefox, internet explorer, ophera e } \\
\text { safari, sem precisar de instalações. }\end{array}$ & $\begin{array}{l}\text { NÃO ATENDE: } \\
\text { A arquitetura atual não é compatível com a } \\
\text { plataforma web }\end{array}$ \\
\hline $\begin{array}{l}\text { N11: O sistema deve ser compatível com os banco de dados: } \\
\text { SQL Server, Oracle, my SQL e com os sistemas operacionais } \\
\text { Linux, Windows e Mac OS }\end{array}$ & $\begin{array}{l}\text { ATENDE PARCIALMENTE: } \\
\text { A arquitetura atual é compatível com o Windows com banco } \\
\text { de dados Oracle. EM } 90 \% \text { das operações utiliza SQL PADRÃO } \\
\text { sendo compatível com } 90 \% \text { dos banco de dados relacionais }\end{array}$ \\
\hline $\begin{array}{l}\text { N06: O sistema deve ser de fácil instalação com tempo } \\
\text { máximo de instalação de } 15 \text { minutos. }\end{array}$ & $\begin{array}{l}\text { NÃO ATENDE: } \\
\text { Atualmente o sistema leva cerca de } 30 \text { minutos para ser } \\
\text { instalado em uma operação complexa. }\end{array}$ \\
\hline $\begin{array}{l}\text { N04: Outros produtos devem ser construídos de forma que } \\
\text { se integrem com este produto }\end{array}$ & $\begin{array}{l}\text { NÃO ATENDE: } \\
\text { Toda integração é realizada de forma manual. }\end{array}$ \\
\hline $\begin{array}{l}\text { N05: A integração de subsistemas deve ser completa em no } \\
\text { máximo } 5 \text { dias. }\end{array}$ & $\begin{array}{l}\text { NÃO ATENDE: } \\
\text { A Integração manual é cara e demorada }\end{array}$ \\
\hline $\begin{array}{l}\text { N09: O sistema deve possibilitar que novos produtos sejam } \\
\text { gerados com reuso de mais de } 60 \% \text { do núcleo. }\end{array}$ & $\begin{array}{l}\text { ATENDE PARCIALMENTE: } \\
\text { O sistema possui uma política de reutilização de classes mas } \\
\text { de forma desorganizada o que pode comprometer a } \\
\text { integridade do sistema }\end{array}$ \\
\hline $\begin{array}{l}\text { N07: O sistema deve ser portado para uma nova linguagem } \\
\text { de forma automática sem necessitar de programação } \\
\text { adicional ou replicação de código. }\end{array}$ & $\begin{array}{l}\text { NÃO ATENDE: } \\
\text { A arquitetura atual não esta preparada para este requisito }\end{array}$ \\
\hline $\begin{array}{l}\text { N12: A nova versão do sistema deve estar no mercado em } 3 \\
\text { anos. }\end{array}$ & $\begin{array}{l}\text { NÃO ATENDE: } \\
\text { Com a arquitetural atual será muito difícil atender a este } \\
\text { prazo }\end{array}$ \\
\hline $\begin{array}{l}\text { N01: O sistema tem que permitir o desenvolvimento de } \\
\text { módulos independentes por equipes geograficamente } \\
\text { distantes. Sem que perda qualidade de produto e da } \\
\text { execução do processo. }\end{array}$ & $\begin{array}{l}\text { ATENDE PARCIALMENTE: } \\
\text { O processo de desenvolvimento da empresa auxilia no } \\
\text { cumprimento deste requisito }\end{array}$ \\
\hline $\begin{array}{l}\text { N13: O sistema deve permitir o desenvolvimento distribuído } \\
\text { das funcionalidades evolutivas e manter o processo de } \\
\text { desenvolvimento. }\end{array}$ & $\begin{array}{l}\text { ATENDE PARCIALMENTE: } \\
\text { O processo de desenvolvimento da empresa auxilia no } \\
\text { cumprimento deste requisito }\end{array}$ \\
\hline
\end{tabular}




\subsubsection{Passo 7-Brainstorm e priorização de cenários}

Além dos cenários apresentados na árvore de utilidade, o processo de elicitação de cenário no Passo 7 permite que o grupo maior de interessados em contribuir com cenários adicionais possa entender como a arquitetura irá acomodar suas preocupações. Os cenários que aparecem na árvore de utilidade são desenvolvidos de cima para baixo, os cenários gerados por um grupo maior de interessados são desenvolvidos de baixo para cima. A combinação de abordagens oferece alguma garantia de que os cenários de alta prioridade vieram à tona. Um cenário em particular pode, de fato, ter implicações em muitas partes: uma das partes interessadas pode estar preocupada com a dificuldade de uma mudança e seu impacto no desempenho, enquanto outra parte pode estar interessada em como a mudança afetará a "integrabilidade" da arquitetura.

Neste exemplo de aplicação não foi necessário fazer um novo levantamento de cenários. Entretanto foi necessário realizar um agrupamento de cenários e a priorização.

De posse da árvore de utilidade foi produzido um método para capturar os cenários semelhantes através de uma matriz identificada por Mapa de Cenários apresentado no Quadro 13. O objetivo deste mapa é visualizar a princípio os cenários semelhantes, facilitando um possível agrupamento.

Avaliando as semelhanças entre os cenários e identificando através do sinal de semelhança na posição linha e coluna dos respectivos cenários, foi possível observar que era possível realizar alguns agrupamentos. O Quadro 14 apresenta os agrupamentos realizados.

Uma vez reduzidos os cenários é possível finalizar a árvore de utilidade definindo a priorização dos cenários. Desta forma os cenários mais importantes serão tratados dentro do período limitado para avaliação. 


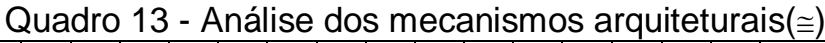

\begin{tabular}{|c|c|c|c|c|c|c|c|c|c|c|c|c|c|c|c|c|c|c|c|c|c|c|c|}
\hline & & 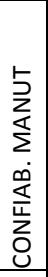 & 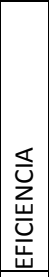 & 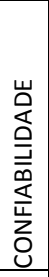 & 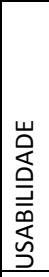 & 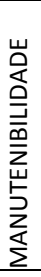 & 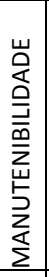 & 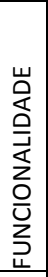 & 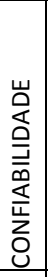 & 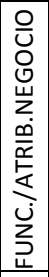 & 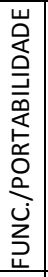 & 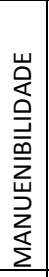 & 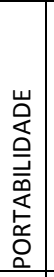 & 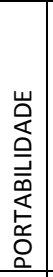 & 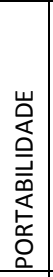 & 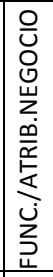 & 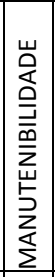 & 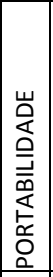 & 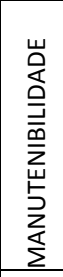 & 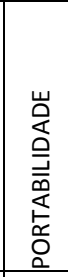 & 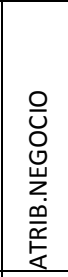 & 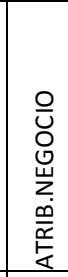 & 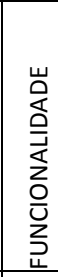 \\
\hline & & U1 & U2 & U3 & U4 & U5 & U6 & U7 & U8 & N1 & N2 & N3 & N4 & N5 & N6 & N7 & N8 & N9 & $\mathrm{N} 10$ & N11 & $\mathrm{N} 12$ & $\mathrm{~N} 13$ & N14 \\
\hline CONFIAB./MANUT. & $\mathrm{U} 1$ & & & $\cong$ & & & & & & & & & & & & & & & & & & & \\
\hline EFICIENCIA & U2 & & & & & & & & & & & & & & & & & & & & & & \\
\hline CONFIABILIDADE & U3 & $\cong$ & & & & & $\cong$ & & $\cong$ & & & & & & & & & & & & & & \\
\hline USABILIDADE & U4 & & & & & & & & & & & & & & & & & & & & & & \\
\hline MANUTENIBILIDADE & U5 & & & & & & & & & & & & & & & & $\cong$ & & & & & & \\
\hline MANUTENIBILIDADE & U6 & & & $\cong$ & & & & & $\cong$ & & & & & & & & & & & & & & \\
\hline FUNCIONALIDADE & U7 & & & & & & & & & & & & & & & & & & & & & & \\
\hline CONFIABILIDADE & U8 & & & $\cong$ & & & $\cong$ & & & & & & & & & & & & & & & & \\
\hline FUNC./ATRIB.NEGOCIO & $\mathrm{N} 1$ & & & & & & & & & & & & & & & & & & & & & $\cong$ & \\
\hline FUNC./PORTABILIDADE & N2 & & & & & & & & & & & & & & $\cong$ & & & & & $\cong$ & & & \\
\hline MANUTENIBILIDADE & N3 & & & & & & & & & & & & & & & & $\cong$ & & & & & & \\
\hline PORTABILIDADE & N4 & & & & & & & & & & & & & & $\cong$ & & & $\cong$ & & & & & \\
\hline PORTABILIDADE & N5 & & & & & & & & & & & & & & & & & & & & & & \\
\hline PORTABILIDADE & N6 & & & & & & & & & & $\cong$ & & $\cong$ & & & & & & & & & & \\
\hline FUNC./ATRIB.NEGOCIO & N7 & & & & & & & & & & & & & & & & & $\cong$ & & & & & \\
\hline MANUTENIBILIDADE & N8 & & & & & $\cong$ & & & & & & $\cong$ & & & & & & & & & & & \\
\hline PORTABILIDADE & N9 & & & & & & & & & & & & $\cong$ & & & $\cong$ & & & & & & & \\
\hline MANUTENIBILIDADE & $\mathrm{N} 10$ & & & & & & & & & & & & & & & & & & & $\cong$ & & & \\
\hline PORTABILIDADE & N11 & & & & & & & & & & $\cong$ & & & & & & & & $\cong$ & & & & \\
\hline ATRIB.NEGOCIO & N12 & & & & & & & & & & & & & & & & & & & & & & \\
\hline ATRIB.NEGOCIO & $\mathrm{N} 13$ & & & & & & & & & $\cong$ & & & & & & & & & & & & & \\
\hline FUNCIONALIDADE & N14 & & & & & & & & & & & & & & & & & & & & & & \\
\hline
\end{tabular}

Quadro 14 - Agrupamento dos cenários semelhantes.

\begin{tabular}{|c|c|c|}
\hline AG1 & $\begin{aligned} \mathrm{N} 3 & \approx \mathrm{N} 08 \\
\mathrm{~N} 3 & \approx \mathrm{U} 05 \\
& \quad \log \\
\mathrm{n} 3 & \approx \mathrm{n} 08 \approx \mathrm{u} 05\end{aligned}$ & $\begin{array}{l}\text { O sistema deve permitir a inserção ou modificação de funcionalidades de forma } \\
\text { rápida barata e sem gerar efeitos colaterais permitindo testes das funções correlatas } \\
\text { no prazo máximo de } 1 \text { dia. }\end{array}$ \\
\hline AG2 & $\mathrm{N} 04 \approx \mathrm{N} 09$ & $\begin{array}{l}\text { Outros produtos devem ser construídos de forma que se integrem com este produto } \\
\text { e com reuso de mais de } 60 \% \text { do núcleo. }\end{array}$ \\
\hline AG3 & $\mathrm{N} 01 \approx \mathrm{N} 13$ & $\begin{array}{l}\text { O sistema tem que permitir o desenvolvimento de módulos independentes por } \\
\text { equipes geograficamente distantes. Sem que perda qualidade de produto e da } \\
\text { execução do processo mantendo o processo de desenvolvimento. }\end{array}$ \\
\hline AG4 & $\mathrm{N} 02 \approx \mathrm{N} 06$ & $\begin{array}{l}\text { O sistema deverá ser executado pelos browsers Firefox, internet explorer, ophera e } \\
\text { safari, sem precisar de instalações sem precisar de instalações. }\end{array}$ \\
\hline AG5 & $\mathrm{U} 03 \approx \mathrm{U} 08$ & $\begin{array}{l}\text { Ao ocorrer uma falha o sistema deve ser capaz de reconhecê-la e de proteger os } \\
\text { dados de em caso de entradas incorretas, através de um controle de ocorrência de } \\
\text { falhas. } \\
\text { Fórmula: (\# falhas evitadas / \# casos de teste) } \\
\text { Interpretação: } 0 \leq x \leq 1 \text {; quanto mais próximo de 1, melhor } \\
\text { Entradas: relatórios de teste e de operação }\end{array}$ \\
\hline
\end{tabular}


$\mathrm{Na}$ priorização os principais cenários de um sistema são categorizados de acordo com os atributos de qualidade a que estão relacionados e então classificados em função de sua importância e complexidade, considerando a percepção de negócio e arquitetura (Quadro 15). As duas variáveis de priorização Importância e Complexidade, apresentadas nas colunas IMP. e COM. respectivamente foram classificadas em alta $(A)$, médias $(M)$ e baixas $(A)$ de acordo com as características dos requisitos.

Quadro 15 - Árvore de utilidade reduzida e com prioridades.

\begin{tabular}{|c|c|c|c|c|}
\hline \multicolumn{2}{|c|}{ Atributos de Qualidade } & Cenários & IMP. & COM. \\
\hline \multirow{4}{*}{ 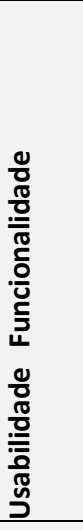 } & Adequação & N1: O sistema deve abranger $100 \%$ das funcionalidades da versão anterior & A & $M$ \\
\hline & Precisão & $\begin{array}{l}\text { U07: Garantir a integridade do numero de horas e ciclos voados durante a } \\
\text { inserção do relatório de vôo, através de uma verificação. }\end{array}$ & A & M \\
\hline & Recuperabilidade, & $\begin{array}{l}\text { AG5: Ao ocorrer uma falha o sistema deve ser capaz de reconhecê-la e de } \\
\text { proteger os dados de em caso de entradas incorretas, através de um } \\
\text { controle de ocorrência de falhas. } \\
\text { Fórmula: (\# falhas evitadas / \# casos de teste) } \\
\text { Interpretação: } 0 \leq x \leq 1 \text {; quanto mais próximo de 1, melhor } \\
\text { Entradas: relatórios de teste e de operação }\end{array}$ & A & A \\
\hline & Compreensibilidade & $\begin{array}{l}\text { U04: O sistema deve ser intuitivo e de fácil aprendizagem com medida } \\
\text { através do número de funções evidentes com o propósito de medir a } \\
\text { proporção de funções que são evidentes ao utilizador } \\
\text { Fórmula: (\# funções evidentes / \# funções) }\end{array}$ & M & M \\
\hline$\frac{\pi}{\underline{0}}$ & Desempenho & $\begin{array}{l}\text { U2 As transações do sistema de manutenção não podem ser executadas no } \\
\text { tempo maior que } 5 \text { segs }\end{array}$ & A & A \\
\hline \multirow{4}{*}{ 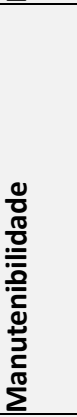 } & Analisabilidade & $\begin{array}{l}\text { U01: O sistema deve permitir o rastreamento da execução da manutenção } \\
\text { da aeronave atendendo o prazo de no máximo } 15 \text { minutos após a } \\
\text { solicitação. }\end{array}$ & $M$ & $M$ \\
\hline & Modificabilidade & $\begin{array}{l}\text { AG1: O sistema deve permitir a inserção ou modificação de funcionalidades } \\
\text { no prazo máximo de } 5 \text { dias e sem gerar efeitos colaterais permitindo testes } \\
\text { das funções correlatas no prazo máximo de } 1 \text { dia }\end{array}$ & A & A \\
\hline & & $\begin{array}{l}\text { U06: O sistema deve se manter estável durante o registro das } \\
\text { manutenções }\end{array}$ & A & M \\
\hline & & $\begin{array}{l}\text { N10: O sistema deve permitir o incremento de plataforma (hardware e } \\
\text { software) sem tirar o sistema do ar. }\end{array}$ & M & A \\
\hline \multirow{5}{*}{ 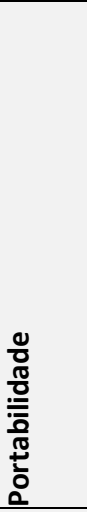 } & \multirow[t]{3}{*}{ Adaptabilidade } & $\begin{array}{l}\text { AG4: O sistema deverá ser executado pelos browsers Firefox, internet } \\
\text { explorer, ophera e safari, sem precisar de instalações sem precisar de } \\
\text { instalações }\end{array}$ & M & M \\
\hline & & $\begin{array}{l}\text { N11: O sistema deve ser compatível com os bancos de dados: SQL Server, } \\
\text { Oracle, MY SQL e com os sistemas operacionais Linux, Windows e Mac OS. }\end{array}$ & A & A \\
\hline & & $\begin{array}{l}\text { N07: O sistema deve ser portado para uma nova linguagem de forma } \\
\text { automática sem necessitar de programação adicional ou replicação de } \\
\text { código. }\end{array}$ & A & A \\
\hline & \multirow[t]{2}{*}{ Co-existência } & $\begin{array}{l}\text { AG2: Outros produtos devem ser construídos de forma que se integrem } \\
\text { com este produto e com reuso de mais de } 60 \% \text { do núcleo }\end{array}$ & M & A \\
\hline & & N05: A integração de subsistemas deve ser completa em no máximo 5 dias. & $\mathrm{M}$ & M \\
\hline \multirow[b]{2}{*}{ 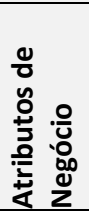 } & \multirow[t]{2}{*}{ Time-to-market } & N12: A nova versão do sistema deve estar no mercado em 3 anos. & A & A \\
\hline & & $\begin{array}{l}\text { AG3: O sistema tem que permitir o desenvolvimento de módulos } \\
\text { independentes por equipes geograficamente distantes. Sem que perda } \\
\text { qualidade de produto e da execução do processo mantendo o processo de } \\
\text { desenvolvimento. }\end{array}$ & A & M \\
\hline
\end{tabular}




\subsubsection{Passo 8-Análise dos mecanismos arquiteturais}

A análise arquitetural é formulada através de um template (CLEMENTS), onde são descritos o estímulo, resposta e abordagem arquitetural existente e será realizada para cada cenário de alta prioridade definidos no passo anterior e apresentados no Quadro 10.

Neste passo, os mecanismos são analisados segundo o seguinte método (CLEMENTE, 2003): atributos de qualidade são realizados por táticas arquiteturais que direcionam os mecanismos de arquitetura.

Os cenários envolvidos dizem respeitos aos atributos de qualidade: eficiência, manutenibilidade, funcionalidade/atributo de negocio, confiabilidade e portabilidade.

Os quadros 16 a 20 detalham a análise arquitetural de cada cenário prioritário. Neste detalhamento é possível observar o ambiente, o estímulo, a resposta e abordagem arquitetural existente para atender o requisito. Nesta fase incluímos também o levantamento dos riscos envolvidos em cada cenário e as sugestões em relação ao monitoramento destes riscos.

O quadro 16 apresenta a análise arquitetural do Cenário AG1, onde a preocupação do usuário está no prazo, no custo e no efeito colateral das modificações. O processo de desenvolvimento adotado, agiliza a inserção de novas funcionalidades e garante a integridade das funções correlatas que foi alterada ou modificada. Entretanto o processo de teste e verificação pode comprometer a velocidade de entrega das solicitações.

Três estratégias arquiteturais são indicadas para alcançar a modificabilidade, ou seja, para controlar quanto será propagado os efeitos da mudança, são elas indireção, encapsulamento e separação.

Indireção: Envolve o uso de mediadores para permitir que produtores e consumidores de dados se comuniquem sem ter um conhecimento direto um do outro. Somente o mediador conhece a necessidade de dados de cada um. Consequentemente produtores ou consumidores adicionais podem ser adicionados sem mudanças para os já existentes. 
Encapsulamento: É similar a indireção; uma interface faz o papel do mediador, separando os detalhes de implementação.

Separação: isola os aspectos ortogonais de uma arquitetura para outra. Por exemplo, separando dados a partir de visões de dados, a criação de novas visões pode ser independente de outras visões existentes. Separando comandos de dados permite que novos comandos sejam adicionados sem afetar os comandos existentes.

Uma decisão importante incide em alterar o processo para simplificar os testes ou diminuir a coesão das funcionalidades relacionadas ou seja manter baixo acoplamento e Alta coesão do software.

Quadro 16 - Análise Arquitetural - Cenário AG1.

\begin{tabular}{|c|c|}
\hline \multicolumn{2}{|r|}{ Análise Arquitetural } \\
\hline Cenário: AG1 & $\begin{array}{l}\text { O sistema deve permitir a inserção ou modificação de funcionalidades de forma rápida barata e } \\
\text { sem gerar efeitos colaterais permitindo testes das funções correlatas no prazo máximo de } 1 \text { dia. }\end{array}$ \\
\hline Atributo & MANUTENIBILIDADE \\
\hline Ambiente & Operação normal \\
\hline Estimulo & Solicitação de nova funcionalidade pelo cliente \\
\hline Resposta & Tempo e custo de desenvolvimento da funcionalidade \\
\hline $\begin{array}{l}\text { Abordagem } \\
\text { Arquitetural Existente }\end{array}$ & $\begin{array}{l}\text { O processo de desenvolvimento adotado agiliza a inserção de novas funcionalidades com } \\
\text { controle das funções afetadas }\end{array}$ \\
\hline Riscos & Má definição da alteração do requisito \\
\hline $\begin{array}{l}\text { Monitoramento dos } \\
\text { Riscos }\end{array}$ & Fazer validação da alteração do requisito. \\
\hline Táticas Sugeridas & $\begin{array}{l}\text { Encapsulamento } \\
\text { DA 1.1 Padronização de interface através de template } \\
\text { DA1.2.Criar componentes/classes para desenvolver interface padrão } \\
\text { Separação: } \\
\text { DA.1.3.Modelagem da base de dados flexível através de normalização } \\
\text { DA.1.6. Manter Baixo acoplamento } \\
\text { DA.1.7.Manter Alta coesão do software } \\
\text { DA.1.4.Realizar e manter a documentação do sistema } \\
\text { DA.1.5.Manter check list de teste dos componentes utilizados ou novos } \\
\text { D.A.1.8.Executar teste e homologação da nova funcionalidade } \\
\text { D.A.1.9.Realizar controle de versão }\end{array}$ \\
\hline
\end{tabular}

O quadro 17 apresenta a análise arquitetural do cenário AG5 onde, a partir da entrada de dados. Ao ocorrer uma falha o sistema deve ser capaz de reconhecê-la e de proteger os dados em caso de entradas incorretas, através de um controle de ocorrência de falhas com coeficiente de falhas evitadas / casos de teste próximo de 1. Cerca de $40 \%$ das interfaces atuais possuem algum tipo de verificação para 
proteção do sistema e a arquitetura atual prevê a ocorrência de falhas de banco e de execução Porém não existe um mecanismo automatizado para essa verificação.

Quadro 17 - Análise Arquitetural - Cenário AG5.

\begin{tabular}{|l|l|}
\hline \multicolumn{2}{|c|}{ Análise Arquitetural } \\
\hline Cenário: AG5 & $\begin{array}{l}\text { Ao ocorrer uma falha o sistema deve ser capaz de reconhecê-la e de proteger os dados em caso de } \\
\text { entradas incorretas, através de um controle de ocorrência de falhas. } \\
\text { Fórmula: (\# falhas evitadas / \# casos de teste) } \\
\text { Interpretação: } 0 \leq x \leq 1 ; \text { quanto mais próximo de 1, melhor } \\
\text { Entradas: relatórios de teste e de operação }\end{array}$ \\
\hline Atributo & CONFIABILIDADE \\
\hline Ambiente & Operação Normal \\
\hline Estimulo & Entrada de dados \\
\hline Resposta & Telas de resposta ao usuário impossibilitando a entrada de dados \\
\hline $\begin{array}{l}\text { Abordagem } \\
\text { Arquitetural } \\
\text { Existente }\end{array}$ & $\begin{array}{l}\text { Cerca de 40\% das interfaces possuem algum tipo de verificação para proteção do sistema. Não } \\
\text { existe um mecanismo automatizado para essa verificação }\end{array}$ \\
\hline Riscos & A arquitetura atual prevê a ocorrência de falhas de banco e de execução \\
\hline $\begin{array}{l}\text { Monitoramento dos } \\
\text { Riscos }\end{array}$ & Ameaça de vírus \\
\hline Táticas Sugeridas & DA.2.1. Controle e tratamento de falhas ( banco, código, entrada de dados). \\
\hline
\end{tabular}

O processo de desenvolvimento adotado possui uma estrutura de testes eficiente que pode ser trabalhada para controlar a incidência de falhas previstas e evitadas. Como decisão arquitetural é possível propor rotina de teste específica para as entradas e ainda criar um mecanismo para criação de rotinas de verificação.

O quadro 18 trata da análise arquitetural do Cenário U02. Neste caso a arquitetural atual não garante que as transações do sistema de manutenção sejam executadas no tempo maior que 5 segundos, pois não existe nenhuma aferição do tempo necessário para execução das rotinas de manutenção das aeronaves. Como decisão é necessário executar a aferição do tempo gasto, atualmente, para então realizar analise no código e das funcionalidades.

Como decisões arquiteturais são sugerias três, como programação no banco de dados e algumas iniciativas referente à implementação das telas do sistema. 
Quadro 18 - Análise Arquitetural - Cenário U02.

\begin{tabular}{|c|c|}
\hline \multicolumn{2}{|r|}{ Análise Arquitetural } \\
\hline Cenário: U02 & $\begin{array}{l}\text { As transações do sistema de manutenção não podem ser executadas no tempo maior que } 5 \\
\text { segundos. }\end{array}$ \\
\hline Atributo & EFICIÊNCIA \\
\hline Ambiente & Operação Normal \\
\hline Estimulo & Tempo de resposta das funções do sistema \\
\hline $\begin{array}{l}\text { Abordagem } \\
\text { Arquitetural } \\
\text { Existente }\end{array}$ & A arquitetura atual não permite este tipo de controle \\
\hline Riscos & Infra estrutura prejudicar o tempo de respostas \\
\hline $\begin{array}{l}\text { Monitoramento dos } \\
\text { Riscos }\end{array}$ & $\begin{array}{l}\text { Programar cronograma de ajustes e manutenção dos componentes da infraestrutura como } \\
\text { computadores e rede }\end{array}$ \\
\hline Táticas Sugeridas & $\begin{array}{l}\text { DA.3.1. Programação no banco de dados para agilizar o tempo de resposta } \\
\text { DA.3.2. Implementar telas limpas e simplificadas } \\
\text { DA.3.3. Carregar apenas informações necessárias, e conforme forem sendo solicitadas. }\end{array}$ \\
\hline
\end{tabular}

O quadro 19 trata da análise arquitetural do Cenário N11. A partir do surgimento de novas demandas quanto a plataforma o sistema deve ser compatível com os banco de dados: SQL Server, Oracle, MY SQL e com os sistemas operacionais Linux, Windows e Mac OS.

A arquitetura atual atende parcialmente a essa demanda pois é compatível com o Windows e com banco de dados Oracle e 90\% dos demais banco de dados relacionais. Somente 10\% das operações não utilizam SQL PADRÃO disponíveis em todos os bancos de dados relacionais. Como decisão arquitetural sugere-se que seja realizada uma tradução das consultas que não estão em SQL Padrão para os bancos de dados citados. No caso dos sistemas operacionais será necessária uma análise mais detalhada das linguagens e técnicas disponíveis para que o sistema seja compatível com os sistemas operacionais citados. 
Quadro 19 - Análise Arquitetural - Cenário N11.

\begin{tabular}{|l|l|}
\hline \multicolumn{2}{|c|}{ Analise Arquitetural } \\
\hline Cenário: N11 & $\begin{array}{l}\text { N11: O sistema deve ser compatível com os bancos de dados: SQL Server, Oracle, MY SQL e com } \\
\text { os sistemas operacionais Linux, Windows e Mac OS. }\end{array}$ \\
\hline Atributo & PORTABILIDADE \\
\hline Ambiente & Desenvolvimento \\
\hline Estimulo & Surgimento de novas demandas quanto a plataforma \\
\hline Resposta & Não se Aplica \\
\hline $\begin{array}{l}\text { Abordagem } \\
\text { Exquitetural }\end{array}$ & $\begin{array}{l}\text { A arquitetura atual é compatível com o Windows com banco de dados Oracle. EM 90\% das } \\
\text { operações utiliza SQL PADRÃO sendo compatível com 90\% dos bancos de dados relacionais }\end{array}$ \\
\hline Riscos & $\begin{array}{l}\text { Surgimento de nova tecnologia de Banco de dados } \\
\text { Monitoramento dos } \\
\text { Riscos }\end{array}$ \\
\hline Táticas Sugerida & $\begin{array}{l}\text { Monitorar o surgimento de novas tecnologias e estudar melhorias continua da arquitetura atual. } \\
\text { DA.4.2. Utilizar SQL padrão } \\
\text { DA.4.3. Utilizar paradigma OO }\end{array}$ \\
\hline
\end{tabular}

O quadro 20 trata da análise arquitetural do Cenário N12. Para alcançar novos mercados é necessário que a nova versão do sistema deva estar no mercado em 3 anos, tempo em que se alcance a execução satisfatória dos testes do novo sistema. A arquitetural atual não atende a todos os cenários analisados e uma reestruturação da arquitetura será necessária. Para atender o prazo estipulado será necessário encontrar uma tecnologia ágil que atenda principalmente os cenários U02 e N11 simultaneamente sem perder de focos os demais cenários prioritários.

Quadro 20 - Análise Arquitetural - Cenário N12.

\begin{tabular}{|l|l|}
\hline \multicolumn{2}{|c|}{ Análise Arquitetural } \\
\hline Cenário: N12 & A nova versão do sistema deve estar no mercado em 3 anos \\
\hline Atributo & ATRIBUTO DE NEGÓCIO \\
\hline Ambiente & Desenvolvimento \\
\hline Estimulo & Novos mercados \\
\hline Resposta & Execução satisfatória dos testes do novo sistema \\
\hline $\begin{array}{l}\text { Abordagem } \\
\text { Arquitetural } \\
\text { Existente }\end{array}$ & Com a arquitetural atual será muito difícil atender a este prazo \\
\hline Riscos & Não encontrar tecnologia adequada a tempo \\
\hline $\begin{array}{l}\text { Monitoramento dos } \\
\text { Riscos }\end{array}$ & Iniciar a curto prazo o estudo de tecnologias que atenda o cenário proposto. \\
\hline Táticas Sugeridas & $\begin{array}{l}\text { DA.5.1. Iniciar pesquisa por linguagens mais adequadas e gerador de código } \\
\text { DA.5.2. Treinamento da equipe } \\
\text { DA.5.3. Utilização do processo certificado. }\end{array}$ \\
\hline
\end{tabular}




\subsubsection{Passo 9 - Consolidar resultados}

Com base nas informações coletadas durante a avaliação são apresentados os resultados aos envolvidos. Informações como analise arquitetural dos cenários prioritários, pontos sensitivos e trade-offs são consolidados em um documento. Os artefatos resultantes do processo de avaliação através do ATAM são adequados para pautar a estratégia da evolução do software.

- Conjunto de Requisitos de Qualidade;

- Conjunto de Riscos e não riscos;

- Conjunto de Pontos sensitivos e críticos;

- Pontos de Conflitos;

- Plano de Monitoramento de Riscos.

Observando os cenários prioritários destacam-se os requisitos de qualidades que dizem respeito à eficiência, manutenibilidade, funcionalidade e atributo de negócio, confiabilidade e portabilidade.

Ponto sensitivo é uma propriedade de um ou mais componentes de atributos de qualidade. Os valores particulares de um ponto sensitivo pode se tornar um risco quando identificados em uma arquitetura. Dentro do trabalho podem ser destacados dois pontos sensitivos:

- S.1.2. Estratégias de normalização podem degradar a performance.

- S.1.1 O aumento do número de componentes pode degradar a performance.

Outro ponto importante da avaliação é a identificação dos Trade-offs. Um ponto de trade-off é uma decisão arquitetural que afeta mais de um atributo e é um ponto sensitivo para mais de um atributo. Levando em consideração todos os requisitos da árvore de utilidade, foram identificados 13 trade-off dos quais 5 podem ser considerados pontos sensitivos pois afetam requisitos que foram considerados com alta prioridade pelos stakeholders. Os 5 trade-offs identificados foram: 
- Eficiência x Confiabilidade: as constantes verificações de segurança do sistema e registros de log afetam a agilidade no uso e o tempo de resposta do sistema.

- Manutenibilidade x Confiabilidade: o rastreamento da execução da manutenção irá levar a uma demora no teste dos módulos inviabilizando a inserção rápida de novas funcionalidades.

- Funcionalidade e atributo de negócio x Eficiência: a portabilidade do sistema e a compatibilidade do mesmo com diversas linguagens pode degradar a performance do sistema devido ao número de camadas necessárias para implementar a portabilidade.

- Portabilidade x Eficiência: as inúmeras possibilidades que o sistema dever reconhecer e tratar gera um gasto de tempo na resposta do sistema.

- Manutenibilidade x Portabilidade: as inúmeras possibilidades que devem ser tratadas pelo sistema comprometem a agilidade na inserção de novas funcionalidades aumentando tempo e custo de desenvolvimento.

Cada risco, não-risco, ponto sensitivo, trade-off identificados esta associado com o alcance de um ou mais refinamento do atributo de qualidade na árvore de utilidade. Os riscos e não riscos devem constar no plano de monitoramento dos riscos.

\subsection{Aspectos do Plano de Ação para Evolução}

O foco da avaliação está na evolução estrutural de um sistema que atualmente atende as necessidades dos usuários. O documento final do resultado da avaliação será a base para a estratégia da evolução a ser adotada pela empresa. Este documento identifica pontos críticos na arquitetura do sistema que deverão ser trabalhados para atender as exigências do mercado garantindo a sua estabilidade e sobrevivência. 
Neste ponto é importante observar e acompanhar as decisões arquiteturais sugeridas nos quadros de 16 a 20. Somente acatar as decisões arquiteturais resultantes da avaliação não irá resolver as questões da evolução. Muitas vezes uma decisão arquitetural afeta o atendimento de outro requisito. $\mathrm{Na}$ maioria das vezes é necessário fazer escolhas entre as decisões a serem aceitas.

Quando consideramos a evolução de software a partir da perspectiva arquitetural é necessário determinar se uma arquitetura requer mudanças e subseqüentemente como executar estas mudanças. Desta forma a avaliação arquitetural se faz necessária para responder estas perguntas. Em casos de arquiteturas complexas onde estão envolvidos vários sistemas e subsistemas ou uma linha de produto se faz necessária uma análise mais consistente nas escolhas utilizadas e nos efeitos que elas provocam nos sistemas envolvidos.

Os artefatos resultantes do processo de avaliação através do ATAM são adequados para pautar a estratégia da evolução do software. O plano de evolução deverá ter como base os seguintes itens:

- Conjunto de Requisitos de Qualidade;

- Conjunto de Riscos e não riscos;

- Conjunto de Pontos sensitivos e críticos;

- Pontos de Conflitos;

- Plano de Monitoramento de Riscos.

As táticas sugeridas direcionam as ações que devem ser tomadas para evolução do software de acordo com os requisitos colocados como meta. Os tradeoffs indicam quais as perdas e ganhos entre táticas conflitantes. E por fim os riscos apontam os fatores e variáveis que devem ser observados, monitorados e controlados durante o processo de evolução. Estas decisões arquiteturais são analisadas com o objetivo de traçar as diretivas para evolução de cada ponto de vista ODP de acordo com o seu nível de abstração. Desta forma o arquiteto e sua equipe poderão elaborar um planejamento estratégico para o desenvolvimento da nova versão do produto. Estas informações irão compor a estratégia da empresa na elaboração do plano para evolução do software. 
Quadro 21 - Táticas Sugeridas classificadas de acordo com os pontos de vistas ODP.

\begin{tabular}{|c|c|}
\hline $\begin{array}{l}\text { Ponto de } \\
\text { Vista }\end{array}$ & Tática Arquitetural \\
\hline Empresa & $\begin{array}{l}\text { DA.5.3. Utilização do processo certificado. } \\
\text { DA.5.2. Treinamento da equipe } \\
\text { DA.1.5. Manter check list de teste dos componentes utilizados ou novos. } \\
\text { DA.1.8. Executar teste e homologação da nova funcionalidade. } \\
\text { DA.1.9. Realizar controle de versão. }\end{array}$ \\
\hline Tecnologia & $\begin{array}{l}\text { DA.5.1. Iniciar pesquisa por linguagens mais adequadas e gerador de código } \\
\text { DA.4.1. Utilizar tecnologias populares e robustas como Java. } \\
\text { DA.4.2. Utilizar SQL padrão } \\
\text { DA.4.3. Utilizar paradigma OO } \\
\text { DA.3.1. Programação no banco de dados para agilizar o tempo de resposta. }\end{array}$ \\
\hline Informação & $\begin{array}{l}\text { DA.1.4. Realizar e manter a documentação do sistema. } \\
\text { DA.1.3. Modelagem da base de dados flexível através de normalização. }\end{array}$ \\
\hline Engenharia & $\begin{array}{l}\text { DA.1.6. Manter Baixo acoplamento. } \\
\text { DA.1.7. Manter Alta coesão do software. } \\
\text { DA.2.1. Controle e tratamento de falhas ( banco, código, entrada de dados). }\end{array}$ \\
\hline Computação & $\begin{array}{l}\text { DA.1.1. Padronização de interface através de template. } \\
\text { DA.3.2. Implementar telas limpas e simplificadas } \\
\text { DA.1.2. Criar componentes/classes para desenvolver interface padrão. } \\
\text { DA.3.3. Carregar apenas informações necessárias, e conforme forem sendo solicitadas. }\end{array}$ \\
\hline
\end{tabular}

Dentro do contexto da aplicação exemplo, o quadro 21 mostra as táticas classificadas de acordo com os pontos de vista ODP. Esta classificação facilitará a ação das diversas competências da empresa, cada uma na sua área específica. No exemplo em questão essa divisão facilitou a separação das tarefas e monitoramento da execução de cada uma pelos seus responsáveis.

Os responsáveis pelos pontos de vistas devem traçar um plano de ação para cada tática sugerida, e acompanhar sua evolução. Deve ser elaborado um cronograma que considere como tempo máximo o período determinado pelo cenário N12 que diz que o lançamento de uma nova versão não deve ultrapassar 3 anos.

A equipe da empresa analisou cada uma das táticas sugeridas e criou um cronograma de ação de acordo com a ordem de prioridade das atividades. Foram observadas prioridade e relacionamentos do tipo dependência entre as táticas.

Nesta aplicação exemplo não surgiram táticas conflitantes, pois os conflitos foram solucionados em uma etapa anterior. Mas ainda é necessária uma fase de brainstorm e divulgação de decisões tomadas a partir das táticas sugeridas.

É importante a atuação da gerência do projeto para acompanhar o cumprimento das decisões tomadas como, por exemplo, acompanhar se os analistas e programadores estão mantendo a decisão de manter um baixo acoplamento e 
uma alta coesão ( DA1.7 e 1.6). Ou ainda se estão mantendo a documentação do sistema atualizada como determina a decisão arquitetural 1.4.

Observe que os envolvidos no ponto de vista de tecnologia devem executar algumas ações importantes como escolher a linguagem e a tecnologia que deve ser adotada. Desta decisão depende uma série de outras.

É possível notar que os envolvidos no ponto de vista de empresa ficam responsáveis pelas ações de gerenciamento.

O desenvolvimento do processo deixou algumas lições importantes no uso do método ATAM como base para avaliação de arquiteturas, como:

Melhorias de Documentação: No início da avaliação, a documentação arquitetural estava incompleta. A avaliação permitiu a atualização de partes consideradas importantes melhorando o projeto de arquitetura.

Coleta de Cenário e foco da avaliação: $\quad$ método adotado estimula aos usuários a definir e manter o foco da avaliação. Isto se mostra muito positivo quando é necessário resolver conflitos de requisitos. A identificação de pontos sensitivos e de trade-off dá aos stakholders esta possibilidade.

O envolvimento dos stakeholders na coleta de cenários e definição dos cenários prioritários auxilia no desenvolvimento do projeto diminuindo as possíveis divergências. A avaliação de âmbito muito vasto perderia a sua eficácia, dando resultados vagos, enquanto um foco muito estreito permite identificar as principais preocupações.

Problema descobertos durante todo o ciclo de vida de software:

método de avaliação de cenários podem ser aplicados durante todo o ciclo de vida do software.

A vantagem de usá-lo no início das atividades de reestruturação do sistema ou até no início do desenvolvimento é a possibilidade de descobrir problemas de projeto numa fase que ainda é possível tomar as decisões adequadas. No entanto, quando o volume de trabalho feito é grande, reverter às alterações, ou perceber que a arquitetura não é adequada para a evolução pode ser muito caro. 
Para reduzir os riscos associados com a evolução de software, o método de avaliação baseada em cenários pode ser usado para melhorar a arquitetura de sistema durante o ciclo de vida do sistema inteiro.

Melhorias para a família de produtos de software: $O$ processo de avaliação descrita não é específico para famílias de produtos de software e pode ser aplicada a qualquer arquitetura de software. No entanto, temos vindo a utilizar o método para avaliar a família de produtos de software arquiteturas e descrevemos abaixo os principais benefícios e lições que aprendemos.

No contexto de uma arquitetura de software da família de produtos, a avaliação deve $\backslash$ considerar a evolução para o conjunto dos produtos da família. Nas avaliações com base no cenário de cada etapa do processo são afetados por esta dimensão.

A fase de seleção de cenários inclui a análise dos produtos da família e como os recursos, facultativo ou obrigatório, são afetados pela avaliação. No exemplo apresentado, a ênfase foi colocada sobre a portabilidade e manutenibilidade do produto.

O fato de que o arquiteto chefe da família de produtos de software sempre foi incluído em nossa lista das partes interessadas garantiu que a avaliação levasse em consideração não apenas o software específico componentes, mas também a arquitetura de software da família de produtos. Além disso, durante todo o processo, a equipe de avaliação tinha de considerar o software do produto na dimensão da arquitetura da família.

\subsection{Resumo}

A aplicação do método começou com 7 cenários de usuários e 14 cenários de negócios que foram levantados na identificação dos objetivos do negócio junto ao cliente. Os cenários dos usuários foram resultados das demandas dos usuários do sistema que possuíam informações acerca das deficiências do sistema e os cenários de negócio vieram da leitura da visão estratégica do cliente.

No Quadro 22 está resumido o número de cenários levantados para cada atributo de qualidade. 
Quadro 22 - Número de requisitos por atributo de qualidade.

\begin{tabular}{|l|l|l|}
\hline Categorias & Atributos de Qualidade & Qtd \\
\hline Funcionalidade & Adequação & 1 \\
\cline { 2 - 3 } & Precisão & 1 \\
\hline \multirow{3}{*}{ Confiabilidade } & Tolerância a falhas & 1 \\
\cline { 2 - 3 } & Recuperabilidade, & 1 \\
\hline Usabilidade & Compreensibilidade & 1 \\
\hline Eficiência & Desempenho & 1 \\
\hline Manutenibilidade & Analisabilidade & 1 \\
\cline { 2 - 3 } & Modificabilidade & 4 \\
\cline { 2 - 3 } & Testabilidade & 1 \\
\hline \multirow{3}{*}{ Portabilidade } & Adaptabilidade & 2 \\
\cline { 2 - 3 } & Instalabilidade & 1 \\
\cline { 2 - 3 } & Co-existência & 4 \\
\hline Atributos de Negócio & Time-to-market & 2 \\
\cline { 2 - 3 } & Custo e benefício & 1 \\
\hline
\end{tabular}

Durante a fase de análise das abordagens existentes para atender os 22 novos requisitos foram detectados que dentre as abordagens arquiteturais existentes atende totalmente somente 1 cenário, atende parcialmente a 11 cenários e não atende a 8 cenários. Esses números comprovam a necessidade da reestruturação da arquitetura para adequar as novas necessidades.

No passo 7 foi realizado um Brainstorm e priorização de cenários para levantar dentre o grupo cenários prioritários, mas foi observado durante a reunião que alguns cenários eram semelhantes e poderiam ser agrupados. De posse da árvore de utilidade foi elaborado uma matriz identificada por Mapa de Cenários. O objetivo deste mapa é visualizar a princípio os cenários semelhantes, facilitando um possível agrupamento. Este passo de agrupamento foi incorporado pelos avaliadores para facilitar a resolução de conflitos que poderiam surgir. Com o agrupamento o número de cenários caiu de 22 para 16.

Na priorização os principais cenários de um sistema são classificados em função de sua importância e complexidade, considerando a percepção de negócio e arquitetura. As duas variáveis de priorização Importância e Complexidade foram classificadas em alta (A), média (M) e baixa (B) de acordo com as características dos requisitos. Cinco cenários foram classificados como alta prioridade.

Levando em consideração todos os requisitos da árvore de utilidade e analisando as táticas sugeridas, foram identificados 13 trade-off dos quais 5 podem ser considerados pontos de sensibilidades pois afetam requisitos que foram considerados com alta prioridade pelos stakeholders. Esses conflitos envolveram 
cenários das mais diversas classificações tais como: Eficiência x Confiabilidade, Manutenibilidade $x$ Confiabilidade, Funcionalidade e Atributo de negócio $x$ Eficiência, Portabilidade x Eficiência, Manutenibilidade x Portabilidade. 


\section{CONCLUSÕES E TRABALHOS FUTUROS}

Este trabalho apresenta um roteiro que busca direcionar as ações de evolução do software em um sistema real. A aplicação do roteiro em um exemplo prático mostrou que os passos do roteiro geram informações relevantes para o direcionar as ações de evolução do problema em questão. Este trabalho não se propõe a revelar um processo sistemático para evolução de software.

O estudo da utilização do método de avaliação ATAM no apoio a evolução arquitetural através de um roteiro que tem como referência os passos do ATAM mais o desenvolvimento de um exemplo da aplicação deste roteiro permitiu verificar de que o método de avaliação selecionado ajuda ao arquiteto conhecer tanto os objetivos a serem alcançados pelo software, quanto as ferramentas compatíveis com a organização para alcançá-los, possibilitando ao software que exiba os atributos de qualidade desejados.

Os requisitos não-funcionais descrevem as qualidades e restrições de como o sistema realiza suas funções, ou seja, como o sistema funciona. Um software, portanto, deve exibir atributos de qualidade que atendam aos seus requisitos. A arquitetura de software contém a descrição de como o sistema alcança aos atributos de qualidade desejados. Essa descrição de como o software atende aos requisitos não-funcionais é feita pelas diversas decisões presentes na arquitetura. Para conceber essas decisões arquiteturais - e, portanto, para projetar a arquitetura - é de fundamental importância que $o$ arquiteto conheça tanto os objetivos a serem alcançados pelo software, quanto às ferramentas para alcançá-los. Em outras palavras, é essencial que ele conheça tanto os atributos de qualidade, quanto técnicas e padrões de projeto arquitetural que, ao serem implementados, possibilitam ao software que exiba os atributos de qualidade desejados.

No estudo desenvolvido a arquitetura do software define o potencial global que possui um sistema de software para cumprir certos atributos de qualidade de acordo com o que esta sitado em [Bosch \& Molin 1999] e [Dobrica \& Niemelä 2002].

Durante o desenvolvimento do exemplo, o roteiro proposto permitiu identificar e direcionar as ações necessárias para alcançara evolução do sistema de software. Isso pode ser observado através das análise das táticas sugeridas para evolução do 
produto. Estas táticas e as demais informações compõem dados que podem nortear o planejamento estratégico da organização no que diz respeito a contratação de pessoal, aquisição de tecnologia e mercado alvo.

A aplicação do método foi eficiente quando se trata de evolução do software, uma vez que permite nortear a avaliação a partir da arquitetura atual do software e dos cenários que o requisitante deseja alcançar. A aplicação foi bem sucedida na avaliação da arquitetura atual mesmo quando ela não possui documentação e na questão de traçar estratégias de atuação considerando a opinião e a necessidade de todos os envolvidos (stakholders).

Em relação às praticas sem método, fica claro a vantagem do uso de um método estruturado que conduza a avaliação. Os resultados são concretos e passíveis de serem utilizados pela equipe do cliente.

Outras conclusões foram obtidas durante o desenvolvimento do exemplo:

- O uso do método ATAM como referência mostrou-se uma ferramenta eficiente na descoberta de falhas, no atendimento dos atributos de qualidade permitindo aos envolvidos na avaliação um entendimento claro da localização dos problemas da arquitetura.

- Por muitas vezes o método facilitou o direcionamento das decisões arquiteturais permitindo apoiar a evolução do software.

- Os resultados obtidos com o ATAM geram documentos importantes para o processo de evolução em curto, médio e longo prazo. Essa documentação tem papel importante na evolução do software e de sua arquitetura.

- Foi possível observar que as alterações que envolvem os requisitos nãofuncionais afetam de maneira mais drástica a arquitetura do software tornando a evolução arquitetural mais lenta e cara. Muitas vezes essas mudanças comprometem a continuidade do software devido a descontinuidade de uma plataforma, por exemplo.

- Uma arquitetura de software estruturada permite que a evolução funcional (originadas das mudanças nos requisitos funcionais) seja realizada de forma mais eficiente, sem causar grandes danos ou efeitos colaterais ao sistema.

- O uso dos pontos de vista ODP constitui uma importante ferramenta para a especificação de arquiteturas e, aliado a um mecanismo de descrição 
compatível, facilita o processo de especificação, definição e controle da evolução arquitetura.

- Dentro do contexto de uma fábrica de software o plano de evolução de um sistema alinha-se com o planejamento estratégico da empresa.

- A identificação de relações entre o resultado da avaliação e a reestruturação da arquitetura de acordo com o padrão ODP.

- A contextualização da evolução de software através do relacionamento com o processo de avaliação de software

Como trabalhos futuros podem ser destacados os seguintes pontos:

- Estudo dos efeitos das mudanças dos requisitos não-funcionais sobre a evolução arquitetural.

- A adaptação do roteiro para realizar uma experimentação de acordo com os conceitos de Engenharia de Software Experimental 


\section{REFERÊNCIAS}

BARCELOS, R. F. Uma abordagem para inspeção de documentos arquiteturais baseada em checklist [Rio de Janeiro] 2006 VIII, 175 p., 29,7 cm (COPPE/UFRJ, M.Sc., Engenharia de Sistemas e Computação, 2006) Dissertação - Universidade Federal do Rio de Janeiro, COPPE.

BAHSOON, R., EMMERICH, W., "Evaluating software architectures: development, stability, and evolution". In: Book of Abstracts of the ACS/IEEE International Conference on Computer Systems and Applications, pp. 47, Tunis, Tunisia, July, 2003.

BARBACCI M., CLEMENT P. , LATTANZE A. ,NORTHROP L., and WOOD W. Using the Architecture Tradeoff Analysis Method (ATAM) to evaluate the software architecture for a product line of avionics systems: A case study. CMU SEI Technical Note CMU/SEI-2003-TN-012, Software Engineering Institue, Pittsburgh, PA, 2003.

BASS L., CLEMENTS P., and R. Kazman. Software Architecture in Practice. The SEI Series in Software Engineering. Addison-Wesley, Reading, MA, 2nd edition, 2002.

BASS. L.; CLEMENTS, P.; Kazman, R. Software Architecture in Practice. Addison-Wesley Professional, 2 edição, Abril 2003.

BECERRA, J. Aplicabilidade do padrão de processamento distribuído e aberto nos projetos de sistemas de automação. Tese (Doutorado), Universidade de São Paulo, São Paulo, 1998.

BENGTSSON, PO. Architecture-Level Modifiability Analysis. 2002. Tese (Doutorado), Blekinge Institute of Technology, Sweden, Dissertation series No 20022, 2002.

BENNETT K. , RAJLICH V., "Software maintenance and evolution: A roadmap". In: Proc. of the Conference on The Future of Software Engineering, Limerick, Ireland, May 2000.

BOSCH J. Design \& Use of Software Architectures - Adopting and Evolving a Product Line Approach, Addison-Wesley, Harlow UK, 2000. 
BOSCH J., MOLIN P., "Software Architecture Design: Evaluation and Transformation", in: Proceedings of the 1999 IEEE Engineering of Computer Based Systems Symposium (ECBS99), IEEE Computer Society, Los Alamitos CA, 1999.

CHÁVEZ, M. Um Processo para o controle da evolução da Arquitetura de Software Baseado em ODP. 2009. Dissertação (Mestrado) - Universidade de São Paulo. São Paulo, 2009.

CHRISTOPH, H. R. Engenharia de software para software livre. 2009. Dissertação (mestrado) - PUC. Rio de Janeiro, 2004. 118 p.

CLEMENTS, $\mathrm{P}$ et al. Documenting Software Architectures: views and beyond. Addison-Wesley Professional, Setembro 2002.

CLEMENTS, P; KAZMAN, R; KLEIN, M. Evaluating software architecture: Methods and case studies. SEl, 8 edição, Abril 2009.

COLQUITT. D.; LEANEY. J. Expanding the view on Complexity within the Architecture Trade-off Analysis Method. In: Proceedings of the 14th Annual IEEE International Conference and Workshops on the Engineering of ComputerBased Systems, 2007

DIAS, S.; Roteiro para atualização tecnológica de sistemas legados baseado na avaliação arquitetural e engenharia guiada por valor. 2010. Dissertação (mestrado). 2010 Instituto de Pesquisas Tecnológicas do Estado de São Paulo Brasil, 2010

DOBRICA, L.; NIEMELA, E. A Survey on software architecture analysis methods. IEEE Transactions on Software Engineering, v. 28, n. 7, p. 638-653. 2002

EICK, S. G. et al. Does code decay? Assessing the evidence from change management data. In: IEEE Transactions on Software Engineering, v. 27, n. 1, p.112, 2001.

GALL, H. et al. Software evolution observations based on product release history. In: International Conference on Software Maintenance, p160-166, 1997, Bari, Itália, 1997. 
GARLAN, D; SHAW, M. An introduction to software architecture. Technical report CMU-CS-94-166, Carnegie Mellon University, Pittsburgh, January 1994.

GARLAN. D.; PERRY. D. Introduction to the Special Issue on Software Architecture," IEEE Transactions on Software Engineering, vol. 21, no. 4, p. 269274, Abril. 1995

GODFREY, M.W.; GERMAN, D.M.; The past, present, and future of software evolution, In: Frontiers of Software Maintenance. p. 129-138; Beijing. Setembro 2008

GORTON, I. Essential Software Architecture. Springer, Junho 2006.

GRAAF. B.; Model-Driven Evolution of Software Architectures,"Software Maintenance and Reengineering, European Conference on. v. 0; p. 357-360, 2007. Los Alamitos, CA, USA

GUIMARAES, J. H.; Método para manutenção de sistemas de software utilizando técnicas arquiteturais. 2008. Dissertação (Mestrado) - Universidade de São Paulo. São Paulo, 2008.

GURP, J. V.; BOSCH, J., Design erosion: problems and causes. Journal of Systems and Software, v. 61, n. 2, p.119, Março 2002.

HINDLE, A. et al. YARN: Animating software evolution. In: 4th Workshop on Visualizing Software for Understanding and Analysis, 2007. IEEE International, Banff, Ont. P. 129-136, 2007

HOHMANN, L. Beyond software architecture: creating and sustaining winning solutions. Addison-Wesley Professional, Janeiro 2003.

IEEE, Institute. "IEEE Std 1219-1998. IEEE Standard for Software Maintenance". New York: Institute of Electrical and Eletronic Engineers. Inc., 1998, 52p.

JAKTMAN, C. B.; LEANEY, J.; LIU, M. Structural Analysis of the Software Architecture - A Maintenance Assessment Case Study". In: Proceedings of the TC2 First Working IFIP. v. 140, p. 455-479, 1999. Apresentado a Conference on Software Architecture.1999 
KAZMAN, $\mathrm{R}$ et al, Experience with performing architecture tradeoff analysis. In: Proceedings of the 21st international conference on Software engineering, 1999, p. 54-63, Los Angeles CA, 1999.

KAZMAN, R. et al, The Architecture tradeoff analysis method. In: Proceedings Fourth Int'I Conf. Eng. of Complex Computer Systems, ICECCS '98, Agosto 1998.

KOTONYA, G; SOMMERVILLE, I.; Requirements engineering: processes and techniques. John Wiley \& Sons, September 1998.

KRUCHTEN, P. B. The 4+1 view model of architecture. Software, IEEE, v.12, n. 6, p 42-50, Novembro 1995.

KRUCHTEN, P.; OBBINK, H.; STANFORD, J. The past, present, and future for software architecture. Software, IEEE, v. 23, n.2, p. 22-30, 2006.

LEHMAN, M. M et al, Metrics and Laws of Software Evolution - The Nineties View, In: Proc. Fourth Int. Symp. on Software Metrics, Metrics 97, Albuquerque, New Mexico, p 20-32; 1997.

LEHMAN, M. M.; Laws of Software Evolution Revisited.; Lecture Notes In Computer Science - Proceedings of the 5th European Workshop on Software Process Technology; v. 1149, p. 108 - 124, Publisher Springer-Verlag London, UK;1996

LEHMAN, M. M; DE Perry and JF Ramil ; Implications of Evolution Metrics on Software Maintenance, In: Proc. Int. Conf. on Soft. Maintenance (ICSM'98), Bethesda, MD, p. 208-217, 1998.

LEHMAN, M. M; JF Ramil ; An Approach to a Theory of Software Evolution, In: Proceedings of the 4th International Workshop on Principles of Software Evolution, p. 70 - 74. Apresentado a International Conference on Software Engineering 2001, Vienna, Setembro 2001.

MACCARI A. Experiences in assessing product family architecture for evolution. Proceedings of the 23rd International conference on Software Engineering (ICSE). ACM Press: New York NY, 2002; 585-592.

MALAN, R; BREDEMEYER, D. Defining non-functional requirements. 
BREDEMEYER CONSULTING WHITE PAPER 2001 Disponível em: http://www.bredemeyer.com/pdf_fies/NonFunctReq. Acesso em: 30 ago. 2009.

MCNAIR. A.; GERMAN. D. M.; WEBER-JAHNKE. J.; Visualizing Software Architecture Evolution using Change-sets. In: 14th Working Conference on Reverse Engineering, p. 130-139, 2007.

MENS, T. et al; Challenges in Software Evolution, In: Proceedings of the 2005 Eighth International Workshop on Principles of Software Evolution, p. 13-22, Setembro 2005.

MENS. T.; DEMEYER, S.; Software Evolution. Springer, Março 2008

NIKORA, A.P.; MUNSON, J.C.; Understanding the nature of software evolution. In: Proceedings. International Conference on Software Maintenance, 2003. p. 8393, 2003.

OLUMOFIN F, MISIC V. Extending the ATAM architecture evaluation to product line architectures. Proceedings $5^{\text {th }}$ IEEE/IFIP Working Conference on Software Architecture (WICSA). IEEE Computer Society Press: Los Alamitos CA, 2005; 45-56

PADUELLE, M. M. "Manutenção de Software: problemas típicos e diretrizes para uma disciplina específica. 2007. 144 p. Dissertação (Mestrado) - Instituto de Ciências Matemáticas e de Computação, Universidade de Sõ Paulo, São Carlos, Sp, 2007.

PARNAS, D. L. Software aging. In ICSE '94: Proceedings of the 16th international conference on Software engineering, pp. 279 - 287 , Los Alamitos, CA, USA , 1994. IEEE Computer Society Press.

PERRY, D. E.; WOLF, A.L.. Foundations for the study of software architecture. SIGSOFT Software Engineering Notes, v.17, n. 4, p 40-52. ACM New York, NY, USA, Outubro 1992.

PORTES, A. A. Fundamental Laws and Assumptions of Software Maintenance, Empirical Software Engineering, v. 2, n. 2, p. 119-131, Kluwer Academic Publishers, Hingham,USA, 1997

PRESSMAN, R. Software engineering: a practitioner's approach. McGraw-Hill Science/Engineering/Math, 6 edition, Abril 2004. 
RANK. S. Architectural Reflection for Software Evolution, In: 2nd ECOOP Workshop on Reflection, AOP and Meta-Data for Software Evolution, Glasgow, UK. 2005.

RIVA C, ROSSO D. C. Experiences with software product family evolution. Proceedings of the 6th International Workshop on Principles of Software Evolution. ACM Press: New York NY, 2003; 161-169

ROSSO D. C. Dynamic memory management for software product family architectures in embedded real-time systems. Proceedings 5th Working IEEE/IFIP Conference on Software Architecture (WICSA'05). IEEE Computer Society Press: Los Alamitos CA, 2005; 211-212.

ROSSO D. C. Experiences of performance tuning software product family architectures using a scenario-driven approach. Proceedings of the 10th International Conference on Evaluation and Assessment in Software Engineering (EASE). British Computer Society: Swindon, 2006; 30-39.

ROSSO, C. D.Continuous evolution through software architecture evaluation: a case study. 2006, JOURNAL OF SOFTWARE MAINTENANCE AND EVOLUTION: RESEARCH AND PRACTICE J. Softw. Maint. Evol.: Res. Pract. 2006; 18:351-383.

ROZANSKI, N.; Software systems architecture: working with stakeholders using view-points and perspectives. Addison-Wesley Professional, Abril 2005.

SADOU, N.; TAMZALIT D.; OUSSALAH M. A unified Approach for Software Architecture Evolution at different abstraction levels, In: Proceedings of the 2005 Eighth International Workshop on Principles of Software Evolution, p. 65-70, IEEE Computer Society Washington, DC, USA,. 2005.

SCACCHI W. Understanding open source software evolution. In: Software Evolution, Madhavji NH, Lehman MM, Ramil JF, Perry D (eds.). Wiley: New York NY, 2004.

SOMMERVILLE, I. ENGENHARIA DE SOFTWARE. (8TH EDIÇÃO). ADDISON WESLEY, MAIO 2007. 
SVAHNBERG. M.; Supporting software architecture evolution. 2003. Tese (doutorado). 2003 Blekinge Institute of Technology - Suécia, 2003.

SWANSON, E. B. The dimensions of maintenance, In: Proceedings of the $\mathbf{2}^{\text {nd }}$ international conference on software engineering, IEEE Computer Society Press: Los Alamitos, p. 492-97. 1976.

TU. Q, GODFREY. M. W., "An Integrated Approach for Studying Architectural Evolution", In: 10th International Workshop on Program Comprehension, p.127, Paris, France, 2002. 